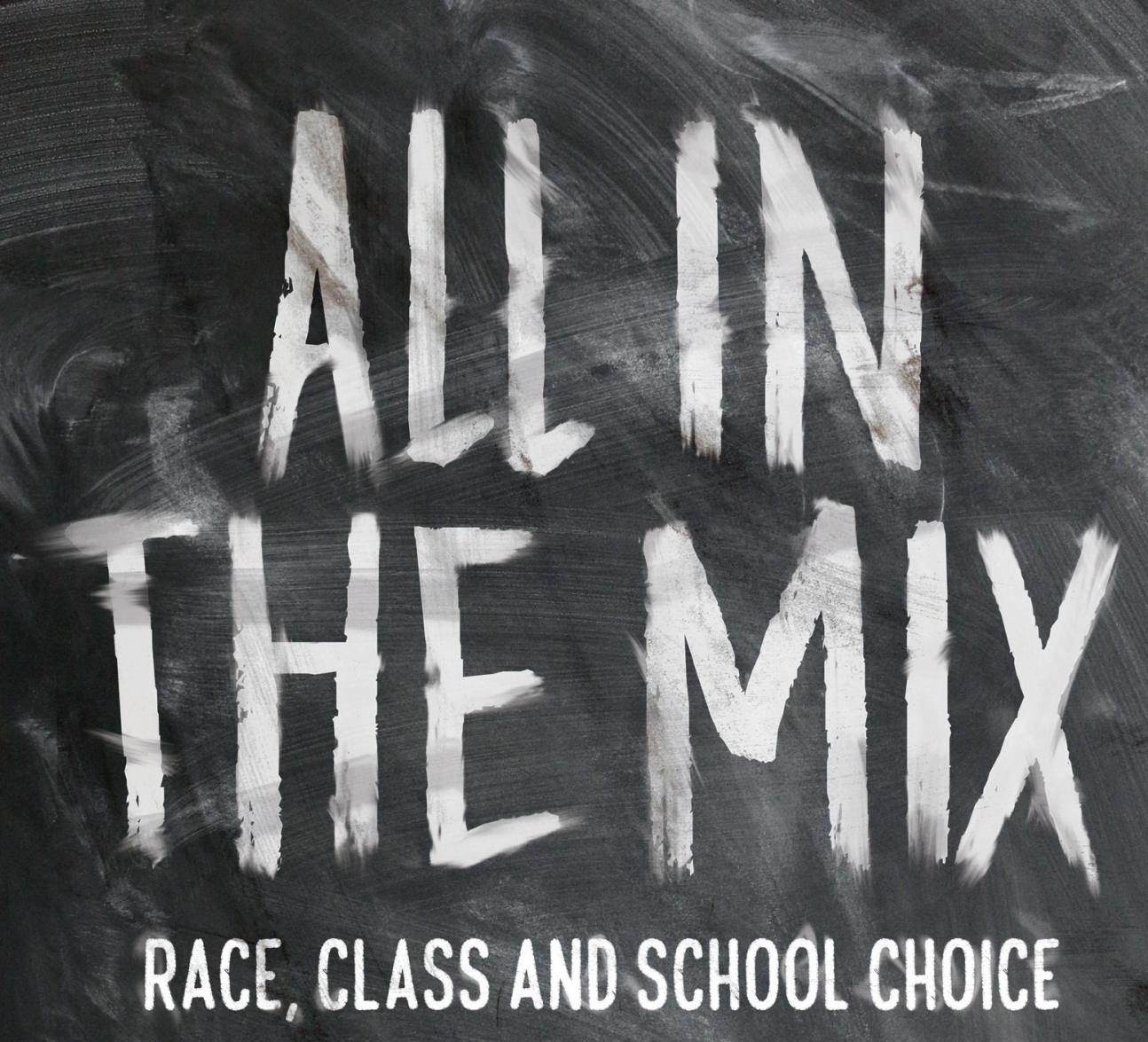

$$
\begin{gathered}
\text { BRIDGET BYRNE } \\
\text { AND CARLA DE TONA }
\end{gathered}
$$




\section{All in the mix}

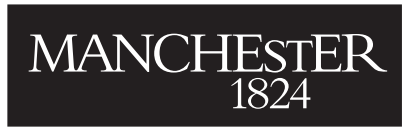

Manchester University Press 
Bridget Byrne and Carla De Tona - 9781526139306 Downloaded from manchesterhive.com at 04/26/2023 12:17:41PM 


\title{
All in the mix
}

\author{
Race, class and school choice
}

\author{
Bridget Byrne and Carla De Tona
}

Manchester University Press 


\section{Copyright (C) Bridget Byrne and Carla De Tona 2019}

The right of Bridget Byrne and Carla De Tona to be identified as the authors of this work has been asserted by them in accordance with the Copyright, Designs and Patents Act I988.

This electronic version of this book is also available under a Creative Commons (CC-BY-NC-ND) licence, thanks to the support of the University of Manchester, which permits non-commercial use, distribution and reproduction provided the author(s) and Manchester University Press are fully cited and no modifications or adaptations are made. Details of the licence can be viewed at https://creativecommons.org/ licenses/by-nc-nd/3.0/.

Published by Manchester University Press

Altrincham Street, Manchester Mi 7JA

www.manchesteruniversitypress.co.uk

British Library Cataloguing-in-Publication Data

A catalogue record for this book is available from the British Library

ISBN 978 o 7I90 9II5 5 hardback

ISBN 978 I 526I 39306 open access

First published 2019

The publisher has no responsibility for the persistence or accuracy of URLs for any external or third-party internet websites referred to in this book, and does not guarantee that any content on such websites is, or will remain, accurate or appropriate.

Typeset by Servis Filmsetting Ltd, Stockport, Cheshire 


\section{Contents}

Acknowledgements

page vi

Introduction I

I Unequal choosing

2 Imagining places

40

3 Choice, what choice?

70

4 Schooling fears

I06

5 Evaluating the mix: negotiating with multiculture

I32

6 Conclusions

I54

Appendix: Participants

I65

References

169

Index

I79 


\section{Acknowledgements}

This book has taken some time to come to publication and we want to start by thanking the parents we interviewed. They often showed a welcome enthusiasm to talk about their very-fresh-in-the-mind experiences of applying to secondary schools for their children and a readiness to think about aspects of this process that they had perhaps not considered before. We would also like to thank the primary schools in Whalley Range, Chorlton and Cheadle Hulme for helping us access the parents; the high schools in the same areas for allowing us to attend open days; and the headteachers, choice advisers and others who gave us interviews as part of this research.

We would also like to thank the ESRC for funding the research (grant reference RES-0oo-22-3466) and the ESRC-funded Centre on the Dynamics of Ethnicity (CoDE) at the University of Manchester for providing the institutional context for this research. Tom Dark at Manchester University Press has been an exemplary (and very patient) editor. Bridget would like to thank many colleagues in CoDE, the sociology department at Manchester and beyond for their interest in the project, support and general collegiality, including: Claire Alexander, Andy Balmer, Alice Bloch, Wendy Bottero, Bethan Harries, Brian Heaphy, Virinder Kalra, Graeme Kirkpatrick, James Rhodes, Nick Thoburn, Vanessa May, Niamh Moore, James Nazroo, Diane Reay, Abril Saldaña Tejeda, Andy Smith, Eithne Quinn and Satnam Virdee. She would also like to thank Khalid, Sara and Sami for their patience, with apologies to Sara for not interviewing children, or taking her advice on the title. 


\section{Introduction}

It's an open evening in the new building of an academy high school in a southern suburb of Manchester on a blustery autumn evening. There are lots of parents and children who have come to check out the school. There is a busy, but ordered feel. Parents and children give out a nervous excitement about their possible future school. We're greeted by staff in the reception and assigned a pupil guide to take us around in small groups. Along with a mother and son, we are led around the classrooms, to see the different subject rooms, perhaps play games on iPads, look at displays, chat to the subject teachers and look at books laid out on tables. As with other school open evenings we've been to, the pupil guide, a year 7 student, is impressively polite, friendly and articulate about the school. He's ready to sell his school, which he clearly feels proud of. He's only been in the school for a term and is happy to show off his newly acquired knowledge about it. Sometimes the things he sees as advantages may 'misfire', such as the presence of CCTV cameras in corridors and stairways - he likes them, but for a potential parent it may seem like oppressive surveillance or raise worrying questions about what would go on if the cameras were not there. But nonetheless, he's a good salesperson - the kind of child that many parents would want their child to be friends with and to be. We have been to several of the local open days as part of this research project, interested in how the schools are presenting themselves to prospective parents and children. Yet the thing that captivates us in this visit is the boy whom we're being taken around with. He is absolutely silent, asking no questions, leaving that to his mother and not seeming to really listen to the conversations. Yet he is looking intently around him, his hand gently, tentatively, touching the objects he sees, constantly tracing an invisible line along walls, across tables, over books. He seems to be engaged in an intense act of imagining. 


\section{All in the mix}

Could he be in this space? This seems to be a visceral imagining, not just about his personality or academic ability but also his very physical being: could he sit at these tables, write in these books?

Open days are one way in which parents and children navigate the process of applying to secondary schools. Parents ${ }^{1}$ are presented with an injunction by the state to make a choice for their children's schooling and education. Since the I980s, the idea of the 'choosing parent' has been paramount in education policy in the UK. Yet the requirement to choose is not necessarily matched by the availability of a range of alternative schools from which to choose. We could see this as part of what Engin Isin (2004) terms the 'neurotic citizen' - the citizen who 'governs itself through responses to anxieties and uncertainties'. For Isin, this citizen is not required to be rational in his or her self-governing, but rather 'anxious, under stress and increasingly insecure' (Isin 2004: 2I6). In order to fulfil this responsibility to choose in a situation of imperfect choices, parents have to establish what their priorities are; what is on offer; and what tactics (De Certeau I984) are available to them to achieve the best outcome for their children. This book seeks to explore how parents choose secondary schools for their children. It considers the ways in which parents talk about their choices and how they are choosing the social setting of their children's education as much as the pedagogical approach or resources offered by the schools such as teachers, buildings and extra-curricular activities. Thus, the book examines how parents talk about social categories - particularly of race, religion and class - in this process of choosing. It also considers how their talk is emplaced coming out of engagement in particular spatial relationships in local areas and schools. This involves an understanding of how places are perceived as racialised and classed and how these perceptions shape the ways parents talk about schools in particular areas. But lingering for a moment on the scene of the boy alerts us to the intensely emotional nature of school choice. It is emotional - for both children and parents - because it takes place within a web of social relations. It is emotional because it is about change. Becoming and belonging. Leaving primary school and moving on to high school provides a clear milestone in the progress from child to adult, from family-or-parentas-the-centre to parent-on-the-sidelines. School choice can set the scene for not just academic success or failure, social mobility, stasis or decline, but also belonging, social acceptance and emotional security or outsiderness, rejection and unhappiness. As one Manchester 


\section{Introduction}

school's motto has it (always shown with ascending type size to stress relative importance):

\section{SUCCESSFUL \\ CREATIVE HAPPY}

Parents are navigating this field of emotions and aspirations as they make decisions about their children's education. Thus schooling and the imaginative leaps that are required to choose schools are affective, more-than-rational, processes which include the - often local and emplaced - collective responses, feelings and emotions around what a 'good' school should look and feel like. At the same time, as we shall see below, race and class themselves are also lived at an affective level framed by and generating a range of emotional responses. Thus, school choice is an intensely affective process in that it involves highly relational and social judgements producing patterns in the way local schools, their populations and their practices are seen. As a result, the class-specific circuits of education (Ball et al. I995) through which people navigate the educational system on behalf of their children draw on geographically localised affective economies (Ahmed 2004a, Thrift 2004, Anderson 2005, Nayak 20I0), producing shared feelings and responses to different schools in different areas. This book argues that being attentive to the ways in which parents talk about school choice can reveal how discourses around race and class are also located. They are shaped by people's experience of living in particular places and they circulate within those areas, producing specific ways of talking about race, class, place and schooling.

School choice opens up a moment to explore the ways in which people imagine themselves, their children and others in social, relational, space. This is crucial because, as will be discussed in Chapter I, choice also increases class and ethnic segregation and inequalities. Choices parents make for their children's education and the ways in which they talk about it come out of understandings of their (and their children's) relationships to others - in the past, present and future. These are also shaped by where they live and, critically, how they see these spaces - of school, of local areas as classed and raced. Schools are a particularly fertile ground for considering people's engagement in and negotiations with social space because they bring together a large number of people into relationships with one another. They are 


\section{All in the mix}

geographically located communities (Crossley 20I5 might see them as important 'hubs') which can play a role in shaping how particular areas are understood and lived in. Schools are communities in themselves: they bring together families, children and teachers in sets of relationships with each other. They are places of encounter which, as Wilson (20I7: 455) argues, can make difference and potentially shift perceptions. Parents considering high school choices may well be shaped by the encounters they experiences in the context of primary schools. However, parents tend to have a slightly more arm's-length relationship to high schools in contrast to primary schools. Primary schools' pick-up and drop-off times structure many parents' days and bring them into close contact with other parents and with the teachers. The transition to high school can feel like a loss of control for parents. They will have much less understanding of and control of their children's relationships with others, especially other students, as they grow up. For many, this can heighten the importance of the social space of the high school as it shapes not only children's academic futures but also a range of other social contacts.

Attention to the networks of relations that schools constitute can help us understand the importance of schools in children's and parents' lives. This relational view would stress the importance of schools as key loci of social interaction which help shape the people children become. They can be sites of what Fortier terms 'multicultural intimacies' (Fortier 2008) which, while represented as positive moments of encounter, can also be threatened by the presence of (too many) classed and raced others who disrupt and unsettle national comfort. In addition, how parents, as social actors, view schools and their role in school choice are shaped by interactions with discourses of school choice produced by a range of actors - the state; schools; the public media; other parents; neighbours; and family members - which also frame affective responses. This book is interested in the role played by discourses of class and race in how parents talk about schools and how they are used to suggest relations of belonging, or conversely to suggest dangers or risks in certain types of interactions. As Wilson argues:

The school is a space of celebrated diversity, of welcome and tolerance, but one that is also fractured by undercurrents of hostility, racism and hierarchical conceptions of belonging that expose the tensions between the official ethos of the school and the everyday interactions of its community. (Wilson 20I4: IIO) 


\section{Introduction}

Forms of relational sociology alert us to seeing schools as hubs of interaction and relationships in which class and race may be seen as 'positions in social space rather than individual attributes' (Crossley 20I5: 82). However, at the same time, schools can be the site of the reproduction of classed and raced inequalities. Those children whose parents, through racialised and classed advantage, have more ability to get the education they want for their children are likely also to get the most out of schooling. This goes beyond merely buying private education and includes a series of decisions which may not, on the face of it, appear directly related to school choice. Most importantly it concerns the choice of where to live. The desirability of an area is shaped by questions of location which include the other people who live in the area and the 'quality' of local schools which is often defined by the types of people who are imagined to be in the schools - as well as the results it attains for its students. At the same time, the education parents want may include insulation from those they see as classed or racialised others. A relational analysis should include the kinds of interactions that people seek to avoid as much as those they seek out or encounter unintentionally. The literature on school choice has long deliberated on the tendency for parents to seek out enough 'people like us' for their children to be schooled with (Butler I997). This also of course includes the desire not to expose children to relations with too many people 'not like us', which may be defined in classed and/or raced terms. These judgements, as with many concerning race and class, are affectual: indirect and often non-reflexive forms of thinking or intelligence (Thrift 2004: 60) in which bodies, emotions and context are intertwined. As Sara Ahmed points out, emotions are not merely personal or interior processes, they also have the potential to create boundaries and borders between bodies and spaces:

Rather than seeing emotions as psychological dispositions, we need to consider how they work, in concrete and particular ways, to mediate the relationship between the psychic and the social, and between the individual and the collective. (Ahmed 2006: II9)

There has been increased attention in the sociology and geography of race which considers the affectual nature of race and racism in particular (Ahmed 2004a, Fortier 2010, Nayak 20I0). The nature of concepts of both race and class is particularly fertile ground for considering the force of affect because of the ways in which they are 


\section{All in the mix}

both located in and beyond the body. However, thus far, much of the literature has focused on the extremes of emotional responses to difference with a focus on expressions and emotions of race hatred. In contrast, as mentioned above, Anne-Marie Fortier directs our attention to 'multicultural intimacies' which include a valuation of a de-politicised aesthetic of multiculturalism and tolerance yet which refuse to see the informal discourtesies that minoritised individuals are subjected to at the institutional as well as at the informal levels of daily life' (Fortier 2008: 95). Bethan Harries also argues that 'naming racism is challenging in a context in which racism has been expunged from the popular public imagination' (Harries 20I7: I39). As we shall see in the book, parents talking about race and class difference and schooling choices often draw on shared affective terrains of multiculturalism, tolerance and the other, expressed in a more muted set of emotions of discomfort and avoidance rather than hatred and aggression. These less extreme imaginings are, like more violent territorial racisms, also responses to emotions of space and places. This may include a nostalgia about places that have been lost - or a sense that some schools have always been 'spoiled' - because they have 'too many' of the wrong sort of (classed, raced) people living in them.

This book considers these emotional responses to schooling and the ways parents talk about them in a context specified in two different ways. Firstly, the book considers the accounts of parents as they are in the process of choosing secondary schools for their children, where the choices (or lack of them) are concrete and urgent. The parents in this study are considering in 'real' time without the distance potentially created by the passing of time, or their children's actual experience in their new schools. Secondly, it explores the emergence of different classed and raced discourses in specific geographical areas, so we are also able to understand how talk about school choice is shared - or contrasted - across different, and relatively wellunderstood, specific contexts. This is important because different contexts provide the opportunity for particular kinds of interactions which then produce their own understandings of the world:

Racialised discourses are always articulated in a context: in an English or history class; in a school corridor, dinner queue or playground; at work or on the streets; in one neighbourhood or another. These different sites can yield complex and shifting alliances and points of tension. (Donald and Rattansi 1992: 27) 


\section{Introduction}

Thus the book seeks to understand how race and class feature in discourses about schools in specific areas. The localness of the studies is important because it gives a sense of the ways particular sets of actual or imagined interactions and the affective context in which they take place shape parent's responses to schools. At the same time, this approach explores what Simkins calls the 'increasingly fragmented local landscapes of schooling' (Courtney 20I5: 4). For Nigel Thrift 'cities may be seen as roiling maelstroms of affect' (Thrift 2004: 57). This landscape of schooling has been in considerable flux in the last two decades - particularly with the rapid conversion of schools to academies which directly impacts on admission policies and therefore the mechanisms of choice. Places are shaped by affectual, shared and more-than-rational responses which may include a sense of nostalgia and loss. They may also include a sense of achievement and pride in what it is seen to represent in terms of successful 'multiculturalism' and cosmopolitanism that it can deliver. These emotions are not personal because they are produced, experienced and expressed in a social context. They are also produced within social structures which are created by policy and politics. The requirement to choose for their children places a responsibility on parents but, as we shall see, also raises expectations that there should be more schools to choose between. The following section will briefly consider the role of education and the state, outlining the shifting emphasis produced by a move from welfare state models to more neo-liberal policies in which school choice is central.

\section{Education and the state}

Education is a key site in which the state intervenes in the development of individual children and in family practices. In this role, education enacts a series of relationships: between national and local government; between these two levels of the state and schools; and between schools and families. Education is also seen as important for national economic development, producing a skilled and productive workforce. State education in particular is often also invested with hopes for progressive outcomes such as social mobility and integration of migrants and for overcoming racism and prejudice. Thus, for many, the question of inequalities in general, and the hope of the reduction of inequalities in particular, are crucial measures to test the impact of state education. Yet the education system is often 


\section{All in the mix}

found to be lacking in relation to overcoming class, gendered, ethnic and other inequalities, which, whilst there have been some improvements, remain persistent (Lupton and Thomson 2015, Francis et al. 20I7). As Bottero (2005: 248) concludes: 'the more advantaged are dramatically more successful in educational terms, and this is true even when we hold measured "ability" constant'. It should be understood that schools are not responsible for producing all inequalities in attainment between children. Studies consistently show that children arrive at school with different levels of 'readiness' for education and that these are related to poverty and deprivation. These disadvantages persist through schooling: 'lower family socioeconomic position is an important predictor of lower levels of educational attainment' (Pickett and Vanderbloemen 20I5: 4). The causal links between socioeconomic inequality and unequal educational outcomes are complex and multiple and include distribution of mental health problems, job security and debt which impact on parenting styles and consistency as well as the provision of good housing and nutrition. These factors also have an impact on parental ability to support education both through direct time input and use of their own educational resources as well as the use of economic resources to get more educational help (Pickett and Vanderbloemen 20I5). As Kerr, Dyson and Raffo argue:

it is not so much that relative poverty 'causes' poor educational outcomes in some linear way, as that it is associated with a range of disadvantaging factors in the home, school and neighbourhood and seems likely to exacerbate the effects of other disadvantaging factors where they are present. The mechanisms linking economic background to disadvantaging factors and so to outcomes are complex, therefore, but the linkages are strong. (Kerr et al. 20I4: 6)

As well as socio-economic inequalities, the UK education system persists in producing unequal outcomes which are shaped by ethnicity and race. Again the causes are complex and multiple and will have significant overlap with questions of socio-economic inequalities. However, studies have shown how ethnic stereotyping by teachers impacts on educational outcomes, with a negative impact particularly on pupils of black Caribbean, Pakistani or Bangladeshi ethnicity (Burgess and Greaves 2013). For both ethnic minority and white working-class students, there may be a cultural gap that teachers fail to bridge in order to effectively capture their students' interests and talents. And the children themselves (and their parents) risk 


\section{Introduction}

being stereotyped and misunderstood. Other ethnic minorities may experience more positive assumptions being made by teachers about their educational abilities and disposition to learn (Archer and Francis 2007; see also Kirby 20I6). At the same time, both classed and racialised expectations and stereotypes will also be gendered.

Potentially running against the tide of thinking of education in terms of social mobility, the question of parental choice of schools emphasises the individual child and family securing desired outcomes for their schooling. The question of parental choice in the English state education system of state provision arises most clearly out of the market reforms of the I980s which began a thirty-year neo-liberal process of bringing logics of the market and consumption into the field of education - seen in both schooling and the university (Lupton 20II, Reay et al. 20II). These processes, although sometimes introduced from different ideological positions and with different aims (Lupton 20II), changed the terms of relations and the nature of the interaction between central government and local government, between schools and between schools and parents. They increasingly shifted the role and characterisation of the parent from those of passive recipients towards those of consumers of an education for their children offered by schools which potentially compete with each other for both resources and pupils (Wilkins 2010). Archer and Francis argue that policy documents concerning school choice are 'covertly raced and classed discourses' which perpetuate inequality by privileging the interests of white, middle-class parents (Archer and Francis 2007: 74). Much academic literature explores how wealth and class practices are key components shaping parents' and children's ability to negotiate the uneven distribution. This has led to a concern for the ways in which class has interacted with this policy of choice. There has, however, been much less focus on examining the impact of race and ethnicity on practices of choosing - on the part of both schools and parents. Yet the process of school choice can potentially lead to race and class segregation as well as increasing disadvantage (Saporito and Lareau I999). This book seeks to consider both how parents' approach to the multiple relations involved in making choices around schooling may be shaped by their racialised and classed positionings, and also how their choices may be classed and racialising practices which serve to shore up or respond to racialised and classed formations. School choice is shaped by difference and inequality - and it can also make difference and inequality. The characterisation of the 


\section{All in the mix}

parent as consumer is often underpinned by assumptions about the rationality of the choices that they make. However, as the book will argue, although parents do at times adopt the attitude and language of the economic consumer, their choices are also emotional and shaped by understandings of belonging and security, of racialised and classed positions and identities formed relationally which are less suitable to being understood as rational market actions (see also Cucchiara and Horvat 20I4). Choices are made in response to a complex web of social relations, the resources on offer and individuals' sense of their 'place' or belonging in these different spaces.

\section{The structure of the book}

Following this introduction, Chapter I, 'Unequal choosing', charts the rise of notions of consumer choice in the field of state education and its relationship to the changing structures of school provision. It considers how a shift towards the 'choosing parent' can maintain inequalities of race and class. It also addresses gaps in Bourdieusian approaches to education, particularly focusing on how racialised processes have frequently been sidelined in this literature. In considering the literature on school choice, this chapter will also point to gaps in the literature which has historically largely focused on white middleclass parents and children. Finally, it will explore the importance of understanding schools as located in particular places - enabling an exploration of spatial processes of school choice. It will examine how ideas of territorialisation and stigmatisation of space can interact with processes of school choice.

Chapter 2, 'Imagining places', considers further the spatial nature of school choice and introduces the three areas in Greater Manchester in which the study is based and the ways in which the fieldwork was conducted. One of the distinctive features of this book within the literature on school choice is its focus on parents living in three distinct areas, which are also relatively geographically close to each other. These are places and schools, about which we have reliable knowledge about the make-up of the schools as well as broader demographic data. This enables us to understand how those places are imagined and lived in and how the schools are understood in the broader 'tactics' (De Certeau I984) of living in places. Chapter 2 sets the scene of the three different areas in which the study is located. In doing so, it describes the areas which have distinct demographic 


\section{Introduction}

make-up and also different profiles in terms of reputation and, as we shall explore, residential mobility. The chapter also explores how the interviewees were contacted and the ways in which they spoke about the areas they lived in, with particular attention paid to what they said about why they had moved into or chosen to stay in the areas. It will show that, when talking about the areas in which they lived, issues of race and class were dealt with quite differently in the three areas, suggesting different discourses that circulated about these social categories in the contrasting locations. The chapter also shows the varied ways in which 'elective belonging' (Savage et al. 2005) can work.

Chapter 3, 'Choice, what choice?', turns directly to the question of school choice - to examine how parents experienced the injunction to choose. It finds that, for many, the feeling that they had no 'choice' increased stress and anxiety around schooling. Nonetheless, the feeling of having 'no choice' often included a prior disregarding of some schools that their children could reasonably be expected to gain admissions to. The chapter also explores what parents said about both private provision (including private Islamic schools) and state selective schools in the form of grammar schools. Approaches to school choice, including to private and selective education, also varied by area. The chapter considers the ways in which parents talked about processes of choice and focuses on one particular account of a mother living in Cheadle Hulme which shows the anxiety that trying to get the best outcome for ones' child sometimes produced. It shows that previous work on school choice which tends to focus on the concerns of the professional (white) middle classes may risk under-estimating the ways in which worrying about schools and education is shared across class and ethnic differences.

Chapter 4, 'Schooling fears', explores some of the emotions stirred up in the process of choosing schools. It examines how much of parents' talk in these areas about school choice, and in particular what they are most worried about, is structured by ideas of class and also race, even when these are not mentioned directly. It will argue that undesirable schools are often characterised by their pupils in ways which suggest processes of othering. The school is assessed in part through the ways in which the children dress and behave - or sometimes how the parents behave. Thus the chapter explores how judgements made about schools are gendered, raced and classed. In these accounts, class is particularly prominent in shaping parents' fears. 


\section{All in the mix}

Chapter 5, 'Evaluating the mix: negotiating with multiculture', focuses more explicitly on (white and ethnic and religious-minority) parents' discussions of ethnic diversity. It also puts those discussions in the context of policies around multiculturalism and integration in which schools have been a key policy site. The chapter argues that parents were more likely to consider diversity as something related to race or ethnicity rather than class. Generally, ethnic diversity is regarded positively. However, the chapter contends that we lack a differentiated vocabulary for discussing diversity and 'mix'. Thus very different situations are seen as representing a 'good mix'. Furthermore, we suggest that there are distinct discourses around ethnic diversity circulating in the different areas, with parents in the area with the least ethnic diversity, in particular, expressing reservations and fears about increasing diversity which is most focused on the presence of more Muslims in their local area in general, and in the school in particular. The chapter will also argue that parents of ethnic-minority children have a particular stake in seeking out schools with an ethnic mix as they see those schools as potentially offering their children security against the racism and racialised othering which they might face in more white schools (and which the parents themselves may have experienced in their own schooling in Britain). Thus the book argues that it is critical that we consider questions of both class and race when understanding parents' views about school choice, but that we should also be attentive to ways in which ideas and imaginations of place frame parents' approaches to schooling and education.

\section{Note}

I We use the term 'parents' because these are the majority of those legally required to choose - and the majority of the people we spoke with - but this is not to forget that many children may have other legal guardians, including the state (in the case of children in care), foster parents or other family members with special guardianship. 


\section{Unequal choosing}

\section{Introduction}

The I980 Education Act, introduced under Margaret Thatcher, included the requirement for local education authorities (LEAs) to consider parental preference more seriously. The notion of parental choice had been established under section 76 of the 1944 Education Act but had been implemented only on an ad hoc basis (Croft 2004). Commitment to parental preference was strengthened in legislation in I988 and I989, with the introduction of the principle of funding following the pupil introduced in I988. For Gunter and McGinty, the Education Reform Act of I988 established the 'independent' school as the ideal model, achieved through 'removing the school from local democratic accountability by building on the self-managing school as a business in a competitive market place' (Gunter and McGinty 20I4: 300-I). This further enshrined the concept of 'choice' in schooling. ${ }^{1}$ Choice, diversity and the market model of schooling have continued to shape policies around academies and free schools. This has also been driven by the desire to take schools out of local authority control on the assumption that schools are better if parents and other actors - for example, those engaged in business, religious groups or universities - play an active role in them. In fact, as the range of social actors brought into the educational sphere widened in the 20IOs, it could be argued that the primacy of the parent as active citizen as well as consumer has slightly reduced. It was the I980 Educational Act that confirmed the statutory right of parents to be elected as school governors, giving them an important role in the governing of schools as the control of schools was increasingly shifted from Local Authorities (LAs) to governing bodies. However, in May 2016 the then Education Secretary, Nicky Morgan, suggested that, in a bid to get the best people with the right skills on governing bodies, there 


\section{All in the mix}

should no longer be the requirement to have at least two parents on governing bodies. ${ }^{2}$

Nonetheless, despite these changes, the primacy of parental choice in schooling as a discourse and policy objective remains. Parental choice has also been a key justification used for arguments around diversification of provision. A variety of schools are seen as offering more choice (despite, as we shall see below, the geographical limitations within which choices are made) (Wilkins 20I0: I74). Over the last ten years, the logic of variety of provision has extended to the introduction of free schools and the shift in the policy around academies (West and Bailey 20I3, Simkins 20I4). Free schools were introduced in 20II with the idea that parents could also create their own state-funded schools if they are unhappy enough with the available choices. In this development, parents as active citizens can, if they have the will and organisational capacity, potentially cross the divide from consumer to consumer-producer. Yet at the same time, it is important to remember that, despite often functioning as a lodestone for political debates on education, free schools make up a very small proportion of the overall school provision, with parentled free schools a minority of those which have had governmental support. ${ }^{3}$ In an as-yet more far-reaching policy, successive governments have increasingly incentivised schools to convert to being academies. Academies, known as "publicly funded independent schools', are funded directly by central government and thus are outside the control of local authorities (Academies Commission 2013: 5). Academisation was initially developed under the Labour government in 2002 and was largely used as a way of dealing with 'failed' schools which were taken away from LA control. Academies were given freedoms that were not available to LA-maintained schools. These included freedoms such as establishing their own pay and conditions for staff; some flexibility in curriculum provision; flexibility in the composition of the governing bodies and freedom over the length of the school day; and number of sessions taught (Long 20I5). Importantly, academies also have more control of admission procedures and exclusion which add another potential layer of selection. The failing school in a disadvantaged area continues to be a potential route to academisation. However, under the successive Coalition and Conservative governments, the possibility of conversion to an academy has now also become a choice offered to successful schools (Gunter 20I2, Gunter and McGinty 20I4, Courtney 20I5: 


\section{Unequal choosing}

802). As a result, there has been a very rapid growth in the number of academies. In May 2010, there were 203 academies in the UK and by November 2012 this had risen to 2456 and then risen again to 6087 by March 2017 (making up 22 per cent of primary schools and 62 per cent of secondary schools). ${ }^{4}$ By 2016 it was declared a government ambition for all schools to become academies (although as yet this policy has not been realised). ${ }^{5}$ The impact of the process of academisation on inequalities in education has yet to be fully studied. Certainly, the effect of free schools and academies on the quality of schools has been unimpressive (Pickett and Vanderbloemen 20I5: 20). However, Stephen Gorard points out that, whilst the first type of academisation (of failing schools) tended to reduce the clustering of poorer children in specific schools, the more recent focus on successful schools becoming academies ignores any concerns for social justice and is likely to increase the incidence of local segregation by socio-economic status (Gorard 2014: 296).

Thus, through a series of structural changes over the last three and a half decades, the relations between the state (in its form of local or central government) and schools and parents have been transformed towards the construction of parents (and occasionally young people) as consumers of educational options for their children. This marks a shift in education discourses away from concerns around inequalities, exclusion or general social welfare towards the 'parentocracy' made up of individual consumers (Reay et al. 20II). This is significant not just for its impact on classed or ethnic inequalities, it also has significant implications in terms of disability. Stephen M. Rayner (20I7) has discussed the impact of the regulated, competitive market on school leaders' ability to respond to the needs of children with special educational needs (SEN) and disabilities. Ball (2003: 49) also notes how SEN programmes were dismantled or de-emphasised at the same time as able student programmes were introduced. In addition, academies tend nationally to have higher levels of permanent exclusions (Long 2015: I0). For Stambach and David, the introduction of the parentocracy also shifts parenting towards a masculine mode as education becomes about competition rather than nurturing (Stambach and David 2005, see also David 1997). As will be discussed in Chapter 3, the act of choosing itself can also be gendered within the household, although in sometimes complicated ways (David I997). Somewhat paradoxically, at the same time as individual parental choices have been emphasised and some schools given more 


\section{All in the mix}

freedoms, what is taught in the majority of state schools has come under increasingly centralised control with the development of - and ongoing adjustments to - the national curriculum. ${ }^{6}$

Politicians and policy-makers tend to claim that parents have been empowered through their new role as consumers of educational options for their children. In 2005 the Labour government, which continued the promotion of market principles in education, produced the white paper Higher Standards, Better Schools for All: More Choice for Parents and Pupils. Its stated aims were to 'radically improve the system by putting parents and the needs of their children at the heart of our school system' (quoted in Reay et al. 20II). Yet the market, as represented by parent choice, may not be a sufficient push for poorerachieving schools to improve standards (Allen et al. 20I4). The operation of education as a market does not necessarily achieve a reduction in social inequalities, as Lupton argues: 'It is reasonable to assume that the more choice, the more unequal the opportunities' (Lupton and Thomson 2015). As we shall see in the following sections, there are concerns about the ability of parents to achieve the same educational opportunities for their children. Is the increased choice equally spread?

Having briefly considered the policy landscape of school choice, this chapter will consider the impact of this expansion of choice on questions of inequality. In particular, it will elaborate how classed and racialised inequalities are maintained through operations of choice. In order to track the classed nature of choosing, the chapter will draw on Bourdieusian theories of class which have been particularly influential in the field of education. However, the chapter will also argue that Bourdieusian understandings of class, as they are often used in the literature on school choice, risk overlooking the importance of racialised understandings of self and identity which may also play a role in shaping school choice. The chapter will track how the current literature on school choice has overlooked questions of race and frequently also ignored the experiences of working-class parents, whether white or of ethnic minorities. Finally, the chapter will explore how the spatial nature of school choice has also been frequently overlooked. It will argue that narrations of place - and spatial tactics and strategies - are key to understanding how schools' reputations are embedded in their geographies. 


\section{Unequal choosing}

\section{Choice, class and ethnicity}

The opportunity to choose their children's schools and have more say in their schooling may be welcomed by some. Yet it can also be perceived as a burden for parents as they negotiate a complex educational system governed by a proliferation of different types of schools with different rules of access. Choosing schools is made more complex through this variation. Courtney has attempted to map the variation in school types in England and has concluded that:

if one includes variations according to pupil sex and age which have largely been omitted from these typologies for simplicity, there are presently between 70 and 90 different types of school in England. This is not to say that parents may choose from this number: a significant proportion selects the pupil, albeit covertly and/or through branding. (Courtney 20I5: 8I4)

Despite this variation, and although there is no simple or uniform schema for admission to schools, distance from residence to school remains an important factor in admissions. This has particular implications for the relationship between schools, inequalities and place, as will be discussed below. LAs, academies and free schools have relative freedom to formulate their own mechanisms of prioritising pupils (within certain bounds established by the 2003 Code of Practice on School Admissions (Croft 2004: 930)). Possibilities of choice are also shaped by the various types of (wholly or partially) selective schools - including grammar schools; religious schools and other voluntary aided schools; academies; technical colleges; and specialist schools. In addition, there is a complicated system of appeals which parents may have to negotiate if they are unhappy with the school their child has been allocated to (Croft 2004). Thus, skills and knowledge are required to navigate the complex terrain of different schools and admissions procedures. As much of this knowledge is acquired through 'hot' sources of personal networks (which will be discussed further below), this can lead to disadvantage for those who, for a range of different reasons, have less extensive or effective local networks.

As suggested above, the dominance of models which have at least some element of proximity of residence to school as a criterion means that parents and children have limits on choice set by their geographical locations. Although those with the economic power to move 


\section{All in the mix}

may be able to move into the catchment areas of particular schools, even for those with the financial resources this is limited by the uneven distribution of different types of schools. Realistically, many families cannot afford to move and those who can are still likely to be tied to particular broad areas and regions by employment and other attachments. Importantly, in discussions of school choice, it is often forgotten that exercising choice tends to be most possible in urban, city areas. In rural areas or small towns, particularly at secondary school level, there may be almost no choice (Reay et al. 20II). The 'market' of schooling therefore has profound geographical rigidities and significant barriers to full engagement. The difficulty of navigating the process of choosing schools was recognised with the introduction of Choice Advisor Services based in Local Authorities in the 2006 Education Act (Exley 20I2). Choice advisers were established to provide a service for the 'disadvantaged' and 'vulnerable'. The establishment of these services risks implying that it is the parents' choosing which may be at fault, rather than any inadequacy in the choices available to them. In her study of LA advisers, Exley (20I2: 8I) found that many saw themselves as "helping working class and disadvantaged parents "make the best of a bad situation"' rather than actually facilitating positive choices.

Whilst choices may be extremely limited in rural areas, even within urban areas, as we shall see in Chapter 3, parents often feel a lack of choice. The education market is affected by limits of supply (schools cannot easily 'spring up' to meet a demand) which means that schools do not operate in a pure market. The cost of some schools being winners in the market for students and funding is that others will be losers. Yet many children still have to attend those 'losing' schools. There are only so many places which popular schools can offer for students and, for many parents and children, the notion of choice becomes a fiction, particularly in those areas where all the possible choices are considered unpopular or undesirable. Thus, as the discourse around schooling has shifted to one of individual parents' choices, the question is raised as to whose choices are increased, and what impact does the notion of choice have on well-established inequalities in education provision and outcomes. For Reay et al (Reay et al. 20II: 68), 'the powerful idea that successful secondary schooling is the result of parents making "good" choices at the point of transition is itself something that conceals the maintenance of inequalities'. The next two sections will consider in more detail how 


\section{Unequal choosing}

classed and racialised inequalities are maintained through the operations of choice. It will also explore how these questions have been addressed in the literature concerned with the sociology of education and of class and race.

\section{Researching class and race in education}

As Andrew Sayer (2005) points out, it is unusual for anyone other than a sociologist to ask you what class you are - because it is considered rude, or obvious. However, at the same time, the sociologist who dares to ask might well not agree with your self-identification - there are many forces going on behind people assigning themselves (or others) a class which may not match up to a schema or concept of class that the sociologist might agree with. Indeed your non-sociologist neighbour might also not agree with your self-identification as there are conflicting lay understandings of class and its markers. Sayer (2005: I) suggests that class talk is emotional and evaluative: '[c]ondescension, deference, shame, guilt, envy, resentment, arrogance, contempt, fear and mistrust, or simply mutual incomprehension and avoidance, typify relations between people of different classes'. However, this list may be unduly negative and ignores some everyday processes of cross-class conviviality which Gilroy (2004) has argued that we need to pay attention to in racialised relations. Nonetheless, explicit examination (in contrast to coded and implicit references) of class is often left to academic rather than everyday discourse.

Amongst sociologists, the study of education is one site where the rise and fall (and rise again) of class theory within sociology has been played out. There are two distinct questions in this ambivalence of the utility or relevance of class within the sociological literature. One is largely focused on identity: can it be possible to talk about class if many declare either that class is irrelevant to them, or if, in the everyday usage, people put themselves in categories which a sociologist might want to disagree with (Are we all middle class - taken to mean 'ordinary' - now? Has class become irrelevant?). Yet at the same time as this question is asked, it is clear that significant social and economic inequalities remain and are reproduced across generations (Bottero 2005). More recent forms of class analysis have argued that there does not need to be a recognisable class consciousness for classed processes to exist. Indeed dis-identification, which involves 


\section{All in the mix}

the denial of a classed identity, may be seen as a classed practice, as working-class is often seen as spoiled identity which should be resisted or disavowed (Skeggs I997, Reay I998, Bottero 2009). In addition, there has been opposition to the singular focus on economic relations as the sole force structuring inequalities and class. In response, there have been more culturally inflected approaches to class which explore how class inequalities are bound up in a range of practices which range from what we eat, how we speak, how we dress, to how we move our bodies and how we spend our leisure time. This raises the possibility of identifying social classes 'who share common lifestyles, identities, social networks and political orientations as well as levels of income and wealth' (Savage 2015:3). ${ }^{7}$

The second dilemma about class as a category of analysis emerges out of the first and centres on questions of categorisation or the counting of class. Traditionally, sociologists have tended to categorise people by their occupation (or often by their father's or husband's occupation), with individual jobs located a place in a hierarchal schema of occupational groups. However, it is increasingly recognised that modern patterns of work and career building do not fit easily into these rigid schema. This is a feature of the changing nature of employment - for instance with the decline of employment in craft or heavy industries and the growth in more insecure employment in a range of occupations. In addition, it has become clear that a focus purely on employment and occupational categories fails to describe the experiences of class as it is built out of more than occupation. Indeed, Mike Savage argues that occupational schemas of class classification were never purely economic but also cultural - intended as 'ways of making cultural judgements about ranking and social importance of jobs' (Savage 2015: 35).

For those taking a broader position on the importance of culture in how class plays out, the dominant approach is that outlined by Pierre Bourdieu. For Bourdieu, the operation of class in society does not require the identification of cohesive or self-identifying groups or class formations. For Bourdieu (I99I), a class is a set of people in a similar position in the 'field' who have shared dispositions and interests which make them act in particular ways (but not necessarily in a co-ordinated way, and not as a group). This produces a concept of classed groups without distinct boundaries, where contesting the boundary itself is in fact a key class practice. For those enacting them, the shared tastes and practices may seem personal and relatively 


\section{Unequal choosing}

arbitrary. However, these dispositions are patterned and produced relationally where they gain social meaning through processes of social interaction, which are already shaped by social hierarchies and differential association. Attention to the patterning of those shared 'dispositions' and the distinctions that they make between social groups alerts us to the importance of understanding how the values given to different social and cultural capitals develop. For Bourdieu, class is hierarchical relationship between social groups which are shaped through ways of being, tastes and lifestyles. According to Swartz, Bourdieu is interested in 'the question of how stratified social systems of hierarchy and domination persist and reproduce from one generation to the next without powerful resistance and without the conscious recognition of their members' (Swartz I997: 6). Thus, education is critical in understanding class and the reproduction of hierarchies and inequalities.

There is a paradox in the fact that education is often considered an important mechanism of social mobility and meritocracy, yet success in education is strongly facilitated by cultural capital and thus the maintenance of class distinctions. As families cannot simply secure the right jobs and futures for their children, education is the means to ensure the maintenance of social privilege, not only through the acquisition of qualifications but also through the transmission of class codes and cultural capital. "The "eye" is a product of history reproduced in education' (Bourdieu I994: 5-6). This 'culturalist' approach to class, which seeks to understand classed practices rather than self-conscious class identities, has been very productive in aiding the analysis of the reproduction of class inequalities in education. Thus for Stephen Ball:

Class is realised and struggled over in the daily lives of families and institutions, consumption decisions, as much as in the processes of production and particularly at moments of crisis and contradiction as parents think about the well-being and happiness and futures of their offspring. Class is about knowing how to act at these defining moments. (Ball 2003: 7)

This approach emphasises the way in which class is lived and understood relationally - manifested in common ways of being, tastes and practices - but class here is not necessarily self-conscious or collective (Bottero 2005). Thus attention is given to relations between people who occupy similar positions within a field - as well as between 


\section{All in the mix}

those who have different social positions which people may want to distinguish themselves from. Who you are not, the tastes you would never display, are as important here as who you are and your tastes and dispositions. ${ }^{8}$ Class positions are maintained through relations and interactions with the 'right' people and the exclusionary practice of distinction as well as the accumulation and transmission of economic, social and cultural capitals from one generation to the next. It can also be maintained by processes of self-exclusion, where activities and spaces are seen as not being 'for the likes of us' or where the risks (to comfort, to a stable sense of self as well as to economic well-being) of engagement can appear to be too high (Bottero 2005).

For Bourdieu, cultural capital can be embodied as a disposition of the mind or body, it can be in concrete cultural goods and it can be institutionalised in the form of qualifications. Education is key in the acquisition of qualifications, although the worth of certificates and degrees may over time become devalued in a period of increasing access to higher education. This leads to a pressure to acquire more advanced degrees (Bourdieu 1994: 133). Yet beyond qualification acquisition, education is also important in the acquisition of taste and the right dispositions which play a critical role in creating cultural capital through distinction (Bourdieu 1994). This makes schools very important in the conscious or unconscious struggle to maintain position. Schooling transfers social capital through promoting social networks which may be important in the parents' lives and will certainly be important for the children (Byrne 2006a). Who your children make friends with and spend their time with shapes this social capital and gives them the social skills to continue to accrue the right social and cultural capital in the future. Education and schooling also provide cultural capital, being one site where children develop tastes and dispositions and where they learn how to act and be comfortable in particular social settings. Cultural and social capital ensure that individuals can feel at ease within a habitus (or in fact several potentially overlapping habitus). For Bourdieu, habitus is a system of embodied dispositions which are produced relationally and which structure the social world - ranging from 'hexis' (ways of using one's body, speaking etc.) to schemes of perception and classification which shape how we perceive and interact with the social world. For Reay et al. (20II), habitus is a set of 'durable transposable dispositions' which emerge out of histories of experience - of individuals, families and social groups. ${ }^{9}$ Those who are at ease at operating within a certain 


\section{Unequal choosing}

habitus will have a superior 'feel for the game' and thus are more likely to thrive. They will also tend to act in ways which reproduce that habitus, thus maintaining the advantages of those in a similar position in the social field. Those who, through social mobility for example, move into fields that they are unfamiliar with may have 'fish out of water' experiences, where they lack the right habitus to feel comfortable and to operate successfully within the field. As we shall argue below, much of the work inspired by this notion of habitus ignores its racialised nature. The experience of being a 'fish out of water' can also be racialised as individuals may experience the impossibility of truly fitting in due to racialised othering. Thus, in predominately white spaces, black and Asian pupils may experience themselves as 'space invaders' (Puwar 2004).

The framework of understanding the relationships between structure, dispositions and practice which Bourdieu offers, whilst invaluable in many ways for educational research, has not often been used in ways which reflect the complexity of social location in education, in particular in terms of race, ethnicity and gender (for exceptions see Smaje I997, Hancock 2005, Reay 2008, Reay et al. 20II). As Archer and Francis suggest: 'theories of social class have been primarily formulated with reference to White communities, and hence care must be taken when extending these notions to minority ethnic communities' (Archer and Francis 2007). In addition, those uses fail to understand the importance of analysing the experience of white communities as white (Byrne 2006b, 2009). Whilst much of Bourdieu's work lacks attention to questions of race and ethnicity, he does allow for other forms of distinction to be operating in the field, such as gender and race (Wallace 20I6). ${ }^{10}$ In considering gender in particular Andrew Sayer argues that '[i]n Bourdieu's analysis, the logic of class and status is given the dominant, contextualising role, with gender as a modifier' (Sayer 2005: 82). The consigning of gender or race to the status of a 'modifier' risks re-inscribing a primacy to the economic, which Bourdieu sought to overcome. Even with a more balanced view on the interactions between class, gender and ethnicity, awareness of the field as both racialised and gendered as well as classed can be difficult to operationalise in practice. ${ }^{11}$ Bourdieu himself does not provide a model for how to achieve this more complex understanding. As Terry Lovell (2000: 36) argues, Bourdieu's sociology is in danger of positioning sex/gender, sexuality and even 'race' as secondary to social class: '[w]hile class penetrates right through his 


\section{All in the mix}

[Bourdieu's] diagrammatic representation of the social field, like the lettering in Brighton rock, gender is largely invisible, as is race'. If we are to understand the multiple interrelations between race, class and gender, then it is possible that Bourdieu's construction of habitus does not offer sufficiently flexible analysis to reach the complex processes behind identification. Archer and Francis (2007) for example, in their exploration of minority ethnic achievement in schools, argue for a multi-layered theoretical framework. As well as using Bourdieu's work, they also draw on post-structuralist theorisations of identification offered by both Stuart Hall and Judith Butler: '[w]ithin this approach, social identities, divisions and inequalities (of race/ ethnicity, social class, gender and sexuality) are understood as being brought into being through social life - through talk, actions, policies, practices and so on' (Archer and Francis 2007: 25-6). This discursive, performative approach relies on a more diffuse notion of power and the performance and embodiment of identities than is usually associated with Bourdieu.

When considering race, everyday discussions of race and ethnicity can be equally contentious as those surrounding class. Race and ethnicity can be conceptually distinguished from each other - with race taken to mean groups identified by their sharing a set of biological largely visible somatic features and ethnicity to be a more culturally inflected notion of human groupings. However, in practice, we would argue that both terms are often used in such overlapping ways (where members of ethnic groups are considered to have some biological 'in the blood' relationship to each other and racial groups are seen as sharing cultural characteristics) that they are often used indistinguishably. Frequently, the terms ethnicity or ethnic group are used to suggest a progressive move away from race when in fact a logic of biological race is still being called upon. These conceptual muddy waters raise problems for scholarly research. Ideas of race (and by extension many renderings of ethnicity) that rest on notions of biology have been conclusively repudiated. There is a scholarly consensus that race has no biological basis - it is not a 'natural' or inevitable way of categorising or regarding human beings and visible physical differences between humans do not have a link to physical or intellectual abilities or character traits (Jones I996). However, this still raises the question of the on-going impact of ideas of race on people's lives and ways of thinking about themselves and others. The enduring power of race as a way of dividing people means that it continues to have effects: 


\section{Unequal choosing}

'although we might say there is no such thing as race as the intrinsic property of bodies, this does not mean that race does not exist as an effect of the very way in which we think, know and inhabit the world' (Ahmed 2002: 47). Drawing on the work of Judith Butler, Byrne has argued elsewhere (Byrne 2006b; 20II) that race needs to be understood as an embodied performative. That is, that the repeated citation of racialised discourses and the repetition of racialised perceptual practices produce the idea of differences, rather than being an effect of them. These socially constructed differences then, through mechanisms of individual and structural racism and racialisation, have an impact on people's everyday lives and life chances.

The fate of different racialised groups within the UK educational system has been given some attention ever since comparatively larger numbers of racialised minority groups entered the education system following the Second World War. Initially, this research focused on essentially conservative issues around how schools might be a site for easing the tensions understood to result from mass immigration of racialised groups - or how they might promote assimilation (Rattansi I992). This researched has included work on the 'underachievement' of racialised groups (Gillborn 2006, Burgess and Greaves 2013) as well as a focus on in-school relationships between children and between teachers and children. There has been a concern in this work on race to consider how racism is present in schools. This has included attention to teacher-child and child-child relations and bullying and lowered expectations by teachers of ethnic-minority children (Hewitt I986, Troyna and Hatcher I992). Scholars have also considered how schools might be sites of education in multi-culturalism and antiracism (Rattansi I992, Yuval-Davis I992, Bonnett 2000). Recently, research has become more attuned to the complexities of understanding minority ethnic experience in British schools. In particular, there is more awareness of the need to differentiate between ethnic groups, and to track how trajectories of arrival, settlement and placement in the system and processes of racialisation produce different outcomes (see for example Archer and Francis 2007). There has also been some interesting work on questions of race, ethnicity and gender. This includes work on racialised masculinities and the ways in which gender and sexuality interact with race in producing different learning cultures and opportunities (see Mac an Ghaill 1996, Archer 2003).

This section has outlined the approach to class and race to be used in this book and the next will focus specifically on the literature 


\section{All in the mix}

concerned with school choice, arguing that there has been a tendency (with some exceptions) for this literature to focus on the experiences of white middle-class parents without reflection on the ways in which their experiences and positions are racialised.

\section{Research on school choice: gaps in the literature}

As mentioned above, the focus on class and the reproduction of inequalities has a long history within the sociology of education (see Ball 2008 for a review) and mirrors in many ways broader shifts and concerns about class in wider sociology. Within the current focus on education and class, there is a desire to track how class - or socioeconomic status - inequalities fare as the education system is moved towards logic of the market rather than social welfare. In addition, education, and the composition of school intake, have been seen as an area of key concern in the 'genteel battles' (or perhaps not so genteel battles) the middle class are engaged in to assert and maintain their positions (Savage et al. I992: I00). As Bev Skeggs argues: 'choice is a particularly middle-class way of operating in the world' (Skeggs 2004: I39). For Reay et al., 'the educational system has become a central mechanism of white middle-class identity formation' (Reay et al. 20II: I9). Of course, with the existence of a private sector of education, as well as selection by geographical area, choice has always been available to those with the financial means to exercise it. Yet there is an argument that, as choice plays a potentially larger role in the state education system, this has the potential to further embed class (and racialised) inequalities. One area of focus has been the clustering of pupils with similar socio-economic status (largely measured through the numbers of children receiving free school meals $(\mathrm{FSM}))^{12}$ in schools and the impact this has on pupils' and wider social outcomes (Gorard 20I2). Schools are more segregated than neighbourhoods in almost all parts of England (Burgess et al. 2007). Burgess et al. have found that:

The interplay of the decisions of schools, parents and LEAs produces an outcome in which there is clustering together of pupils scoring well in the Key stage tests, and a clustering together of pupils from poorer backgrounds. This is unlikely to be to the advantage of the latter pupils. (Burgess et al. 2006: I4)

They found that clustering of pupils according to socio-economic background was higher where there was more choice. But they also 


\section{Unequal choosing}

found that sorting was lower in LEAs with comprehensive schools, even where there was choice. Burgess and Briggs (2006) have shown how pupils eligible for FSM attend lower-performing schools than those not eligible for FSM living on the same streets, suggesting that spatial dynamics and housing price alone cannot explain the difference. Nonetheless, as Allen et al. (20I4) demonstrate, empirical observations which show differences of school choice outcomes cannot explain the nature of the relationship between school choice and social class. Qualitative research, which is able to explore parental perceptions, is better placed to open up at least the parental side of the choice equation in ways which can illuminate some of the classed and racialised practices in choosing schools as well as the effect of different processes which enable some parents to achieve their most desired outcome.

One possible explanation suggested by both quantitative and qualitative research is that choice is a mechanism through which the middle classes can and do seek each other out, or seek to avoid undesirable others. It is interesting that there has been much less consideration of the possibility that some working-class parents might be equally seeking each other out - perhaps in the desire to find schools where their children will fit in and be comfortable. In the case of middle-class parents, it is argued that, for this group, the demographic make-up of individual schools is considered particularly important because much of the learning and socialisation which the middle classes most care about is to be done from interactions with fellow pupils as much as with teachers. Not all of the middle-class focus on education is concentrated in school choice, of course. Much of what middle-class parents do in the educational field may be outside of the context of schools, in extra-curricular practices such as music and sports and in everyday ways of being in a family and modes of interaction and conversation: the 'concerted cultivation' that Lareau describes in the USA (Lareau 2002). Nonetheless, in a context where choice amplifies the importance of parental action, there has been intense focus in the literature on the extent to which the middle classes may be 'working the system' - or, as Bourdieu described it, having a better 'sense de jeu' (sense of the game). For Stephen Ball,

choice policies, or post-welfare education policies, offer a social and political context, and produce social fields or social spaces, in which the middle class feel both at home and at risk, comfortable but uncertain. (Ball 2003: I67) 


\section{All in the mix}

Ball highlights the tensions implicit in having choice. Choice may seem like a good thing - especially if a sense of having discernment and good judgement is an integral way of your being in the world. Yet at the same time, choice introduces uncertainties and the feeling of the possibility of missing possible options, or making the wrong choices. It also raises the possibility for feelings of rejection and disappointment for children at an important and difficult point in their lives, in the transition to secondary school. In addition, as Sayer argues, 'for the middle classes, parenting has itself become deeply competitive' (Sayer 2005: I29).

It is a common thread in the literature on school choice and the middle classes to explore the desire to find a school filled with enough 'people like us' who will teach children 'how to be'. ${ }^{13}$ In a previous article, Byrne (2009) critiqued much of the literature on school choice for the way in which it failed to account for respondents' racialised positions - often by simply failing to explicitly report respondents' racialised position, particularly when they were white (Ball 2003, Croft 2004, Devine 2004, Bruegel 2006 and Raveaud and van Zanten 2007). ${ }^{14}$ Thus there was no analysis of how the accounts of white middle-class respondents, in particular, reflected concerns about racialised difference as well as class difference. More strikingly, the quotations from the respondents in this body of research often revealed their thinking about issues surrounding race and ethnicity and school choice, but these parts of their accounts were not commented on or analysed. In addition, the concerns of both workingclass and ethnic-minority parents have been somewhat overlooked in the literature on education and choice with its focus on white middle-class experience (see for example Benson 20I4, Perrier 20I2, Cucchiara and Horvat 20I4, Ball 2003, Ball and Vincent 2007, Devine 2004, Jackson and Bisset 2005, Power et al. 2003, Raveaud and van Zanten 2007, Reay et al. 20II, Snee and Devine 20I4). While this literature makes much of the desire for sufficient 'people like us' to give the middle classes a sense of safety and community, it largely fails to explore not only how this is experienced by working-class parents but also how this might be a racialised as much as a classed desire. There is a risk that, by focusing on 'middle-class' anxieties, practices and strategies around school choice, the assumption builds that somehow only those positioned as middle class (and often assumed to be white) are concerned to exercise choice and worried about how they exercise it. If we consider questions of belonging (May 20I6), then the desire 


\section{Unequal choosing}

to be with 'people like us' might be similar for those positioned as working-class and those from racialised minorities, who also don't want their children to suffer from snobbery or racism - or to have a 'fish out of water' experience (see also Reay and Ball I998).

In a study of primary school choice, Burgess et al. (20I5) found that the choices of parents from lower socio-economic-status groups were more associated with a preference for schools with larger proportion of FSM-eligible pupils, in contrast to parents with higher socio-economic status who were less likely to apply to those schools. Feelings of recognition and a sense of belonging may lie behind these differences. In addition, for ethnic minorities, the extent to which 'people like us' is racialised as much as classed may have a particular urgency in the wish to avoid experiences of racism (Ball, et al. 20II). Debbie Weekes-Bernard (2007) found that some Black and Asian parents faced a complex negotiation between wanting their children to be in a comfortable situation where they would not face racism, and at the same time wanting to avoid schools stigmatised for having too many ethnic minorities. The preference for more local schools may be the outcome of a combination of financial constraints and concerns for schools which are more comfortable for both parents and children to operate in. As Claire Alexander argues:

'choice' for BME families is not straightforwardly allied to notions of individual educational achievement or aspiration, but to an intersection of factors. These include structural barriers to accessing necessary information, institutional constraints on the kinds and quality of schools available to those families living in deprived areas, the demand for ethnic, gender or religion-specific provision and less tangible considerations around location, safety and reputation. (in WeekesBernard 2007: piii)

Quantitative research does suggest that racialised choices are being played out in schooling. In a study on schools in England, Johnston et al. found that: ' $[\mathrm{b}] \mathrm{oth}$ whites and non-whites are more concentrated into schools with their co-ethnics than predicted by a random allocation model' (Johnston et al. 2004: 246). In this study, they found evidence of higher levels of segregation in schools than in residence. In areas that were more ethnically mixed, they found a greater concentration of both whites and non-whites (this was particularly the case with Asian populations) (see also Burgess et al. 2005 for similar findings). 


\section{All in the mix}

Thus, the choice ambitions and practices of those with fewer economic, social and cultural resources can often be overlooked and their engagement in processes of choice ignored. For Reay and Ball (I997: 93):

Working class patterns of educational choice are characterised by ambivalence, and appear to be as much about the avoidance of anxiety, failure and rejection as they are about 'choosing a good school for my child'.

The selection of and attendance at school involves a series of dispositions and practices which draw on different classed capitals. Economic resources play an important role. This occurs at the mundane level of ability to visit schools that are further from home and also to contemplate sending a child to a more distant school, which may involve transport costs or require having the time and the car to drive children to school. But economic resources may also work at the level of moving house in order to fall into the catchment area of a 'better' school. Or indeed, as we shall see in Chapter 2, people may move to a particular area before having children because it has enough 'people like us' and then realise, less than coincidentally, that they also like the nearby schooling. Cultural and social resources are also important in giving parents the ability to access and assess the 'hot' and 'cold' information on schools - from appraising Ofsted reports to using networks to evaluate schools. There is evidence that different classes tend to use different sources for this and, as we argued in Byrne and De Tona 20I2, there are particular challenges faced by migrants who did not have their own education in Britain. The middle classes may well have a better 'sense de jeu' which enables them to get the most out of the education system. For example they recognise the importance of 'traditional' subjects which fit in to current 'hierarchies of knowledge' and help to secure access to the more prestigious universities (Francis et al. 20I7; Toth, et al. 20I5). ${ }^{15}$

Diane Reay (I999), looking at the experiences of both working-class and middle-class mothers, argues that middle-class parents are much more confident in dealing with the education system in general. This is likely to translate into confidence in negotiating the possibilities of choice. The middle classes may make more vigorous and successful use of the appeals system, and researchers have found that middleclass parents are quick to argue that their child is specifically gifted and/or needs special assistance and treatment which may assist their 


\section{Unequal choosing}

position in the appeal process (Ball 2003: 62, Devine 2004: 222). In the transition from primary to secondary schools, the middle classes may also be better at enlisting teachers' and other support, including private tuition where entry to grammar schools is based on exams which primary schools do not equip children for.

As we shall argue in this book, race and class are interwoven in the ways they shape the fears, anxieties, aspirations and desires and the social practices that are produced as a result of them. Thus the literature on school choice has frequently ignored the extent to which class and race should be understood as mutually constituted, even in those cases where issues of race do not seem to be present, because the research participants are all white (Byrne 2006b, 20I5). An important exception to this tendency to overlook productions of whiteness is Diane Reay and her colleagues who have explicitly examined the experiences of white middle-class parents in choosing 'mixed' innercity schools 'against the grain' of what might be suggested as general middle-class choices. For some, they argue, these choices serve to display their liberal credentials and secure their class position: mixed schools can offer a form of 'multicultural capital' (Reay 2008, Reay et al. 20II). In addition, more studies have now explored ethnic-minority processes of school choice. However, this has also tended to explore the experiences of middle-class respondents (Weekes-Bernard 2007, Francis and Archer 2005, Archer 20I0, 20II, Vincent et al. 20I2, Ball et al. 20II). Yet ethnic minorities may bring particular concerns to the question of school choice which interact with class in different ways. Some have highlighted how ethnic-minority middle classes share many of the parenting practices and strategies of the white middleclass counterparts (Lareau and McNamara Horvat I999, Archer 20I0, Ball, et al. 2002). However, there are complex racialised elements that set their experiences apart from those of the white majority. This may include concerns about their children facing racism in schools (as we shall see in Chapter 5), but may also relate to their ease as parents in interacting with school structures. For example, there is evidence that schools are more accepting of white parents' assertiveness than that of minority-ethnic parents, who also feel more ambivalent and reflexive and ultimately less confident in adopting the 'complaining parent persona' (Archer 20I0: 465, see also Ball et al. 20II). For racialised minorities, even those with economic and cultural capital, this may not translate easily into the ability to achieve the outcomes they want. Debbie Weekes-Bernard argues that: 


\section{All in the mix}

the current education market and its promotion of increased parental choice may require parents from some BME communities to engage in processes of 'flight', which may result in their children being educated in schools, and their families living in residential areas, where they form a clear minority. (Weekes-Bernard 2007)

Such flight then has potential social and cultural implications and the same parents were often worried about their children suffering increased racism as a result. This racism may include hostility and stereotyping from other children, but also from teachers and the school structures (Gillborn et al. 20I2, Archer 20II, Vincent et al. 20I2).

Nonetheless, as argued above, the greater part of the literature on parents choosing schools is focused on white middle-class parents and often fails to explicitly consider their racialised positions. At the same time, there has been growing concern about the achievement (rather than the choosing) of white working-class children - and particularly boys - in UK schools (Gillborn 2009). David Gillborn has critiqued the way that this concern for the 'white working class' tends to focus attention on questions of ethnicity (for example, looking at the differences in achievement between white boys on FSM and black African boys on FSM rather than class (the differences between the achievement of white FSM and non-FSM boys). Thus the slightly better achievement of African FSM boys serves to distract from the larger inequalities within the white group, where the white non-FSM boys are hugely overachieving compared to the white FSM boys (Gillborn 2009). In a popular discourse where the 'white working class' - or what are sometimes called the 'left behind' - are seen as a source of support for right-wing parties (depending on the era, of BNP, EDL; and, in the context of Brexit, UKIP and leave supporters), these constructions of the 'problem' of the white working class can mean that 'politicians and commentators invoke the threat of racist violence as a means of disciplining calls for greater race equality' (Gillborn 2009). In addition, as for the most part the only social statistics collected on school children are whether they are in receipt or not of free school means, the conflation of FSM and working class serves to obscure diversity of outcomes and experiences within the working classes - which includes denying the class status of ethnic minorities (Bottero 2009).

The following section will explore how school choice depends on certain spatial practices and relationships. This is a commonly overlooked factor in research on school choice, despite the importance of 


\section{Unequal choosing}

geography in decisions around schools which includes the role place plays in consideration of reputation of desirable and undesirable schools.

\section{Choices and relations as spatialised}

The question of place and spatial location has been an underdeveloped area in reference to much of the writing on school choice. ${ }^{16}$ Even for those schools which do not have distance from school as a criterion for residence, practical questions of getting children to and from schools dictate limitations as to which school they can apply to. This means that there are important interrelations between schools and local areas, and that parents negotiate school choice spatially. This spatial relationship is not confined to simply thinking of the schools that are near enough or convenient; also, as shall be discussed in Chapter 2, schools are understood at least partially through the reputation of area - and vice versa. A 'bad' school can play an important role in the stigmatisation of an area and can be the means through which both race and class are narrated in particular spaces. In addition, the potential for children to feel a sense of belonging in the school will be influenced by a more general sense of belonging in the area. While Bourdieu does not see the 'field' as a geographic space, it nonetheless has spacialised dynamics. Following De Certeau, we would suggest that places are made and claimed through engagements with wider social processes and societal structures. They are relational - the result of relations between people and between objects and people. Places are also storied - in that they are lived in and told through stories (De Certeau I984). We argue that schools can play an important role in shaping the narratives of particular places. Nonetheless, the spatial boundaries of a school community constructed by catchment areas may contrast with the 'tactics' of those who live in the surrounding areas and walk their cities through unofficial routes, daily encounters and shortcuts (De Certeau I984). Places and the interactions which take place in them provide one structure through which stories of the self, of community and belonging, of change and history, are told. Stories of place, particularly urban places, are temporal - telling of economic and population change, of people coming together, moving in and moving away. As Harvey points out, there is an 'intimate connection' between the 'development of capitalism and urbanisation' (Harvey 2008). 


\section{All in the mix}

Places are the setting of work and home-making and of politics, consumption and leisure as well as the setting for schooling. Inevitably, they are deeply gendered, classed and raced (Massey I994, Neely and Samura 20II). Stories about place are an integral part of race-making (Knowles 2003). For Harvey, the urban dweller is defensive, territorial and competitive about their urban space, creating spatial barriers or 'bounded space' (Reay et al. 20ıг: 56). Places, and stories about place, are relational and can tell us about who is constructed as an outsider and who has taken the place of the 'native' with claims to place as 'home'. Stories also carry valuations of place, with modes of narrating stigmatisation, degeneration, regeneration or gentrification. With migration, be that regional, national or international as the basis of producing the urban, these narratives have racial and cultural difference woven through them. Accounts of place are bound up in the elusive notion of reputation and the ways in which places are shaped by geographies of fear, neglect, pride, aspiration, nostalgia and trust, tied up in the production of affect (Thrift 2004). Space is a social product - produced through the relations of things and social relations within multiple temporalities For De Certeau 'haunted places are the only spaces people can live in' (De Certeau I984) while for Lefebvre: 'The past leaves its traces; time has its own script. Yet this space is always now and formerly, a present space, given as an immediate whole, complete with its associations and connections' (Lefebvre I991: 37). Places are not necessarily clearly defined, but shifting with porous boundaries. As will be shown in Chapter 2, people relate differently to schools which they have perhaps attended themselves or at least known of for a long time. These are indeed 'haunted places' with pasts that are not forgotten just through a change in the name of the school (a common move in attempts to 'rebrand' schools which have had poor reputations). We will see some of this 'haunting' where parents who have grown up locally still read schools through the reputation and their experiences of them in their childhoods, rather than relying on the current accounts told by the schools or Ofsted reports. ${ }^{17}$ In addition, the intake of a school can be one means through which a place comes to be understood as having a particular spatial parameter; as we shall see in Chapter 2, it interrelates with a wider narrative of place and community. Schools play an important role in gentrification, with white middle-class parents sometimes hoping for a critical mass of 'people like us' to turn a school around (Ball 2003, Reay et al. 20II). 


\section{Unequal choosing}

This may mean at times that the older-established white and nonwhite working class become priced out of an area.

Places, like schools, are heavy bearers of reputation where class and race can both work to mark places as somehow failed - thought of as problem places and problem people through what Paton et al. 2016 describe as 'territorial stigmatization'. This occurs in what Lefebvre calls 'representational space' - the space of the imagination which is produced through symbolic images rooted 'in the history of people as well as in the history of each individual belonging to that people' (Lefebvre I99I: 4I). Representational space is to be distinguished from the 'representations of space', the more official abstract mode of representing space which, in the context of education, is conceived by government and local planners as well as by school heads and admissions committees. But Lefebvre is also interested in spatial practices - the everyday interactions and the site of daily routines and the everyday ways of moving through the city for work, home and pleasure. Different spaces produce different modes of performance and competence to participate in: what Bourdieu might characterise as dispositions - or what Lefebvre calls 'spatial codes':

a means of living in that space, of understanding it and producing it. As such it bring together verbal signs (words and sentences), along with the meaning invested in them by a signifying process) and nonverbal signs (music, sounds, evocations, architectural constructions). (Lefebvre 1991: 48-9)

This is perhaps particularly true of the intensely social and also disciplined space of a school. The act of choosing schools requires relating to and deliberating on the implications of all these conceptualisations of space - from everyday practices, to official renditions, to emotionally overlaid questions of reputation - all of which, as we shall see in the following chapters, are also raced, classed and gendered. For parents, these acts of choosing are happening at a time when often they feel that their children are particularly vulnerable to the pressures to modify themselves to fit in. Thus, in thinking about schools as places of intense interaction and formation of the self, this question of representational space, with modes of stigmatisation and valorisation can potentially have a deep impact. Just as there can be territorial stigmatisation, places can also be remade through processes of gentrification. Savage et al. (2005) argue that particular sections of the middle class ('liberal metropolitan' - as opposed to the 


\section{All in the mix}

'corporate' or 'postmodern') embrace, and create, a sense of belonging in areas that they are attracted to because of their diverse and colourful nature. For Savage et al, these middle classes claim a sense of belonging - 'elective belonging' - through having made the decision to move into the area rather than narratives of having come from areas. Butler and Hamnett, examining the interplay between gentrification and education, argued that 'Non middle-class households do not have the necessary resources to devise and execute the complex strategies adopted by middle-class households for their children's education' (Butler and Hamnett 20II: 7).

As mentioned above, schools are often engaged in forms of branding in order to attract the 'best' children and parents. Courtney defines branding as 'any appellation or status representing or invoking a characteristic, or set of characteristics, which may be claimed by or attributed to a school to associate with other schools possessing the same status, and which is consequential in an education market' (Courtney 20I5: 8I3). This may take the relatively low-level form of a school advertising its results, but is also built on renewal of school buildings (the New Labour government in particular had a large programme of improving school buildings) and promotion of new uniforms with implied disciplinary codes that often go alongside school uniforms. Reputation is also developed in reference to 'competitor schools' in the same 'circuits of schooling' (Ball et al. I995). As we shall see in Chapter 3, these visual markers of schools do make an impression on both parents and children. At the same time, the reputation or brand of the school can also serve to mark the children who attend it and, by extension, their parents as either stigmatised or with social status. As Reay et al. note (20II: 2I), '[s]chooling is, then, a high-stake business in the formation of identities'. These brands and identities can be part of a complex interplay between the school itself, its reputation and intake and the reputation and intake of the surrounding area.

\section{Conclusion}

This chapter has set out both the location of this book within the literature and the gaps that it seeks to address. Questions of class, race, gender and inequality have long been central to research on schooling and have played an important role in the rise and fall and rise again of class analysis within sociology. The field of educational research has been particularly central to an approach to class which is influenced 


\section{Unequal choosing}

by the works of Bourdieu. However the chapter has outlined the ways in which the intersecting nature of class and race has been overlooked in research on school choice, including work influenced by Bourdieu. There is a tendency to focus on middle-class experiences and aspirations. The same would hold for gender and religion - which will be explored in later chapters. The chapter argues that, if we are fully to understand parents' accounts of choosing schools, we need to track how discourses of both race and class contribute to their understanding of desirable - or undesirable - schools. It is important to ask whether and how parents' talk about school choice is performative of race as well as class. In the literature on school choice, these questions are more often asked of parents who don't have racialised or classed privileges, although racialised and classed considerations are also likely to be as important in understanding the practices and motivations of the privileged. The chapter has also explored how choosing schools is spatialised, dependent as it is on certain geographical rigidities of practical and financial limitations. As the next chapter will explore in more detail, schools have an intimate relationship to the areas in which they are sited. Schools' reputations are dependent on the areas in which they lie, as location largely determines who attends the school. At the same time, changing representations of schools can alter the ways in which not only schools but also areas are understood.

\section{Notes}

I Lupton (20II), following Barker (20I0) prefers the term 'school markets and competition' to refer to the 'systems for organising school provision in which educational providers (schools) produce educational commodities (curriculum, teaching, facilities, ethos and so on) and compete with each other to "'sell'" them to consumers (parents, pupils)' (Lupton 20II: 3IO-3II). However, we will continue to use 'school choice' as a short-hand for describing that process - as we are focused on the specific process of parental choice.

2 www.theguardian.com/teacher-network/2016/may/04/parent-governors -schools-battle-engage-families, accessed i6 January 2017.

3 In December 20I6, fewer than I per cent of state-school-educated pupils went to free schools (Parliamentary statistics on free schools: file://C:/ Users/msrssbb3/Downloads/SNo7033\%20(I).pdf, p. 4).

4 www.gov.uk/government/publications/open-academies-and-academy-pr ojects-in-development, accessed 24 February 2017. 


\section{All in the mix}

5 www.tes.com/news/school-news/breaking-news/government-scraps-edu cation-all-bill, accessed 24 February 2017.

6 In term of governance, as a result of increased academisation, there is less direct oversight of schools by local authorities or other elected institutions - placing even more importance on market-based accountability for raising standards in schools.

7 See Bottero (2004) for a critique on this extension of class to the cultural.

8 Although there has also been a recognition of a broadening of classed practices by the middle classes which resignify formerly working-class practices (such as supporting football or liking popular music), which consumed in a similar way to classical music or cricket can be understood as a cultured omnivorous and middle-class practice. These examples alert us to the importance of considering how class is a question not just of what tastes you have but also, importantly, how you display those tastes.

9 See also Reay (2004) for a discussion of the misuse of habitus within educational research.

IO See Puwar 2009, Go 2013 and Loyal 2009 for a discussion of Bourdieu's reading of race, particularly in the context of Algeria.

II Although see Hage (I998) for an interesting take examining the cultural and symbolic capital wrapped up in racialised ideas of the nation and national belonging.

I2 Generally, statistics on income or class background is not collected in schools. However, 'free school meal' provision, which is an incomerelated benefit, is often used as an indicator of deprivation (although it relies on parents applying for the benefit and does not capture the deprivation of some immigrants who, depending on their residency status, are not eligible for FSM). See Gillborn et al. (2OI2) and Gorard (20I2) for further discussion.

I3 Although Reay et al. in contrast focus on 'against the grain' choosers who are prepared to 'risk' sending their children to inner-city multi-ethnic schools.

I4 This is a familiar characteristic of whiteness and white privilege which is protected by the ways in which it is ignored, silenced or unexamined; see Byrne (2006b).

I5 The Russell Group universities recognise this advantage and are trying to counter this uneven knowledge by being transparent about what they see as 'facilitating subjects'.

I6 See Kerr et al. (20I4) for a discussion of the importance of understanding the role of place and neighbourhood in educational outcomes.

I7 Ofsted, or the Office for Standards in Education, Children's Services and Skills, is a government body, established in I992, that inspects and regulates schools in England (and other services providing care and education to children). Every school in England is regularly inspected by Ofsted, 


\section{Unequal choosing}

which publishes a public report (available online) on the results of the inspection. Schools are graded from 'outstanding' to 'inadequate' and Ofsted has the power to place schools into 'special measures' if it judges schools to be inadequate. 


\section{2 \\ Imagining places}

\section{Introduction}

This chapter considers the spatial nature of school choice and introduces the three areas in Greater Manchester in which the study took place: Cheadle Hulme, Chorlton and Whalley Range. In the UK, despite the diversification of different types of schools and modes of admission, schooling remains driven by location. Given that 'choice' is limited (discussed further in Chapter 3), the clearest way for families to exercise choice over schooling in the public sector is to move to be nearer a desirable school. Every year, newspapers run articles explaining the extra cost of buying houses near good schools. In just one example of this, in 20I5, The Telegraph claimed that 'house prices in the postcodes of the best-performing, non-fee-paying schools [are] around 28 per cent higher than their surrounding area'. ${ }^{1}$ But of course this is a very uneven and unequal mechanism for choice - only some people have the means to move into the 'right' areas, whereas others are constrained by lack of resources, or, in the case of some migrant groups, lack understanding that this might be a way to exercise choice over schooling and that where you live might have a profound impact on your child's schooling (see Byrne and De Tona 2012 for further discussion). Whilst (as will be discussed below) the primary schools selected in this study may not have exactly matched the demographic make-up of different areas in which they were located, the chapter will explore how experiences of going to particular primary schools also played a role in shaping interviewees' perceptions of the area in which they lived. Running alongside questions of schooling itself, residential choices bring together spatial and social identities which are often heavily classed and racialised. Savage et al. (2005: 207) argue that 'one's residence is a crucial, possibly the crucial, identifier of who you are'. This intertwining of social and spatial identities 


\section{Imagining places}

means that where you live does not just reflect who you are: it also plays an important role in shaping who you are and - particularly when thinking about schooling - who your children become. In considering the spatial nature of school choice, this chapter will first explore the different features of the three areas of the study. The areas are not equally geographically close: Chorlton and Whalley Range are neighbouring areas in the south of Manchester, less than three miles from the city centre; Cheadle Hulme is ten miles from the centre, also in the south of Manchester. Yet, as with many cities in the UK, the demographic make-up of these small areas is relatively distinct, in terms of ethnicity and class. As the chapter will explore, these differences play out in how the areas are talked about by the interviewees. Having introduced the area, and the interviewees, the chapter considers the different narratives about place produced by interviewees in the different areas. It will show how, for some more than others, there was a sense of what Savage et al. term elective belonging, but should perhaps also be understood as affective belonging (Savage et al. 2005) in the areas in which they have chosen to live. Some interviewees have strong attachments to the area and do indeed feel that where they live in some way represents something about themselves - they are the kind of people who live in that area and have shared values and ways of being.

This has a knock-on significance for schooling as, even when they weren't thinking consciously about schools when they moved to the area, those with strong affective belonging are often reassured by the presence of people like them. As a result, they are relatively more happy with the choice of school which is available to them even if the process of choice can be stressful. As Michaela Benson argues, residential mobilities are entangled with the 'making and remaking of classed identities', even though it can happen with limited reflexivity, so that it appears to some as a 'natural' residential trajectory (Benson 20I4). Thus, as we shall see, for some, the question of choice is exercised before children are considered. For some of the interviewees, their pre-children residential choices influenced by spatial as well as social identities mean that they are already in areas with sufficient 'people like us', so do not have to make moves into new areas explicitly with the aim of getting into the right catchment areas for their children's schooling - they are already there. Thus what was essentially a prior process of choice can make the decision not to move to get access to different schools appear like a non-choice, masking 


\section{All in the mix}

how practices of race and class have shaped decision-making. ${ }^{2}$ Simon Burgess et al. (20I5), drawing on the Millennium cohort study, conclude that there is not a great deal of evidence that people move to get near better schools. However, it may not be possible in a quantitative survey to explore the complexities behind decisions to stay in, or move into, an area. Considerations about schooling may be enfolded into other broader questions of affective belonging which would not necessarily be accounted for in answers to a survey.

The happy 'coincidence' of finding oneself living in an area with enough parents like oneself is not the experience for everyone interviewed for this research; or present in each of the areas to the same extent. There are others who may move to a new area as a more conscious choice - in order to achieve for themselves (or their children) forms of social mobility through education. These practices fall less easily into a narrative of a natural, unreflexive, relationship between self and place as they require concerted effort and intention. In addition, as the chapter will show, it can at times risk feeling like 'a fish out of water' (Bourdieu I99I) where individuals can be made to feel that they are not sufficiently 'people like us'. Thus the chapter enables the exploration of accounts of people who feel less securely middle-class, or less securely respectable (Skeggs I997). As argued in Chapter I, these voices tend to be overlooked in research on school choice which is focused more on the (white) professional middle class which is confident of its place in society and also entitlement. At the same time, we will consider how migrant parents may not initially have the knowledge to understand the relationship between schools and place and they and others do not necessarily account for their living in particular areas as the result of conscious decisions or choices, even when they are generally happy with and comfortable in the area. This chapter will begin with an introduction to the fieldwork element of the research, introducing the demographic characteristics of the three areas and of the primary schools through which the parents were contacted. It will also explain how participants were contacted and brought into the study and give a brief overview of the participants and the content of the interviews. The chapter then considers the question of geographical mobility in the lives of the participants and the extent to which they narrate it as connected to questions of their children's schooling. 


\section{Imagining places}

\section{Cheadle Hulme, Chorlton and Whalley Range: the research sites and the schools}

In order to track the ways in which school choice is a spatial process, we sought to interview parents in three areas in Greater Manchester: Cheadle Hulme, Chorlton and Whalley Range. These areas were selected because of their socially mixed populations and different class and ethnic compositions. Chorlton and Whalley Range are neighbouring wards ${ }^{3}$ within central Manchester, and Cheadle Hulme is in Stockport, part of Greater Manchester. Ward-level census data for 20 II show that Chorlton has a large middle-class population (with 47 per cent of residents employed as managers, directors or professionals). As we shall see, the local perception is that it is dominated by a particular kind of middle class, what has been referred to as the 'new middle class', who as parents are 'liberal-minded, favouring more progressive forms of educational provision that are based on implicit forms of control' (Power 2004: 25-6). Whalley Range and Cheadle Hulme have similar occupational profiles, both with around 35 per cent of residents who are managers, directors or professionals. In terms of the ethnicity of residents in the areas, Whalley Range is most ethnically mixed, followed by Chorlton and Cheadle Hulme. Ward-level statistics from the 20II census show that 90 per cent of Cheadle Hulme residents, 82 per cent of Chorlton residents and 48 per cent of Whalley Range residents were white. This compares with the Manchester average of 67 per cent white. Thirty-one per cent of Whalley Range residents were Asian/British and io per cent Black/ Black British. International migration also figures more strongly in Whalley Range, where 26 per cent of the population were born outside the United Kingdom or EU, compared to 9 per cent of those from Chorlton and 7 per cent from Cheadle Hulme. ${ }^{4}$ In terms of religion, the majority of residents in Cheadle Hulme were Christian ( 65 per cent) with the next largest group being those of no religion (22 percent). In Chorlton, residents declaring no religion were a larger group than in Cheadle Hulme and of a similar proportion (around 40 per cent) to Christians. Muslims made up 8 per cent of the population in Chorlton. In Whalley Range, Christians and Muslims each made up about a third of all residents (with another third having no religion). Cheadle Hulme has a particularly high rate of owner-occupation (83 per cent - compared to 57 per cent for Chorlton and 45 per cent for Whalley Range) and a higher rate of married residents. Cheadle 


\section{All in the mix}

Hulme has voted Liberal Democrat in both local and national elections in the last couple of decades, whilst both Whalley Range and Chorlton consistently elect Labour representatives.

Thus we have a series of comparisons which the three areas offer. All are residential, more-or-less suburban areas with fairly good public transport to the city centre. Chorlton is the most prosperous area, with higher house prices, a higher percentage of professional and managerial residents and a higher average income. It has a relatively large white population compared to the Manchester average, but with fewer white people than Cheadle Hulme, which has a similar average income to Chorlton, but cheaper housing (with more owner-occupiers) and a slightly older age profile, with markedly more married residents. Whalley Range, by contrast with both Cheadle Hulme and Chorlton is the poorer area, with lower house prices and lower owner-occupation and lower average income (although a similar number of managers and professionals as Cheadle Hulme). It has markedly less white residents than either Chorlton or Cheadle Hulme and has a large South Asian, Muslim population. The demographic characteristics of the areas were broadly reflected in the school populations, although, as will be discussed below, ethnic minorities are overrepresented in all three areas schools compared to the general population of their ward.

In order to locate parents living in these areas who were in the process of choosing secondary schools for their children (currently in the last year of primary school and therefore ten to eleven years old), in September 2009 we approached three primary schools (one in each area) to locate parents. One headteacher made the very helpful suggestion that we should come to a parent-teacher evening and approach parents or carers ${ }^{5}$ there. Although this provided a selfselecting group (those parents who chose to come to speak to teachers about their children's progress), all schools confirmed that there was generally a very high turnout for parent-teacher evenings, especially in the last year of primary schooling. In terms of the primary schools ${ }^{6}$ which the children were already attending, in Whalley Range (Heath Primary School) the large majority of children came from ethnic minorities and there was a much higher than the national average take-up of FSM. ${ }^{7}$ In Chorlton (Longford Primary School), just over 50 per cent of the children were from ethnic minorities and there was a below-average eligibility for FSM. ${ }^{8}$ Finally, in Ashover Primary School in Cheadle Hulme, under 25 per cent of the children 


\section{Imagining places}

were from an ethnic-minority background, few of whom were at an early stage of learning English, and there was a lower than average eligibility for FSM. It is clear that the schools cannot be simply read off as representing the larger areas in which they are found. So, for example, taking just one characteristic, Whalley Range has a population of which 48 per cent are white, whilst at Heath Primary school only II per cent of students are classified as white. Equally, whereas the ward level statistics show 79 per cent of Chorlton residents are white, at Longford Primary, this figure is $5 \mathrm{I}$ per cent. For Cheadle, the figures are 87 per cent of residents are white whilst 76 per cent of students at Ashover Primary School are white. The differences between area statistics and school-level ones will be influenced by different age demographics for the different ethnic groups, with older residents tending to be white. But they may also indicate the effect of parental choice of primary schools and it may be that, in Whalley Range in particular, there is an element of 'flight', by parents who sent their children to schools in neighbouring areas. One parent who lived in Whalley Range did tell us that he had lied about his address in order to get into Longford Primary in Chorlton. ${ }^{9}$ In addition, as school catchments do not coincide with ward boundaries, school populations may reflect this. Heath Primary also draws pupils from neighbouring areas with higher numbers of ethnic minorities (such as Moss Side). Nonetheless, although the schools do not represent their very local areas exactly, this chapter will consider the parents' perceptions of those broad areas in which the schools were set and how they talked about how they came to live in the areas and therefore in the catchments for different schools. The next section will describe the characteristics of the sample and the interviews themselves.

\section{The parents}

Following the suggestion of the headteacher and approaching parents at primary school parent-teacher evenings proved a successful way of locating research participants. There was plenty of time to introduce the research as parents waited to see the teachers and the fact that we had been given permission to approach the parents suggested a school endorsement of the research which helped establish our credentials as researchers. We had more interviewees from Chorlton (I9) and Cheadle Hulme (I9) than Whalley Range (I4). The Appendix provides a table providing key features of all the participants who were interviewed between October 2009 and March 2010. Some 


\section{All in the mix}

Whalley Range parents did not want to take part in the interviews as they were not confident in speaking English. However, 50 per cent of the interviewees from Whalley Range were migrants, and almost all were ethnic minorities. Therefore we would argue that language, whilst an important factor, did not skew the sample too heavily (see Byrne and De Tona 20I2 for a further discussion of the experience of migrants in choosing schools). In general, the ethnic mix - as well as the social class position - of the interviewees broadly matched that of the schools in all areas. Once we had explained the nature of the research, and interviews, we then arranged to actually interview the parents later, generally in their own homes for their convenience. The interviews were conducted either just before or soon after the deadline for parents to submit their school choices for their children to the local authority. Thus, experiences of open days and weighing up the options were fresh in their minds. The majority of the 45 interviews (with 5I participants, as in some cases both parents were present at the interviews) were conducted by Carla De Tona, with a minority done by Bridget Byrne. Both Carla and Bridget are white and broadly middle-class and Carla was a migrant (from Italy via Ireland). The majority of the interviews were conducted with women, with only II men taking part, often in the form of joint interviews with their partners. This mirrors other research done on school choice and reflects perhaps women interviewees' greater willingness to volunteer for research as well as their greater involvement in their children's lives and schooling (see Chapter 3 for further discussion). In some cases, women either did not work outside the house or worked parttime, so had more flexibility in being available to be interviewed.

The interviews ranged over a series of topics, including how long the respondents had lived in the area; when and why they had moved there (if they were not born in the area). We explored the choices they had made around the primary schooling of their child and asked about their experiences of visiting schools and navigating the process of choosing a secondary school. We also asked what they were looking for in the schools and how they came to the decision in the family who had a voice and who made the final decision. The interviewees were prompted to compare their processes of choosing schools with what they remembered of the choice around high school for themselves as children. Finally, we elicited their views of the whole process of arranging secondary schooling. In general, the parents had a lot to say about these issues. They were in the 'thick of it' in terms of visiting 


\section{Imagining places}

schools, talking about them with friends and family and making the choices. They seemed to respond with enthusiasm to an opportunity to discuss their experiences although, as we shall see, some were more reluctant to talk directly about issues of race and class. As will be discussed in Chapter 3, for many the process of choosing a school for or with their children was quite a stressful process which they wanted to talk about. However, not all the parents were making the choice for the first time - for those with older children, it was often the case that the younger sibling would follow the older one and the decision was effectively made. These parents also had the security of knowing that their child was guaranteed a place because of the sibling policy. They were also able to reflect on the process of choosing school having also got to know the secondary schools a bit better through their children attending them. Some who had older children were able to compare the processes of choosing now with several years ago. As the next section will discuss, there were different broad trends in the ways in which interviewees in the three areas accounted for their experiences of geographical mobility and stasis and how they related to their localities.

\section{Moving for schools}

The respondents in this study, although living in relatively close geographical areas, had different characteristics in terms of their geographic mobility and quite distinct profiles in terms of movements into the area - whether these were international migrations, movements within Britain or coming from within Manchester. As we will discuss in more detail in this chapter, the interviews in the areas also gave quite different reasons for moving into the areas in question. Cheadle Hulme had noticeably higher rates of interviewees who had grown up in the area, or only moved relatively locally, while Whalley Range was characterised, as might be expected, by more international migration, and Chorlton by a mixture of local, national and international migration. It should be noted that these reasons were given in response to a question which asked whether local schools had been a factor in them choosing to move into or stay in the area. Thus it inevitably relies on their memories of their motivations. In addition, in responses to these types of questions, there may also be an element of performative parenting and/or belonging. For some, saying that you planned your move into the area on the basis of schools demonstrates serious and conscientious parenting and is a way of stressing the 


\section{All in the mix}

importance of education. However, for others, a more relaxed attitude about schooling (particularly at primary level) can be a demonstration both of confidence in one's own capacity as liberal middle-class parent to be able to ensure the good education of their child whatever the school, and a more 'right-on' attitude about schooling, and, as we shall see in later chapters, about the 'mix' in school.

In Cheadle Hulme four respondents had grown up in the area (compared to two in Whalley Range and just one in Chorlton - who had moved between Whalley Range and Chorlton). Furthermore, of those who had moved into Cheadle Hulme, the vast majority had grown up in nearby areas of Manchester - most often other parts of Stockport. Only three of the interviewees who lived in Cheadle Hulme had not grown up in Manchester (one had migrated from China and the others from London and Oxford). This is perhaps reflective of the classed profile of the residents in Cheadle Hulme who tended to have working-class or lower-middle-class jobs that often require less geographical mobility. The respondents from Cheadle Hulme, although they had often moved only from nearby areas, were relatively recent arrivals to Cheadle Hulme, having lived there for an average of 7.6 years (compared with I0.5 years in Whalley Range and 13.0 years in Chorlton). This meant that most had moved since they had had children and the majority said that schooling had been a major factor in choosing where to live. This somewhat contradicts much of the literature on school choice which, because of its tendency to focus on (often professional) middle-class schooling choice, fails to see the ways in which other parents also use tactics of geographic mobility in order to get their children into 'the right' or perhaps 'better' schools. As we shall see throughout the book, these interviews show that many parents of relatively modest income paid a great deal of attention to which schools their children were likely to go to and they were also prepared to move into areas which had what they considered to be better schools. Whether schools were better was often read off the general population of the area being better as in 'quiet' and not 'rough', in ways which we argue are raced and classed. In many cases, this move was discussed in terms of avoidance of the wrong type of mostly classed, but sometimes also raced, others. In the following sections, we examine how the parents living in the different places described the areas in which they lived and in which their children's primary schools and prospective secondary schools were located. The following section focuses on the responses of Cheadle Hulme 


\section{Imagining places}

parents, who were more likely to say that they had moved to get their children into better schools. Their sense of what they were looking for (and particularly what they were trying to avoid) demonstrate a more liminal position in terms of class. Here, residential mobility is used to ensure that their children go to the right schools, with the right classmates, in order to achieve or retain a middle-classness that might otherwise be perceived to be at risk.

\section{Moving to 'quiet' Cheadle Hulme and leaving the 'rough' behind}

As mentioned above, many interviewees from Cheadle Hulme had moved to the area from other often quite local areas in the period after having children. The reputation of local schools - as well as the behaviour of other parents and children, as we shall see below, played a crucial role in their decision to move into the area. However there were also other children-related reasons which prompted the movement (or stasis). Staying closer to home meant that they were also able to draw on family support - including, importantly, for childcare. As Emily explained:

The reason we came back to this area was, it sounds awful, but it was childcare because I wanted to go back to full-time work. My sister, she had just had her two children, so they were quite young, and she had a part-time job in a school. So it was kind of like ideal because the kids would be with her when she wasn't at school. (Emily, Cheadle Hulme, white, council worker)

As they had mostly lived relatively locally, respondents were also able to draw on their local networks to gain further knowledge about schools. Nonetheless, this also meant that they had at times to grapple with the changing state of local schools, where school reputations shifted over time. For some interviewees, or their partners, it could be difficult to reconcile their own childhood experience of a poor school with its contemporary reputation of being a good and improved school. The interviewees in Cheadle Hulme stand out compared to those in Whalley Range and Chorlton because the majority of those who had not been born in the area, said that schooling was an important factor in their choice to move to Cheadle Hulme. This often involved moving into what was considered a 'better' area. Residential mobility here was central to social mobility. It was a conscious rather than an unreflexive choice and represented a strategy which was adopted 


\section{All in the mix}

at the particular life-stage of having children and thinking explicitly about their education.

When describing the classed nature of Cheadle Hulme, the respondents perhaps inevitably also reflected on their own class positions and often demonstrated the ambivalence about class which was discussed in Chapter I. For some there was a perception of overlap between the area itself and their own sense of themselves. Here we see the intertwining of residential and social identities (Savage et al. 2005, Benson 20I4). Whilst some chose to describe themselves as 'working-class' and others as 'middle-class', there was a shared sense across the Cheadle Hulme parents that they were, as one interviewee put it, 'middling'. For example, Emma was a white secondary-school teacher who was married to a scaffolder. She characterised Cheadle Hulme as middle-class and her explanation of this shows the slippages that occur between considering the area and her own family:

I don't know why I would say middle-class. I think it's because we're not loaded. We've not got lots of money. It's not very posh. It's full of people who work, have enough money to get by most of the time. So it's not deprived. It's kind of in the middle. We're not up here with wads of money and social status, but we're fortunate enough not to be in maybe poverty or the lower band, if you like.

This narrative, where the social make-up of area could be summarised with reference to the self, was common in Cheadle Hulme as well as Chorlton and is indicative of forms of affective belonging where self and area are considered as mutually reflexive. However, as will be discussed below, this was not entirely sustainable for all the respondents as some had been made to feel that they didn't have the right kind of class markers (due to being 'young' parents or coming originally from a 'rough' area and having mixed-race children). Thus those on the edges of respectability (Skeggs I997) could be made to feel that they perhaps did not have the same level of 'fit' with the area and were looked down upon by others. This produced an affective burden of a feeling of fish-out-of-water rather than the feeling of comforting sameness.

For many of those who had moved into Cheadle Hulme soon after having children, the explicit desire was to find a 'better', often 'quieter' area. They had often moved to Cheadle Hulme from relatively nearby areas, still within Greater Manchester. For example, Annette, a white mother who worked in a pre-school nursery, had initially come from 


\section{Imagining places}

the south of England to live with her husband in Wythenshawe, an area some five miles away in Manchester. She explained her reasons for wanting to move away from Wythenshawe:

It's a particularly rough area of Manchester. It's not very nice. He had a nice house but the area wasn't very nice. It didn't bother him 'cause he was at work all day, but I was at home with the children and I didn't want to live there. And I didn't want my children to go to school there either actually. [...] we moved because I had looked at the primary school in - our local primary school where my eldest daughter was starting, there was no way I would have sent her there. The school itself was fantastic. Marvellous equipment. But I waited while the parents picked up and I just didn't want - I just didn't want my child to be part of that.

Here we see that it is not the school (or at least the material resources of the school) itself that is the critical issue but the nature of the area: 'rough'. This is a territorial stigma (Waquant 2008) which is nonetheless attached to the people of the area - rather than causing a reflection on social factors such as levels of deprivation. But roughness has an important implication for what kind of education parents thought could be gained in local schools. Considering the schooling of children - as well as being much more based in the area as a full-time mother - gave Annette a different sense of the area than her husband, and possibly herself before she had children. Her lack of affective belonging was highlighted as a mother. For Annette and others, schools and the streets around them could also be one locus of identifying the nature of the area. An assessment could be made by observing the behaviour of the children and perhaps more particularly their parents where feelings of denigrated difference (and potential fears around contagion) were sometimes invoked. The question of the behaviour of the children as a marker of an area cropped up in other interviews. For example, Jessica was a childminder who had also moved from a nearby area into Cheadle Hulme to be nearer to better schools. She explained that an important element in assessing an area 'would be how sort of like rough and street-wise is a nicer way of saying it [...] Yes, children who like to play on the street a lot and know their way around.' Annette also described looking at the behaviour of children and young people to assess the nature of an area: 'Just looking whether they look like louts or whether they [...] You know, if they look like, you know, if they look very rough and whether they look very smart and stuff, I suppose.' 


\section{All in the mix}

The act of viewing the behaviour of parents and children at pick-up and drop-off times was a common way to assess a school. Undesirable behaviour (perhaps parents shouting or swearing or a lack of discipline) around the school or generally in the area is seen as dangerous - something that children need protecting from - but also potentially contagious - representing undesirable models that the children might follow. There is an urgency in the need to shield children who are being saved from the contamination of class and the risk of becoming the wrong kind of people. Diane Reay writes powerfully about denigrated schools in the education system which are seen as 'beyond redemption' often by middle, upper and working classes alike:

Working class bodies are marked as degenerate or deficient or, in many cases both. There were also shades of paranoia; a fear of contamination in which mixing with the 'rough' children is seen to pollute 'nice' sons and daughters who risk being led astray or worse. (Reay 20I7: 6I)

In this study, as in Reay's, the term 'rough' functions as a euphemism for a classed perception of behaviours as well as styles of parenting - those who let their children play unsupervised so that the children become 'street-wise'. As Annette saw it, schools reflected the population they served: 'the reason they're poor performing is because the sort of children that go there are parents who are not that bothered about what their children are doing in the evening or where they are'. In the case of Wythenshawe which Annette is referring to, the understanding of it as 'rough' is racialised as white - in the often disgust-filled category of the 'white working class' - but nonetheless we see the conjoined 'stigmata' between deprived places and racial and ethnic difference (Waquant 2008). In this case, there is an othering and moral judging of a category of the white working class which is cast out from the 'right' forms of parenting and that can be seen as responsible for the deprivation they suffer, because they do not care enough about their children (Skeggs 2005, Tyler 2008). At other times, there were different racialising processes behind the notion of 'rough'. Despite living around eight miles away and otherwise not having any clear relationship to the place, in explaining what she means by 'rough' Jessica immediately thinks of Moss Side, an area of inner-city Manchester which has historically large numbers of African-Caribbean residents (and a reputation in the I980s and I990s particularly for gun crime). Moss Side functions as a referent for violence and risk: 


\section{Imagining places}

For me it's ... Sort of like Moss - do you know [...] There's places like round Stockport well not maybe as bad as that (laughing) with the shootings and things but it's got a reputation that way and there is - and there's areas that I feel in Stockport that have, for me, have got a reputation that I just wouldn't - I wouldn't move there. I wouldn't be happy there. So I didn't want my children being bought up there.

The affective response to Moss Side is clear here - it is a place that it would be impossible for Jessica to be happy in and where she couldn't imagine her children growing up.

Yet, for some respondents in the research, moving away from where they grew up to live in Cheadle Hulme was a conscious act of social mobility. Rachel, a white student nurse, had grown up in Gorton. She explained that, because her children were mixed-race (she was white and the father was black), she felt that life might be difficult for them. She had moved from Gorton, 'an area where it's quite ... a lot of things happen' to Cheadle Hulme: 'they need to have the best start ... I thought I want to give the children better than I had.' It is notable that Rachel does not fall back on the more pejorative language used by others and indeed hesitates to describe what she sees as the problem with the area she grew up in, falling back on the vagueness of 'a lot of things happen'. Nonetheless, despite her attempt to get something 'better' for her children, she found that the move to Cheadle Hulme had certain costs as her daughter had suffered for looking different from the other children:

See when we lived in Gorton, ${ }^{10}$ there was no problem because there's a lot of ethnic, different backgrounds, ... whereas when we moved to Cheadle Hulme there's not many. There's a few Asian people, I don't know if they're Indian, but not many mixed-race children. So I didn't know there'd be a problem, [...] I didn't even think she'd have a problem. Then children were saying you're brown, you know, just the things were you're brown or why does your skin look like chocolate? You know what children do.

As well as her daughter being made to feel different because of her racialised position - in a way that Rachel did not think would have happened in Gorton - Rachel herself experienced some of the costs of moving into an area which had more professional middle-class occupants than where she had grown up. She argued that 'we shouldn't really class people ... we're all equal'. Nonetheless, she felt that there 


\section{All in the mix}

were times when class was imposed on her through being made to feel like an outsider:

I feel lower class when I go to football with my son and we go with the private school and it's just where they train, they're not from the private school, but then a lot of the children, which I didn't know, go to the private school. A lot of the parents are doctors and then when they ask me what I do, and I say I'm a student nurse. They say 'oh we're paediatricians, we're this we're ...'. Then I feel like ... then they ask a few things about me and I say 'well I'm from Gorton really' and then I feel even lower and then it ... Whereas really you know, I go to work, I go to university I'm kind of middle-class. But I feel even lower when I'm with somebody higher class.

It is possible to sense from this account how Rachel feels the emotional burden of carrying a sense of territorial stigma about where she comes from and how this puts her potentially out of respectability (Skeggs I997). Rachel explains that she hadn't realised that the children going to the football club would be from private schools, suggesting that if she had known she would have perhaps avoided it. This indicates a 'tactic' (De Certeau I984) which she perhaps used in other circumstances for navigating the classed and racialised city (and was possibly reinforced by encountering classed and racialised hierarchies within the NHS). In the following chapter, we will see how parents in Cheadle Hulme considered private education and the risks it posed for making their children feel socially, culturally or economically inferior. In Rachel's account, we see the double edge to the idea that judgements are made about schools and areas by observing the people in them. The risk arises that you might be the person whom others judge badly. Similarly, Steve, a delivery driver, and his partner Melanie, a beauty therapist, had grown up around Cheadle Hulme and moved back to the area because they also valued it being 'quiet'. They also considered it important that they were comfortable in the area. This again for them suggested a kind of 'middling' position. Steve suggested that people in Prestbury (a village in Cheshire) might not want their children to go to school in Cheadle Hulme. And equally, 'I wouldn't want mine to go to school in Cheadle Heath' (a neighbouring area to Cheadle Hulme which was considered less affluent). Cheadle Heath, as well as other areas associated with 'council houses and people on benefits', was a common reference point as an area to avoid. Thus Cheadle Hulme for Melanie and Steve stood 


\section{Imagining places}

somewhere in the middle of a social order. This is the Monty Python version of the class system, where there is a clear order of looking down on others and being looked down upon. Whilst they describe Cheadle Hulme as somewhere that they are 'comfortable', they also remembered how, by having children at a younger age than was the norm for the area, they had felt that they were looked down upon when their children were younger.

Melanie: Cheadle Hulme's always been known for being quite well to do. [...] The majority of people are hardworking, care about it, the area tends to be a lot nicer than where people don't care, yeah. I don't want to sound snobby or anything cause we're not rich or anything like that -

Steve: No, we both work and just sort of take each day as it comes so we're by no means, can criticise other people because we're no better than them, but like -

Melanie: We work and we just want the best for our kids. That's all there is really.

Steve: We were young when we had them and now we've got to - Yeah we were very young. In fact there's an interesting one for you, when we first had Morgan and we took him to school a lot of the parents looked down

Melanie: - Didn't even speak to me.

Steve: Looked down at Melanie because she was very young, about I8, I9 $-[\ldots]$

Melanie: And going to school in this area whereas a lot of the other parents were say thirties - forties. Between like mid-thirties and forties they probably thought, young, baby - She must be on benefits, yeah it is a stigma attached.

In this account by Melanie and Steve, we see a multiple negotiation around hierarchies of value concerning parents and children. Having children young made them feel that others regarded them as one of those people 'right at the very bottom [... who] seriously don't care about their kids' education'. At the same time they suggest that they have a kind of affective belonging with an area which they distinguished from others because in Cheadle Hulme people 'care' about the area. In this context they claim respectability and affective belonging because they 'want the best for our kids'. Yet at the same time, they are situated as 'middling' because they 'take each day as it comes'. They are not like the 'rich' who have the means to plan for, and make investments in, the future. 


\section{All in the mix}

This section has considered some of the accounts of respondents in Cheadle Hulme who had often moved to the area in order to enable their children to go to 'better' schools. The next section explores the accounts of parents from Chorlton who tended to say they had come to Chorlton before having - or thinking of - children.

\section{Finding yourself in 'a good place to have children': Chorlton}

As discussed above, the parents from Cheadle Hulme, who had often moved to the area after their children were born, were more likely to say that schooling was an important factor in their choice of where to live. However, this may in part be a result of a slightly different classed discourse in discussing schooling and the ways in which the reputations of schools and places are closely intertwined. The parents from Chorlton were more likely to have moved there before having children - often when they were students or soon after graduation. Thus, when they first moved to the area, the nature of the schools was not necessarily relevant to their lives. As Michaela Benson argues:

The choice over where to live appears to be remarkably unreflexive and it is almost second nature to live in a particular type of residential environment. (Benson 2014: 3IO3)

Thus the idea of moving to improve the choice of available schools doesn't crop up significantly in Chorlton as the interviewees are able to narrate their move into the area as preceding children. Nonetheless, it was clearly related to the sense of moving to a place with enough 'people like us' or which in Bourdieusian terms, fits their habitus closely..$^{11}$ Thus, staying in Chorlton can then appear as a non-decision and a 'natural' residential trajectory (Benson 20I4: 3IO4). At the same time, some of the parents in Chorlton may, as Kelly, a school teacher, explained, have stayed in the area more consciously, once facilities for children, including local schools, became more important considerations:

We stayed here because we were thinking of our children. [...] after we graduated, we got together at university and after we graduated we did have the opportunity to move away but we were always planning to have children and it's, it's a good place to have children.

As we shall explore further below, for those parents from Chorlton what makes 'a good place to have children' goes beyond simply the 


\section{Imagining places}

quality of the schools, but includes also a range of lifestyle and consumption choices available. Indeed, the original move may also have been motivated by living (and consuming) among people with similar outlooks and perspectives. Chorlton emerges from the interviews (as well as in local popular representations) as a place with a distinct identity - which is viewed as middle-class and largely white, but with an openness to difference and what might be billed as 'alternative' lifestyles. It is, according to Savage et al. (2005), a place of elective belonging where people can belong by choosing to live there. This might also be characterised as affective belonging where belonging can arise out of sharing a range of values and lifestyles. For example, Harrison explained that he and his wife had decided to always have one parent at home full-time, with Harrison working (in advertising) for the first seven years and then they swapped it around so that he gave up work and his wife returned to work in the NHS. He summarised this situation as: 'we're very Chorlton in this house', taking it for granted that there would be a common understanding of what being 'very Chorlton' would imply. This sense of a shared understanding and identity in Chorlton contrasts with Cheadle Hulme which, as we saw above, is described as a pleasant and, more particularly, a 'quiet' place to live, but none of the interviewees give accounts of their local area as having a distinctive culture. It is interesting that, when describing why Chorlton is 'good' for families, there was almost no direct reference to schooling in the interviews. However, it may be that the importance of schools is so taken for granted that it is not regarded as worth commenting on. Chorlton was important for the way it contained like-minded people who perhaps were also engaged in the kind of 'concerted cultivation' which Lareau (Lareau 2003) identified.

As discussed in Chapter I, the literature on class and school choice tends to focus on the kinds of professional middle classes which predominately featured in the Chorlton sample. The Chorlton sample was dominated by middle-class professionals, often working in the public sector. Despite what might be expected from the media coverage given to the links between house prices and school catchments, only one couple spoke about schooling as influencing their choice of moving into Chorlton. This stands in contrast to Cheadle Hulme, an area characterised by less securely middle-class and working-class interviewees, many of whom said that their main reason for moving to the area was schooling. This does not necessarily mean that the 


\section{All in the mix}

quality of local state schools was irrelevant to the parents in Chorlton (indeed not a single interviewee in Chorlton was considering a private school for their child, so all were dependant on the local state school provision). However, perhaps they did not refer to schooling directly because it was implicitly behind other assertions about what they like about Chorlton, which include suggestions that it has 'enough' people 'like us'.

As suggested by Harrison, who saw his full-time caring role as 'very Chorlton', for many of the parents whose children went to the Chorlton school there was a sense of identity and a shared habitus connected to living in Chorlton. This was, as we shall see, a picture of a particular type of liberal and largely white middle-classness. At the same time, many expressed awareness that Chorlton was not exclusively white or middle class and the norm was to represent this mix as a positive aspect to living in the area. As we shall see in Chapter 5, mix was good (Savage et al. 2005, Byrne 2006a). In terms of class, Harrison explained that he was 'slightly different' from a lot of the people he knew in Chorlton because he came from a 'very workingclass background'. He described how he had been 'plucked out of the terraces' to go to a grammar school and seen as 'a bit dirty' by the sons of solicitors and barristers who went to his 'very traditional' grammar school. Whilst he saw himself as coming from a different background, he was also comfortable living in and identifying with the area. As mentioned above, many of those whose children went to the Chorlton school had moved into the area before they had children. They had often come from other parts of Britain and had moved to Manchester as students and then stayed on. Some had initially lived in other areas of (south) Manchester. For some this could feel like a well-worn track, as Fiona, a white freelance project manager, suggested: 'Chorlton seems to be the place that you move to after you've lived in Hulme. I think Chorlton, Didsbury or Hebden Bridge. You know, it's the three places, either that or London.' Here we are presented with a very exclusive list of acceptable places to live for this imagined community, including only one other place in Manchester (Didsbury). Hebden Bridge is a mill town in Yorkshire where residents have a reputation of working in the arts and is sometimes dubbed as 'the lesbian capital'. ${ }^{12}$ Fiona explained that she and her photographer husband had both become 'sick' of living in Hulme, a more inner-city area of Manchester (with some of the associations that the 'inner city' carries with it). For Fiona and her husband, Chorlton had various attractions 


\section{Imagining places}

which centre around consumption and lifestyle which made it an obvious choice (Benson 20I4):

Chorlton seemed like the most interesting option. It's quite a pleasant place to stay and, as a parent not getting into the city at night very much, there's quite a good selection of bars and restaurants, so it's enough to keep everybody happy.

Other interviewees who also appreciated the area for its shops and restaurants also described Chorlton as having a 'friendly' and 'village-y' atmosphere. The portrait painted of the area went beyond ideas of friendliness to include a particular orientation towards the world and others. Kelly, a white primary school teacher, explained that:

It's a good place to have children [...]. There's a lot of families with kids the same age and families with the same ideals, the same way of wanting to bring their children up. [...]. Things like, we're vegetarian and there's lots of vegetarians around which doesn't sound like a big issue, but if you want a vegetarian school dinner, you need to be at a school where there's other kids having that.

Kelly went on to say that:

I like the mix in Chorlton. [...] There's all kinds of people in Chorlton, which I like about it. But I also like that people are very accepting of each other. You can be a vegetarian and that's fine. Or you can be, I don't know, you can speak a different language and that's fine, or your parents can be gay and that's fine.

This was a view shared by several others of the Chorlton interviewees who found Chorlton, in the words of Fran, a white midwife, a 'nice place to live':

There's quite a diverse culture in terms of like people are quite alternative here. There's a lot of people that are maybe like, into like other things like lots of musicians and arts ... nice bars and cafés and you know people with the same sort of ethics I suppose ... like we don't eat meat. There's a lot of vegetarian places around here. A lot of people we know around here that are similar to us - we met at uni so it's just sort of the natural place to be really.

In a similar way to Fiona quoted above, it felt 'natural' for Fran to live in Chorlton where there were other people like her with similar values, and who were catered for by the local shops and restaurants. 


\section{All in the mix}

This is a celebration of diversity which seems to be represented by a particular bundle of ethical and consumption choices that could be summed up in the notion of 'alternative' (see Chapter 5 for further discussion). Chorlton benefits from being on good transport routes to the centre of Manchester but was, as described by several of the interviewees, 'friendly' where there were plenty of bars, shops and facilities which meant that people could stay local.

However, the interviewees were also conscious that the middleclass Chorlton that they described was not the sum total of the area. Whilst it was described frequently as 'friendly' there was also a sense of class division in the area which was characterised by geographical separation. Fran's husband Ken, who had not gone to university and worked as a courier, explained:

Well it's very much the two-tier thing that we said - there's this end of Chorlton where it's all middle-class and there's the other end of Chorlton near the school where there's a [...] lot of council - two big council estates near there and it's definitely a two-tier feel to it.

This feeling of the two sides to Chorlton was shared by others.

Nonetheless, as perhaps indicated in the euphemistic feel of the quotation, in Chorlton, as with Cheadle Hulme, there was sometimes a reluctance to talk about class difference, compared to other differences which can be embraced under the rubric of 'diversity' (Byrne 2006b). Terri, a white health worker, when asked about the class make-up of the area, hesitated at answering a question which she felt was asking her to take a superior or judgemental position:

Erm, class, I don't know, I mean it's difficult, I mean there's a lot of professionals who live in Chorlton but then you've also got areas like the Nell Lane estate where that's a council sort of estate, so I don't know, you don't like to make judgements on people's class do you? But it's quite, there are a lot of professionals in Chorlton, but it's mixed I think. [...] Well I mean just because you live on a council estate doesn't mean you're not a professional does it?

It's clear from the hedging and hesitation in Terri's quotation that class is something that she would prefer not to talk about, or thinks that it needs to be spoken about with care and delicacy. One exception to this reluctance was the project manager Fiona, quoted above, who volunteered a classed picture of the area without having to be prompted: 


\section{Imagining places}

It's quite a deprived area, really. It's a funny place. It's a mix of real arty-farty types and, you know, real kind of traditional working-class people. It's quite nice. [...] there's lots of sort of ex-students there as well. It's a, you know, it's an interesting mix because it's really quite - you know it's got its feet on the ground but also there's a real arty [scene].

Here we get a sense of a more unusual rendition of Chorlton being a comfortable or interesting area to live in because of the 'mix' in terms of class that it provides. This question of how class can and cannot be talked about will be returned to more generally in Chapter 5 which examines how parents talk about the social mix in prospective secondary schools. The chapter will also explore the experiences of a few ethnic-minority respondents who feel that they are excluded from this mix, despite the discourse of valuing a multicultural as well as a class mix.

The following section will explore how the residents of Whalley Range spoke about the area and how they had come to live there. In contrast with both Chorlton and Cheadle Hulme, where moving to the areas is presented as a positive choice, those parents who lived in Whalley Range tended not to talk about their move to Whalley Range using a discourse of choice. They were largely happy with the area and the primary schools their children are in (as will be explored in Chapter 3). However, as migrants to Britain, many have 'ended up' in the area in ways (drawn by factors such as the availability of cheap housing or joining family in chain migration) which tended to preclude a presentation of their move as an expression of choice. This also meant that their children's potential schools were not on the agenda when they thought about how they came to live in Whalley Range. Interviewees cannot necessarily give a storied narrative (Byrne 2003) of their 'decision' to move to Whalley Range, as it was not necessarily such a purposive decision. Nonetheless, some do describe their reasons for wanting to stay - many of which are associated with the convenience, support and safety provided by living in an area with high numbers of ethnic minorities, and, in particular, Muslim concentration. Whalley Range provides them with shops that sell the food they want to cook with, with mosques to pray in and with feelings of safety from hostility or racism as they walk the streets - and, as we shall see in Chapter 5 - for their children in schools. 


\section{All in the mix}

\section{Whalley Range (and Moss Side): accidental and affective belonging: 'I didn't have a clue'}

As mentioned above, the majority of parents in Cheadle Hulme said that schools had been a major factor in determining their move to the area. In contrast, in Whalley Range, almost no parents said that schools had been a factor in choosing Whalley Range to live (although as we shall see, some regretted this). The majority of the interviewees in Whalley Range were international migrants. ${ }^{13}$ This reflects the make-up of the school, rather than the area of Whalley Range (see the discussion on the research sites above). The majority of the parents had moved to Whalley Range before they had children, and residence in this area was often presented as accidental or perhaps fortuitous, rather than the result of a considered choice. Some of the more recent migrants did not have the requisite knowledge to think about the impact that where they lived would have on the schools their children attended - or have the information about schools to make that kind of judgement. As Fauzia, a homemaker from Bangladesh, explained: 'I didn't have any clue at that time'. When her daughter reached school age, she consulted her GP and landlord about schools and chose the nearest one as she didn't drive (see Chapter 3 for further discussion about knowledge and choice). In a similar way, Samer, who lived in Whalley Range, although his son went to the Chorlton school, explained: 'I wasn't aware how important the school is really. We bought the house and thought everything will come after, whereas it should have been the other way around' (Samer, chemical engineer from Iraq, Whalley Range). As we shall see in Chapter 5, Samer had moved into Whalley Range to escape the racism that he and his wife faced in a more white area of Manchester.

Helen, a teaching assistant of African-Caribbean descent, was one of the few parents in Whalley Range to talk about considering schooling in reference to where she lived. Helen had moved to the borders of Whalley Range and Moss Side to be near her parents. She laughed that, for her elder daughter, she had started thinking about high school 'when she was one or two years old'. She explicitly linked this to thinking about area:

You always worry about secondary schools and their reputation and [...] you have to think about where you're living and the schools close to where you're living at the time so you kind of have to think about in 


\section{Imagining places}

advance. Is it okay to stay, I think, here or should I get lost, go and move somewhere else where there's a better school around?

Helen was initially worried about living on the borders with Moss Side, with similar concerns as to those raised by Jessica (from Cheadle Hulme) above. In particular, she was concerned about its association with drug-dealing:

That was in the past I don't know - to be honest [...] To me, it's a very quiet suburban area but maybe to somebody else who knows the sort of people that are involved in that sort of thing it might not be such a quiet area.

Helen uses the same term as several of the respondents in Cheadle Hulme, of 'quiet' for what is desirable or attractive about an area. However Helen recognises that what she sees as 'quiet suburban' would not necessarily be the same for others - perhaps such as Jessica and others in Cheadle Hulme. Helen has not seen - or doesn't know the signs, she suggests - evidence of criminal behaviour. Thus, for her the area is 'quiet'. Jessica by contrast didn't have to see Moss Side to know its reputation. Nonetheless, what they share is a caution about behaviour and playing on the streets. As Helen explains, 'I didn't make it a habit to send my eldest on to the streets to play'.

Concerns about the area of Moss Side were not confined to Helen. Leyla, who came from Somalia and lived in Moss Side, worried that it wasn't particularly safe for children: 'sometimes they fighting, black people [...] many times the police come'. On the other hand, she felt that she had good neighbours and friends, particularly other Muslims. Thus we see that racialised understandings of areas are certainly not confined to white respondents. In fact, in the interviews, it was often non-white respondents, and particularly relatively recent immigrants, who were most explicit in talking about race. This may well be a factor of a slightly less good command of the English language producing more straightforward, forthright speech. It could also be that these respondents had yet to absorb certain cultural codes about a reluctance to name race (Harries 20I4). By contrast, with interviewees who have grown up in Britain, it is necessary sometimes to 'decode' some of their language about class and race (Byrne 2006b). As with the respondents in Cheadle Hulme, there were references to other to areas being 'rough'. In a similar account to Annette in Cheadle Hulme, Marion, a white domestic worker bringing up her grandchildren, described Clayton, where she had lived before, as 


\section{All in the mix}

'rough, so rough $[. .$.$] and the children were so rude, horrible there'.$ Moving to Whalley Range constituted for Noreen an escape. However, responses to the ideas of children 'playing on the street' varied. For some, it posed a threat perhaps both to the 'quietness' of an area, and also might suggest that local children were 'rough'. Yet Halima, who had grown up in Whalley Range, felt that the Whalley Range of her childhood was more 'child-friendly' because children could 'play freely' and 'not care'. In contrast, where she now lived in Chorlton:

is very quiet, people go to sleep earlier, so kids can't play out that much. There are children playing but even though we've got a park behind us, it's just still, it's different, not many children are around there.

In Halima's account, being 'quiet' was seen as negative and there is a sense that perhaps the quietness also involved scrutiny which made the children less free. Thus not only are there differences in how 'quiet' any particular area may be perceived as; there is also a potential dispute in the value of quiet. For the respondents from ethnic minorities, busy-ness and the presence of other ethnic minorities made Whalley Range an easier, safer place to live, forming an elective belonging which was different from those in Chorlton. There is also perhaps a racialised element to this difference of opinion on whether 'quiet' is something to be desired in a local area. In contrast to other areas which she saw as 'quieter', Fauzia, originally from Bangladesh, liked where she lived, close to the South Asian groceries near to her: ${ }^{14}$

Here, because all the shops are in Clarendon Road, this road is always busy, and the mosques are there. So people go to pray five times [a day]. So I feel safe walking through Clarendon Road [...] because there's all these people moving around.

The ethnic mix, and the provisions and affect that it produces, was what attracted many of the respondents to Whalley Range. That Whalley Range was not characterised by any particular ethnic group was attractive to Margie, a fashion designer, who came from Ghana but had moved to Britain from the Netherlands. She said she didn't want to live in an area which was mostly inhabited by what she referred to as 'black people'. In the Netherlands, she felt that in these areas 'they just want to get closer to themselves so they could help themselves'. In contrast, by living in a whiter area in the Netherlands, she and her husband 'discovered that we could teach our children to learn from both cultures'. At the same time, she was also wary of 


\section{Imagining places}

areas which might be 'full of pure British people [...] who don't want to get mixed up with other races'. Other interviewees in Whalley Range had expressly moved out of other, whiter areas where they had experienced racism and said that Whalley Range felt safer or more 'comfortable' because there was less fear of racism in general and Islamophobia in particular. ${ }^{15}$ For Margie, Whalley Range offered a mix with which she could feel 'very comfortable'. As we saw in the previous section, this language of mix and the 'right mix' was something shared by the residents of Chorlton. However, as will be discussed further in Chapter 5 , the relatively flat language of 'mix' can be used by different people to describe sometimes startlingly different demographic situations. ${ }^{16}$

The interviews with parents in Whalley Range are notable (in contrast to those in both Cheadle Hulme and Chorlton) for the relative absence of mentions of class in discussing the area - as well as a general avoidance of class-talk, even when asked directly about it. This was also the case when it came to talking about schools. For Helen and others, as will be explored further in Chapter 5, 'it's difficult to apply class to racial groups' and it would seem that this also applies to areas which are regarded as occupied by large numbers of ethnic minorities (Glick Schiller and Salazar 20I2, Vincent et al. 20I2). Whilst many of the Whalley Range parents had things (generally positive) to say about living in the local area, references to class, or what one might see as classed talk (such as Marion's reference to Clayton as 'rough' above) were the exception. In perhaps the only other extended classed discussion, Nasreen, a British-born woman of Bangladeshi origin, used the differing housing stock in Whalley Range and Moss Side to make distinctions. That Whalley Range's housing (described as 'leafy' by another interview) does have some streets of large detached and semi-detached Victorian houses (often divided into flats and some in disrepair) was important to Nasreen, compared to the smaller redbrick terraces of neighbouring Moss Side. Nasreen, a Bangladeshi translator, explained why she preferred to live on the western side of Alexandra Park (which forms a boundary between Moss Side and Whalley Range):

It's more about culture [...] even just the houses; when you look at the houses they're very old and they've got character. Whereas when you go to the other side of the park, I'm sorry but it's just plain boring terraced houses and I shouldn't really judge. But you can kind of imagine the 


\section{All in the mix}

type of people who would live there, do you know what I mean? [...] You have a standard and you stick by it. I have a standard and I stick by it. This part of the park I really do like and I'd like to stay on this side of the park.

This is an account laden with notions of classed judgements of culture, 'interesting' versus boring, and also of the clear slippage to conditions of living and the nature of people. However, it is worth remembering that this is an exceptional account in terms of the parents from the Whalley Range school. In Chorlton and Cheadle Hulme, as we saw in previous sections, narratives of class were much more readily provided, and they were also linked to ideas of ethnic difference as well as consumption and lifestyle.

\section{Conclusion}

This chapter has introduced the fieldwork on which this empirical study is based, covering more than fifty parents in three areas of Greater Manchester, including detailing how the respondents were contacted and the nature of the interviews. It has shown how the respondents largely reflected the demographic characteristics of the areas in which they lived - or more particularly the primary schools which their children went to. The three areas of Cheadle Hulme, Chorlton and Whalley Range offer the study the possibility of examining the ways in which race and class arise in the interviews with parents who live in, and whose children attend schools in, areas with distinct patterns of ethnic and class make-up. This then allows examination of the interviews in the known context of both the areas in which the parents live, the primary schools their children attend and the high schools they hope their children will get into (or those they most fear getting placed in). In the analysis of the interviews, the chapter has also explored the varied ways in which residents described different areas. It shows how spaces are constructed as both racialised and classed - and sometimes through oppositions to other places. In this way it begins the exploration of the intertwining of discourses of class, race or ethnicity, religion and other kinds of difference which feature in the different constructions of affective belonging (or alienation for those who are positioned more liminally). The participants were asked about what they thought of the area they live and how they came to be there. This provides an opening into the 


\section{Imagining places}

question of how spaces come to be placed in a biographical narrative and how this shapes what is said about them.

Much of the literature on school choice tends to focus on the professional middle classes and their concerns around schooling. This chapter argues that working-class and intermediate middle-class participants also put a great degree of emphasis on education and, in Cheadle Hulme, had moved into the area explicitly in order to be in the catchment for what they considered 'better' schools and as a move away from schools attended by a demonised working class. Thus the move into Cheadle Hulme was characterised as a transition from a 'rough' to a 'quiet' area where those who lived there were described as 'middling'. What is interesting about the material from Cheadle Hulme is that it suggests that we need to rethink the sometimes implied assumption from the literature on school choice, that this is a particularly middle-class obsession. In the interviews with parents from Cheadle Hulme, who have a variety of occupations and do not necessarily identify themselves as 'middle-class', we see that they have intense interest in their children's schooling and also frequently made schooling the primary factor in their residential movements. These accounts are largely absent in a literature which tends to focus on the more securely middle-class and their concerns around schooling.

By contrast with those living in Cheadle Hulme, the parents in Chorlton had often moved into the area earlier in the life course, before the schooling of children was a consideration. These participants had often moved into the area after university and were attracted to its location near the city centre, and the eclectic mix of bars and cafés as well as shops. They also enjoyed what they experienced as a concentration of like-minded people, who shared similar values and lifestyles - creating a different kind of affective belonging. Once they had children, they had decided to stay in the area (or did not feel the need to move on) partly because they were confident that the schools reflected their values. Finally in Whalley Range, the participants did not have the same discourse of choosing the area in which to live. Many had arrived in the area as migrants, following a range of routes, but often found themselves in a diverse area which felt comfortable. The idea of choosing an area because of its schooling was also not present. These parents' narratives of their relationships with where they lived provided a less secure narrative of choice and deliberation, although they were in general happy with living in Whalley Range. It 


\section{All in the mix}

is clear that places are frequently understood as both racialised and classed. This can produce different responses of belonging or outsiderness and, as we shall see in Chapters 4 and 5, responses of desire and fear. Thus Cheadle Hulme is felt by some to be comfortably 'middling' whilst others feel marked out by having had children 'too' early, or because they came from the 'wrong' area. Some Chorltonites were able to recognise themselves almost as part of a branded group with a set of liberal attitudes and consumption patterns. Some religious and ethnic minorities feel a security and comfort in Whalley Range in which some appear to have almost accidentally ended up whilst others positively chose to live in an area where the density of other ethnic minorities offered protection from racism.

The following chapter, Choice, what choice?', examines in more detail what the parents from the different areas of the study said about the process of choosing primary and secondary schools for their children and how they expressed frustration at what they saw as a lack of real 'acceptable' choices. It will also explore how responses to schooling differed by class and ethnicity as well as religion.

\section{Notes}

I www.telegraph.co.uk/finance/property/house-prices/II8II580/Mappedthe-price-of-living-near-the-best-schools.html, accessed o6 July 2017.

2 See also Byrne (2003) for a discussion of where a 'natural' life-course trajectory can appear almost unnarratable.

3 As they are neighbouring wards, many, but not all, children from the schools in both Chorlton and Whalley Range are likely to get into some of the same high schools.

4 Office for National Statistics, http:// neighbourhood.statistics.gov.uk.

5 We use the term 'parent', although in one case a child had a grandmother as his main carer, so she took part in the research.

6 The names of the primary schools, high schools and interviewees (but not the areas) have been changed to protect anonymity.

7 This information comes from the relevant Ofsted reports for the schools, but is not cited in more detail to maintain anonymity. The Ofsted reports do not give detailed statistics, but overview figures as have been reported here.

8 See Chapter I for further discussion of FSM.

9 One of the most likely options for parents seeking to avoid the schools of Whalley Range would be to go to Longford Primary in Chorlton. As the interview with Tej and Jas discussed in Chapter 3 illustrates, this 'flight' 


\section{Imagining places}

from particular ethnic-minority concentrations is not confined to white residents.

Io See Harries (20I7) for discussion of the reputation and lived experience of Gorton.

II This contrasts with Byrne's research in Clapham, Byrne (2006b), where some interviewees suggested that, although Clapham was an attractive area to live in, because many more middle-class neighbours sent their children to private schools the mix was not right in the local primary schools (see also Byrne (2006a)).

I2 www.bbc.co.uk/news/magazine-I6962898, published 20I2, last accessed 9 December 2017.

I3 See Byrne and De Tona (20I2) for further discussion about migrants choosing schools.

I4 See also the literature on the positive effect on physical and mental health of living in an area of ethnic density, for example Bécares et al. 20 I2.

I5 See Byrne (20I4a) for discussions of migrant experiences of racism and the development of understanding of geographies of racism.

i6 See also Byrne (2006a). 


\section{3 \\ Choice, what choice?}

\section{Introduction}

The focus on the question of choice in both policy and rhetoric around schooling can suggest that the parent or carer is king or queen of the process who should have the power to decide on the school their children attend. As we saw in Chapter I, the neo-liberal concept of choice as an automatic 'good', with the parent as an individualistic and rational consumer for their child, has been a driving logic in education policy since the I980s. Yet, as we discussed in Chapter 2 , admission to schooling is generally tied to geography in terms of nearness to school being a criterion of admission as well as the practicalities of a child attending a school which is far from where they live. Much of the geography of choice is, of course, mediated by classed and racialised geographies and the level of income of the parents, as well as sometimes being dependent on the employment situation of one or both parents. Thus, as we have seen in the previous chapter, one process of choosing a school, for those who can, is to move into an area which has a desirable school or choice of schools in it. In many cases, the process of choosing the 'right' area is a socially structured, relational and affective process. Areas and schools are assessed in similar ways, raising similar questions for parents: do they have people living in them whom I feel comfortable with? Would I like my children to grow up and be educated with the children of these people? This process can include judgements about the wider social and political values held by people living in the area and is highly classed and raced. Being comfortable in an area is a result of a mixture of values, consumption patterns and an affective sense of ease which is both racialised and classed (Ahmed 2004a, Thrift 2004, Nayak 20I0). It also carries with it memories of the parents' own schooling - these feelings could be summoned up quite viscerally: as 


\section{Choice, what choice?}

one mother put it, trying to work out what was best for her child was 'like me being back in secondary school on my first day with my little map in hand'.

Where you live and where your children go to school are both intimately linked to identity. The school you send your child to (as with where you live) will play a role in shaping who your child becomes. They both also say something about you as a person (Cucchiara and Horvat 20I4). The middle-class mothers of Maud Perrier's study (Perrier 20I2) engaged in an anxious 'concerted cultivation' of their children's education (Lareau 2003). They are haunted by the spectre of both 'bad' mothers, who do not demonstrate sufficient interest in their children's schooling and development, and the 'overly pushy' middle-class mothers who do too much (Perrier 20I2: 658). This chapter considers some of these anxieties in the process of choosing. It considers what it means to be offered a choice - or indeed be required to go through a process of choosing - yet to have few actual choices available. Chris Taylor argues that 'there now exists a mosaic of different educational markets, where the two key components of the reforms, choice and diversity, are unevenly distributed' (Taylor 2001: 368). For many parents, the experience is in part an 'unresourced choice' (Adams 2006) as they feel they are at the poorer end of this distribution. This chapter explores parents' experience of navigating this mosaic. As Chapter 2 set out, in Cheadle Hulme parents were more likely to say that schooling options had been part of their decision to move into the area - often from relatively local areas. This was often a specific decision to move away from schools with the 'wrong' kind of children in it. In Chorlton, by contrast, respondents had often moved to the area before having children. They had been attracted by the presence in the area of like-minded people (as well as, as we shall see in the following chapter, enough of and the right kind of 'mix'). In Whalley Range, there was less of a sense of agency described in coming to the area - although many welcomed what the area had to offer - particularly in terms of green spaces, local South Asian grocery shops and mosques which made them feel part of a community. The connection between school and area was less a part of the explicit decision-making process for some of the parents in Whalley Range (as we will discuss further in this chapter).

This chapter will examine the almost universal complaint by participants in the research that there is 'no choice' at the heart of school choice. It will track how the policy that parents should choose 


\section{All in the mix}

schools for their children produces a feeling of lack, both in terms of there being no 'acceptable' choices available and in the assumption, if there is only one school to choose from, there must be something wrong with it. Here we might see them as the neurotic citizen that Isin describes who 'governs itself through responses to anxieties and uncertainties', responding to a wider affect structure (Isin 2004: 223). The chapter will then explore parents' considerations of selective schooling - in terms of non-state private fee-paying schools and state selective education in the form of grammar schools (and some academies). The chapter will argue that, as with other elements of school choice, there are distinct local discourses at play. For some Whalley Range and Chorlton parents who were Muslim, the question of private schooling was mostly focused on the merits of Islamic education whilst for others there were political or ethical objections to selective education. In Cheadle Hulme, parents tended to be more sympathetic to both private and grammar schools, but worried nonetheless about whether their children would fit into these affluent middle-class contexts which were characterised by high cultural and social capital. Drawing on a more detailed case study of a mother from Cheadle Hulme, the chapter will argue that research which considers only the experiences of professional middle-class respondents fails to capture the anxiety around school choices of working-class parents who also invest a great deal of energy in navigating the 'mosaic' of school choice. It will also examine the gendered nature of parents' involvement in education. However, the following section sets the context for these affective processes of choice by examining the ways in which parents considered the choices (or in particular what they saw as the lack of choice) they were presented with as their children moved to secondary schooling.

\section{'Not a choice at all'}

The parents in all three areas were largely agreed that the idea of 'choosing' schools was often a fairly empty idea with choice being strictly limited (Raveaud and van Zanten 2007). This contradicted policy rhetoric around the question of education, where emphasis is put on parental choice. Thus Meredith, in Cheadle Hulme, was disappointed in this discovery: 'I was just under the impression that parents had more of an input into the school that the child goes to.' Her experience was that: 'I can only send him to a school that he can 


\section{Choice, what choice?}

get to and there's only two schools he can get to. So you don't really get a choice.' For Fiona in Chorlton, the choice seemed even more restricted:

I think there's really only one choice for children in Chorlton and it's the only one they get in. Unless you are - want to go to a faith school. For boys anyway, because there's the Queen's Road High School for girls but obviously he's not going to get in there. [...] I don't feel I've got a choice. There's only one school you'll get in.

There were other schools which Fiona could have realistically expected her son to get into (for instance a boys' only school and an academy). Both of these schools were situated further away from where she lived, with a more working-class and ethnically mixed demographic and were generally less well regarded than Parkside High. It seems that, for Fiona, as with almost all the parents we spoke to in Chorlton, these schools represent non-choices which have been already ruled out before serious consideration is given to the choice of available schools. Nonetheless, both Fiona and Meredith were suggesting that they had been sold the concept of choice which then wasn't available. Choice suggests that a decision will need to be made between viable options and, for both these parents, this did not feel like a real 'resourced' choice (Cahill and Hall 20I4). At the same time, many families had enacted choice much earlier in the process - before the filling in of local authority forms - in decisions to stay in, or move to, particular areas, as discussed in Chapter 2. Yet, choice and control over where to live was available only to those with the means to move and the knowledge that where they lived would determine the schools their children went to. In the previous chapter, Samer is quoted as explaining how, because he had come only relatively recently from Iraq, he had not realised that moving into an area was effectively choosing his children's schooling. This was just one of the ways in which the landscape of choice was particularly difficult for migrants to navigate (Byrne and De Tona 20I2).

Despite these differences in abilities to control the relationship between residence and schooling, the account of having 'no choice' was almost universal in the interviews, with a large number of interviewees expressing frustration that they were being asked to exercise choice between a very restricted number of options. Cliff, a white NHS manager living in Chorlton, saw this limited choice as part of a financial policy which reduced the number of secondary schools: 


\section{All in the mix}

We don't have a choice. No you don't have any choice if [...] everybody is clearly going to want the best local school [...] I think one of the things that's gone wrong is that, in order to make financial efficiencies, you tend to have a smaller number of very large secondary schools now with big distances in between them. And that cuts down choice because basically everyone wants to go to that one and then the next good one is so far away you can't get into it, you can't get into it. Whereas, when you had a larger number of slightly smaller high schools, then you had more choice didn't you? You might then have lived in a place where there were a couple of schools nearby that were acceptable but I don't think most people live anywhere like that now.

In the phrase 'that were acceptable' we see the possibility that, before making his 'choice', Cliff has already disregarded some schools that his son could potentially get into as 'unacceptable' - i.e. ruled out before a choice is made. Nonetheless, the tendency for secondary schools to get larger, and therefore choice to be more limited in any particular area, was noted by several respondents and is borne out by historical trends which have seen a reduction in school numbers and a corresponding increase in the average size of secondary schools (Bolton 20I2). Thus the rhetoric of school choice, and the increasing attention given to it by policy and media, has coincided with a narrowing of options for many parents. It was this paradox which some parents explicitly criticised. Kelly was a white teacher from Chorlton who was perhaps drawing on professional knowledge to criticise the discourse of choice:

So I think it's misleading in some ways to tell you that you have such a big choice. [...] I think it's just some daft government thing to make people feel empowered or, I don't, I think it's just getting more and more complicated 'cause you've got you know, sort of academy schools and comprehensive schools and grammar schools and private schools and church schools and they're all funded slightly differently and it gets increasingly difficult to then compare them properly doesn't it?

The experiences of Cliff and Kelly highlight how education policy in the last two or three decades has produced a proliferation of different kinds of schools, not necessarily more schools, which made processes of choosing more complicated for parents and does not make them feel, in Kelly's word, 'empowered' to choose positively. Thus school choice is made in an affective context where parents are given the responsibility to make a choice, but in an environment where it does 


\section{Choice, what choice?}

not feel like choices are available, thus producing anxiety and potentially a feeling of failure as a parent.

For some, this perception of not being able to exercise real choice because of a lack of alternatives led to a potential devaluation of the school in question. As Sara explained:

It's not like oh I've chosen Parkside High because I think it's the most amazing, fantastic school. I've chosen it because, well it's not a choice, well it is a choice, but I've chosen it 'cause that's the school, that is the only school [laughs] really that I think is via ... you know, in, in the area. (Sara, white student, formerly social worker, living in Chorlton)

Rather than making positive choices for schools they wanted their children to go to, parents often ended up feeling that what they were doing was accepting the school that was most available as 'good enough'. As mentioned above, this sense that there was only one possible school did in fact reflect implicit choices where other potential schools were ruled out of consideration.

Some parents, who framed inclusion in the 'local' or 'community' in a positive way and articulated a desire for their children to go to the 'local' school, found it easier to accept what was available. As Rebecca, a white local government officer from Chorlton, explained: 'it's about them being where their friends go, being somewhere they can walk to, being somewhere that's part of the local community'. As we shall see in Chapter 5, many parents (particularly in Chorlton) put a particular value on their children going to school which they saw as part of, and representative of (in terms of ethnic and, to a lesser extent, class 'mix'), the 'local'. Where the interviewees had stayed in an area in which one or both of the parents had grown up, there could also be a sense of familiarity and ease in the school choice. Jen, a white shopworker in Cheadle Hulme, explained that her son was going to go to his father's high school: 'Martin went, you know my husband, he went to that school and he was sort of quite happy there and I think he's always assumed that Josh would just go there'.

Whereas, as we shall see below, for some parents this kind of assumption might have been countered by the 'non-local' parent, here Jen presents this as something she is happy with. Although, at this point in the interview, Jen produces a narrative on not really choosing, this is not to say that she did not make a series of choices around her children's schooling. Jen explained that the family had moved from the area she'd grown up in because she wanted to avoid a 


\section{All in the mix}

particular high school. The move was required because of an effective narrowing of available options:

Well when I went to school there was a lot more sort of secondary schools. Now there isn't is there? So erm, when I, I suppose when I was going to school yeah there was, there was probably about six you could choose from.

There were others whose experiences of local schools left them more determined not to send their children to the school in question. Pam, an African-Caribbean midwife whose child went to school in Chorlton but lived in Whalley Range, explained how one school 'just wouldn't be on the list' of possible schools for her children as 'I went to the predecessor of that school and that was rubbish'.

Thus, as this chapter has shown, some parents were able to present the process of applying for a school for their children as relatively straightforward and stress-free due to an acceptance of, or accommodation with, a narrowing of choice. However, they were in the minority of cases as, for many others, the responsibility of choosing the right school for their children (perhaps particularly where the available choices were limited) was experienced as very stressful (this will be discussed in more detail in a later section of this chapter, considering the experience of Natalie). The next section will address one possible choice available (to those who can afford it) - that of opting out of the state system and trying to get into a private school, or, alternatively, pursuing selective state education in the form of a grammar school. As the section will show, the selective education system raises political and ethical questions for parents (as well as involving overcoming financial and academic barriers). Such choices are also influenced by class and questions of lifestyle and consumption, as well as summoning up memories of the respondents themselves passing or failing the Eleven-plus and the impact it had on their own educational biographies.

\section{Selective education}

A key way in which choice is driven by class and economic income is through private provision. ${ }^{1}$ There were some differences between the parents or carers in the three areas as to how they approached the question of both private and state selective education. As might be expected, this is partly driven by income and geography (in terms of 


\section{Choice, what choice?}

the proximity to grammar schools in particular). But it also indicates differing local discourses in response to both private and state selective education. This section explores these local differences in considering private and selective education showing how, in Chorlton, many parents produced a clear ethical or political response to private education and to children receiving different education because of their parents' ability to pay. Many also opposed selective grammar schools on a similar basis, given the use of tutoring to help children pass the Eleven-plus. These objections sometimes also extended to a questioning of what actually represented a 'better' education. In Cheadle Hulme, although many said that they could not afford to send their children to private schools, they tended to have a less overtly hostile attitude to the concept of private schooling. However, even within this relatively positive approach, some of the parents in Cheadle Hulme also raised questions of social justice and also asked whether private school would be the right place for their children if they could not keep up with their peers materially. The parents in Whalley Range fall somewhere between the other two in terms of their responses to questions around private schooling, but generally had less knowledge about the difference between private and state and less strong views overall. However, as we shall explore below, some of the Muslim parents in both Chorlton and Whalley Range had considered sending, or indeed sent, their children to private schools. We argue that school choice needs to be understood relationally and as experienced in particular affective contexts. People's attitudes to schools and the choices available to them are be influenced by others around them - from the intimate space of the family to discourses circulating in the local area, the school gates around pick-up times and wider media coverage. We will also discuss how educational choices can be shaped by individuals' own experiences of schooling - especially in the case of those who had attended grammar schools. The impact of some of these choices on parents' friendships will also be explored. The following section examines the views of those parents who had considered private Islamic education for their children.

\section{Private Islamic education}

Four of the parents interviewed (three living in Chorlton and one in Whalley Range) had sent their children (often the eldest child and not necessarily the one about to apply to high school) to private 


\section{All in the mix}

Islamic schools, either locally or for boarding. These Islamic schools generally cost about a third of the amount for the local private schools in Manchester and Stockport. The parents' reasons for sending children to Islamic private schools were largely about wanting to ensure that their children learnt more than the 'basics' of Islam. They also included concerns about mixed-sex education beyond primary level and the risk of children 'letting go of Islamic values' (Nasreen). Some of these respondents had sent their first child to an Islamic private school but realised that they could not afford to pay fees for all their children and had therefore returned to state education for their younger children.

Shahida's son went to a local private Islamic school for boys. She suggested that this was largely because 'my husband wanted to' and her in-laws influenced the decision even though they were in Pakistan (we will discuss the gendered process of decision-making later in this chapter). The fees for the school were being paid by her father-inlaw. However, it was too expensive to send her daughters to a private school also, so she had applied for the local girls' state school. Whilst the school being single-sex was very important to Shahida, her husband and his family, she also asserted that she 'wants more' for her girls 'to go to college, university, be something'. She now thought that:

In some ways it's better that they have gone there [state primary school], that they've seen things in a different way, in a different light, that they've seen things other than just being cocooned in a Muslim school. And they've been able to interact with other Muslims and non-Muslims. [...] So in a way I'm glad that they've actually gone to a non-Muslim school now. Because things have changed. Your views [change] over fifteen years because things have changed, the world has changed, hasn't it? And these are the next generation, these are the ones that are going to grow up and have to go in the big wide world and get jobs and work and interact, so in a way, I think I'm glad that they've gone there.

Here Shahida is presenting a version of the discourse of mix and exposure to difference (Byrne 2006a) that we will explore more in Chapter 5 . However it is also tied in with reservations about mixedgender education and the possible threat that that might pose to her children. For Shahida, whose husband is away in Pakistan, teenage daughters in particular are a heavy responsibility. 


\section{Choice, what choice?}

Not all Muslim parents wanted to send their children to Islamic schools. Sadia, who taught in a mosque, also explained how her brother had regretted his choice to send his daughter to an Islamic girls' school in Bolton, as this meant that she was required to do a long, tiring daily journey. Saira, who had considered an Islamic school for her children, decided against sending her children there: 'I would rather have my kid in a state school [...] because it's a mix of different cultures, different religions, that's the thing.' Similarly Samer, an Iraqi living in Whalley Range who felt socially isolated from the Pakistanis who lived nearby, explained that he saw religion as a 'private matter' and so did not want his son to go to an Islamic school. Whilst the question of religious schooling raises particular questions for parents which relate to family dynamics and their relationship to their religious identity and to community, the following section considers parents' responses to other forms of private schooling and shows, in particular, the area-specific nature of discourses around private schooling.

\section{Going private}

Samer, as we have seen, was uncomfortable with the idea of Islamic schools; he had also considered sending his son to a non-Islamic private school but couldn't afford the fees. He thought that a system based on ability to pay was unfair: 'if you are rich you can put your children in a better starting point in life, you know, because I pay taxes'. Here he is making an ethical claim to fairness which should be achieved through the tax system and publicly funded schools. You could also argue that, through his assertion that he pays taxes, he is making a claim for belonging and rights within the UK (see Byrne 20I4). Samer's son was sitting the Eleven-plus for entrance to the nearest grammar school (which will be discussed further in the next section), but he regretted that he had decided not to get private tuition for his son: 'I didn't believe in it, I thought I could teach him, I could prepare him, you know.' Samer's son went to school in Chorlton, and Samer was not alone in this context in providing a critique of selective education. It is perhaps unsurprising that some parents in Chorlton, a generally left-leaning area of Manchester, had quite strong views about private education. The only interviewee in Chorlton or Whalley Range who was currently considering a private education for their children who were about to finish primary school 


\section{All in the mix}

was a parent intending to send their child to an Islamic school. ${ }^{2}$ Opposition to private education was explained by Kelly, a teacher, and Cliff, who worked in the NHS (both are white):

We don't really believe in private education. I don't think it's ... I don't know, I think if you're part of the community, it's important to go to the community [school]. (Kelly)

From an ideological perspective [...] I don't agree with private education because people's wealth already gives people an enormous advantage and if you're eager then to buy a bespoke education it just feels uncomfortable. (Cliff)

However, Cliff's partner Ann interjected: 'but you would use it if the alternative was appalling', to which Cliff conceded: 'if the alternative was appalling, yeah, absolutely, yeah, of course yeah'. Here we sense some of the struggle behind certain school choices, where parents might find themselves in contexts which might lead them to go against beliefs which make up part of their sense of self as individuals and as parents (see Cucchiara and Horvat (20I4) for an example of this). These choices and beliefs can also lead to a sense of important fault lines between people. Fiona, a white freelance project manager, explained how she differed from some of her friendship groups: ${ }^{3}$

I've got lots of friend that'll fight tooth and nail, some without question, haven't even considered the local high schools. They've just paid for them to go to private schools. We're just different in that way.

Here she sees herself as 'just different in that way' from others, presumably white middle classes, in a way that fitted into Fiona's sense of living in Chorlton as discussed in Chapter 2. Here, not trying to get one's child into a private school is presented as a positive choice which was bound into her relational view of herself and her family. Fiona's sense of relaxation about her position was not shared by all. Pam, a single-parent midwife who had come from Jamaica as a child, described a feeling of exclusion for herself and her children from the opportunities that fee-paying parents achieved for their children:

Everyone would like their child to go to a private school. It's the best start in life really if you had the finances but it's just not possible. [...] It's like, it's almost like a closed system to those who haven't got the finances to even step beyond the door. It's like it's a different world altogether. [...] You see I'm not going to win the Lottery tomorrow and if 


\section{Choice, what choice?}

I had all the money in the world I'd send the kids to private school but it's not gonna happen.

For Pam, the inability to send her child to a private school was perhaps part of a more general feeling of exclusion what she saw as a 'different world altogether'.

Ken, a white courier living in Chorlton, shared Pam's conviction of the superiority of private education. He explained how, because of the underfunding of public services, a state-educated child 'cannot compete with fee-paying children' whose parents will make bigger demands on the school because they are paying so much for their children's education. Ken sets out a market-logic in schooling in which it would be safely assumed that the best education would be received by those who could pay for the best, leaving those without sufficient resources automatically given an inferior education and their parents feeling a sense of exclusion.

In Whalley Range, there was a relatively unusual situation where a former private school had been converted into an academy under New Labour in 2007. This was also a potential school for children from Chorlton and other areas as only a small proportion of decisions on admissions were based on distance from home to school. This school's reputation was shaped by its former fee-paying status, which was enhanced for visitors to the school on the open days by the original Victorian wood-panelled building and assembly hall, the academic-gowned sixth-formers who greeted visitors and the army cadets who displayed their military kit in the dining room. As Helen (a black British teaching assistant who lived in Whalley Range) explained, 'because it was a fee-paying school, I assumed that they [the students] had a positive attitude to learning'. Here we see that the benefits on offer from a private schooling may be not so much the facilities on offer but a sense of a better kind of fellow pupil. Class is rarely mentioned in parents' accounts, but it is clear that partly what is being bought is a disposition of both other parents and their children. Cindy, a white social worker living in Chorlton, explained why she was so keen for her child to go to this school, which spells out these assumptions:

And I kind of felt, and so did Mark [partner], that obviously there are still going to be children in that school up until like last week who were fee-paying children, do you know what I mean? So I kind of - sounds a bit kind of wrong this but in some respects I think, you 


\section{All in the mix}

know, education's really important and I just thought possibly parents (not that I could have ever afforded it) who are willing to pay fifteen thousand pounds a year to put their child through education are going to have like some kind of mentality, ethos, about their child's academic learning.

Cindy expresses a feeling of guilt about this preference to have her child surrounded by richer parents. She worries that it 'sounds a bit kind of wrong' and stresses that this is a considered choice on behalf of her children: 'education's really important'. This is, perhaps, a suggestion that, although following a fee-paying - or pseudo-fee-paying route - might clash with some of her values, this could be justified because of the importance of education. There is also perhaps feeling that these are altruistic choices, made on behalf of her children, rather than for herself.

In some sense, the prospect of a school which looked and felt like a fee-paying institution seemed to destabilise some of the choicemaking of the local area in Whalley Range and Chorlton. This was not helped by the uncertainties caused by this school's admissions criteria in which only had a small proportion of decisions were based on catchment area. This uncertainty in Chorlton and Whalley Range was also fuelled by the possibility of applying for admission to state selective education in the form of grammar schools in the neighbouring local authority area - this will be discussed in the following section. Nonetheless, there were some exceptions to the idea that private was always best. Whilst many parents took for granted that private fee-paying schools would offer a superior education for all children, Michael, a white company manager living in Chorlton, cautioned against the assumption that every child would benefit from going to a private school with high academic standards:

It suits some kids and not some others. We have seen, we've got friends and they put their kids through [a prominent local private, fee-paying school] and they've come out with really poor results, really poor. [...] A lot of people, a lot of parents think their kids are incredibly intelligent and they are not. Unfortunately, they are not and they cannot accept that. And that doesn't mean that you can't make them better, and they can do well, but not everyone is a genius in this world.

Despite his apparent hesitation about fee-paying education as better for all, Michael still suggested an implicit hierarchy where the most 'intelligent' children would be better served in private schools. 


\section{Choice, what choice?}

Whilst the general consensus in Chorlton was against private education, in Cheadle Hulme it was possible to detect a different local discourse around school choice and the private/state difference from the parents' accounts. Rachel, a white student nurse and single mother, explained that she was not considering a private school for her child. Nonetheless she expressed the pressure she felt at pick-up times from after-school activities:

I think, see in Cheadle Hulme there's a lot of private schools as well, so in Cheadle Hulme it's quite: 'what school do you go to?' and you say: 'Cheadle Hulme' and they go: 'oh the private one' and then you go: 'no the other one' and they go: 'oh'. Just like the way some people ..., but I think you can be educated just as well in one, I just think maybe the discipline, because they have to be paid for your child to go, they do a lot more with them.

This is a very different account of the school-gate or other parental discussions as represented by parents either from Chorlton or from Whalley Range. However, Rachel also expresses more equivocation about the inherent superiority of private schools. In Cheadle Hulme, five parents (out of a total of I9) had entered their children for exams for entrance to fee-paying schools and several more expressed having thought very seriously about the idea of applying to a private school. Several had also sent their children to private tuition in order to support their learning and/or prepare for entrance exams. The anxiety around this issue can be felt in Sharon's account. Sharon, a white single parent working in the public sector, acknowledges that there might be social justice questions around private education, but she presents private schooling as a way of providing her daughter with a better education than she had herself:

I'm not saying it's right, I'm not saying it's wrong but I, and I feel that every child should have the opportunity. I don't think it's fair that they don't but I do believe that private education, I just [feel] right down to my core [it] is the best education they can have. You know, it's - it's - it's, oh I don't, I don't even know. I'm not so educated myself that I know how to express it all, and obviously I want better for, for, for Rose [...] I feel like the - the - the ... there's an overall; the - the teachers are more enthusiastic to educate, the children that go there seem to be a - a better thing of child, they're not as disruptive. I'm not saying that, that you - that you - you don't get naughty disruptive but I don't think it's allowed as much in a private school, it would be dealt with a lot quicker. 


\section{All in the mix}

That child would be removed than they would in a State school. I just think everything is dealt with as a whole in these schools in a much better way.

As with Rachel above, discipline becomes a key marker of what a private school has to offer. In both their accounts, there is perhaps a suggestion that what lies behind this improved discipline is the exclusion of the wrong kind of child (who possibly has the wrong kind of parents). However, Sharon expresses a sense of her uncertainty and feelings of inadequacy faced with questions around education. The hesitation she expresses may partly root from the sense that she is treading in difficult ethical terrain, particularly when describing the qualities of other children. But yet she is presenting the narrative that the most important element that a fee-paying education provides is not so much physical and pedagogical resources but other children with the right dispositions, as much as academic ability. Sharon also makes clear the extent to which the desire to get the 'best' education requires both financial costs and a daily effort to ensure that her daughter will become the 'disciplined' child who will not only pass the entrance exam but also be able to perform the role of the ideal student:

For the last year she's being going to a private tutor. She goes once a week, but then I sit, we have all the work that he sends home and I sit and do all that with her. She hates that part of it, but I make her do homework every night as a structured thing in the house, she has some kind of homework. If she finishes, she does different things, she does a bit of dancing, and she does karate. [...] She doesn't like it, but I know that their, their homework regime is going to be very high standards at this next school, if she gets there. So I'm kind of trying to get her used to it now. So but she does go to a tutor, once a week, and I do as much at home with her, on top of that as I can.

In Cheadle Hulme, several of the children in the school were applying for admission to private schools. This, and the fact that some teachers promoted private or selective education, prompted others to think of it more seriously, and face the possible reality that they couldn't afford the fees. Melanie, a white beauty therapist working in Cheadle Hulme, explained that a teacher at the school had suggested that her son would do very well at private school. As she couldn't afford the full fees, if she wanted her son to go to private school he would have to apply for a bursary, which also seemed out of reach: 


\section{Choice, what choice?}

One of the ladies that comes into the salon, she works at [a local feepaying school] and she was telling me about an open day there and I think it was like, I mean don't quote me because this is completely a load of rubbish, but as an example maybe for every three thousand children that apply for a bursary maybe only, I don't know, five actually get one, so they've got to be the best of the best.

Alongside the unreachability of private schooling, Melanie, in common with several other parents in all three areas, worried about whether her son would be made to feel different in private schooling because he did not come from a wealthy family:

And I thought about it and actually thought, 'Well even if he did get through, I don't [think] it'd be fair to him because I don't think you could, we personally, could give him the lifestyle that the other kids would have'. [...] Like your house and you know if he's used to mixing with children from a private school and they're all from massive houses and they've got unlimited money and the school trips are costing hundreds and hundreds of pounds, we couldn't afford to compete on that level could we?

This led her to criticise inequality in the schooling system:

And I don't think, and I don't think that's fair, I mean [...] the lady I work with, her son goes to [a prominent fee-paying school] and it is a different life, and Jack, her child, has been to a private primary school and he's completely different to my kids, no disrespect to either of them but they are, they're worlds apart.

She went on to describe what she saw as the cultural or 'lifestyle' difference, or what Bourdieu might call habitus (Bourdieu I99I, see Chapter I) between her own state-educated children and the boy from the private school. This included his eating practices: 'Taylor and Nancy would want pizza and chips, whereas he would be ordering sushi.' The boy in question acted 'like a mini-adult and all he wants to do is have a debate with you'. In the end, she felt that her son would 'probably be happier with people like him[self]' rather than those so different. Melanie's concerns reflect an awareness of a set of different cultural practices, and embodied cultural capital, which mean that if her son went to private school he would face a need to learn a whole new way of being, which was not necessarily conducive to his happiness.

As with Melanie, another parent in Cheadle Hulme had been encouraged by the headteacher of the primary school to consider 


\section{All in the mix}

selective education for her daughter, including applying for a bursary for the local private school. Natalie, a white office worker (whose account we shall discuss in more detail below) described herself as 'tied up in knots' about the schooling decision. She was also concerned about what it would be like for her daughter to be surrounded by children with many more material resources:

If other children are coming from very affluent financial background and then you've got Grace that we're struggling [...] we're scrimping and saving in order to pay to give her that sort of education. [...] children will take any opportunity to pick on another child: 'where did you go for your holidays?' 'we went, you know, to Wales in our caravan. Where did you go?' 'I went to the Maldives darling, for six weeks!'

Thus parents have not only to navigate their own affectual responses to schooling and school choice but also to imagine how their children will cope in the different contexts. Natalie's daughter had weekly private tuition and she describes being been reassured by a tutor that there were many other parents who were equally conflicted about their decisions: 'He said "I've got other parents that one day they think this, the next day they think that."' Annette, who had a very academically able son, described how she had 'sleepless nights' over the decision of whether to send her son to a private school (which her husband favoured). The question of whether or not to send him to a private school had become a matter of debate in her wider family. Her sisters pushed her one way - 'just send him to the local school' - whereas her brother thought he should be sent to a private school because he was 'exceptionally bright'. This pulled her in two different directions: 'you just feel like an awful mother. You know, am I doing the right thing? So it was really, really difficult.' Here we see some of the pressures on parents, but perhaps particularly mothers (as we shall see in a following section), where others' perceptions of whether they were making the right choices for their children could position them as an 'awful mother' with all the social sanction that that label could imply. For Annette, a key part of the decision was to think of the impact this would have on her elder daughter who was already at a state high school:

She already - she quite often says oh, I feel like I'm the younger sister 'cause he's so much brighter than - it's obvious to her that he's brighter than her. She asks him things and he's two years younger than her. So I thought if we were to actually isolate him more and put him into a 


\section{Choice, what choice?}

private school, it would make her confidence - she hasn't got a lot of confidence anyway and it would reduce her confidence level more.

As we shall see below, the question of the impact on siblings of failing to follow their older siblings into selective education was also raised by parents in discussing grammar school education.

Being made to feel 'poor' and the impact on siblings were not the only reservations that parents had in considering private schooling. Several also expressed opposition to the social selection that feepaying schools necessarily involved. Meredith, a white working-class woman who lived in Cheadle Hulme, had considered the most local private high school. But she worried that her son might stick out 'for having a K reg car, that kind of thing'. But she also raised the question of what her son might miss by not going to a school with more of a social mix:

I'm not into snobbery and stuff so I think it's good that all schools get a mixture of people because otherwise, that's what life is isn't it, a mixture of people so if you're only used to one type of person, it's not preparing you for the real world.

Meredith is expressing an idea that the cultural capital offered in private schools might be too narrow (or even outdated). This echoes some of the findings of Reay et al. (20II) where middle-class white parents making 'against the grain' choices to send their children to inner-city high schools hoped that exposure to this 'cosmopolitan' mix would help their children in the 'real world'. Emily, a white local council worker, also felt that private schooling was not necessarily a good preparation for life.

There was a time we talked about the private school. I said no because maybe they've got better facilities, but I've seen people who go to ... And again, it's only what you see with your own eyes. They come out and think that they're sort of better than everybody else. You know, it happened to me [...] The girl round the corner, Heather, went to [a local private school], and actually, we both came out with the same number of GCSEs. She just came out with a real chip on her shoulder and thought the world owed her a debt of gratitude because she was elite, superior. And actually, do you know what? She wasn't. It was just because her mum and dad had a big bank balance and nothing more.

It could be argued that both Emily and Meredith, who would be very unlikely to be able to afford private schooling for their children, might 


\section{All in the mix}

also be shaping these discourses as a defence against the hurt in not being able to offer your children what is considered 'the best' which Pam described above. Yet this concern about private school education providing too narrow a social experience was also expressed by other parents. Samantha, a white nurse living in Cheadle Hulme, explained:

Some children, you know, go to a private school and they come out with lots of exam results but socially they're not able to make good social relationships with other people. And lead a, you know, a full social side of their life and that would be just as bad I think as coming out of school with you know poor qualifications.

For Stan, a waiter living in Cheadle Hulme who had migrated as a young adult from China, this construction of a narrow social group in private schools also had an ethical element:

If I put my kids into private school then does that mean that I'm teaching her to don't mix friends with a state school? Right so I think it's very wrong. [...] And I feel that a lot of kids go to private school, they feel that they are very special, right? Especially with England. English kids or whoever kids go to private school, they really, really believe that their classification is higher than anybody else. Under the circumstance I feel that it is not a good way of educate my kids and I'm a foreigner and I have - I have no intention to bring up my kid being prejudice in their mind to start off with. So she will be doing state school with everybody else. [...] Right and that's - that's fair.

Stan identifies a classed element to English national culture, although he went on to argue that this was shared (or adopted) by many others in the Chinese diaspora living in Manchester - an approach to class and education which he rejected.

This section has shown that there were different discourses circulating in the different areas about private education. For some, notably those living in Chorlton, the question of private education raised political and ethical issues which shaped the way they spoke about the sector and how they saw themselves in relation to parents who would pay for private education. For others, their inability to pay the private fees meant their children were automatically ruled out for financial reasons from what they assumed to be a superior form of education. At the same time, they harboured doubts as to whether their children would in any case be happy in a setting where the other children would be so different from themselves. For most of the 


\section{Choice, what choice?}

respondents, grammar schools ${ }^{4}$ do offer a form of selective education which is (largely) not based on financial status. The following section will discuss how, just as earlier experiences of schools in an area can influence parents' perceptions, the respondents' own experience in different sectors within the educational landscape sometimes shaped their views of the available choices, particularly in relation to grammar schools.

\section{Selective education: grammar schools}

None of the three areas in which the parents lived had selective grammar schools. ${ }^{5}$ However, in all three areas, it was possible to apply for admission to the selective state grammar schools in the neighbouring authority of Trafford - although this would require a longer journey to school for their children. The journeys involved were perhaps most feasible from Chorlton and, to a lesser extent, Whalley Range and Cheadle Hulme. Thus it was in Chorlton that the question of selective state education was a particularly contested topic. It is also interesting that it is with reference to discussing grammar schools that the question of the parents' own educational experience seems to have the most direct impact. For those interviewees who had sat the Elevenplus $^{6}$ and therefore either been (or failed to go) to grammar schools, this pass or fail provided a linchpin on which educational narratives would pivot. As Reay et al. (20II: 38) found in their study, educational choices as parents were often shaped by a person's own experience of education - although this would vary between those who were seeking to avoid their children experiencing what they had done, and those who sought to replicate it. Cliff, a white NHS manager living in Chorlton, explained how he had failed the Eleven-plus in the early I970 and went to a secondary modern school which 'basically was a holding place for people who had failed the Eleven-plus. There was no expectation that anybody would come out with any proper qualifications.' Before discussing the question of his preferences for his son he stated:

It might be worth noting that I am ideologically opposed [to] sending my children to a Trafford school because they still make a distinction between grammar schools and secondary schools. Which I absolutely ideologically oppose. [...] Well it's just mad, you know. Everyone talks about how good grammar school is but nobody actually ever talks about the other schools where people who failed the Eleven-plus go to and 


\section{All in the mix}

generally they're poor schools. Schools and where people don't flourish as well. So I'm opposed to them.

Cliff's sense of the overall effect of selective state schooling on educational outcomes and social mobility is supported by current research (Boliver and Swift 20iıa, 20IIb). Cliff had an elder son, who had had to take the Eleven-plus because they were living in Trafford at the time. His son had also failed the exam and, drawing on his own personal experience of education, Cliff felt that his son's later educational success ('which only shows how ridiculous a test at the age of eleven is') was due only to their move into the Manchester educational authority. In a similar vein, Rebecca, a white local government worker living in Chorlton, explained that she had specifically avoided living in Trafford because she didn't want her child to be in the Eleven-plus system:

I just think it's really cruel. Why would you want to put your child through an exam if they didn't need to, to get into a school? I think it's really cruel to do that to a child at eleven, it's a lot of pressure on them. Because it's not like an exam [where you can say], 'oh you can do better next year' or whatever. It's like a real - that affects the rest of your life. So I think it's wrong to put children through that at that age.

Rebecca had gone to 'the local school' and she raised issues of the social mix in a similar way to accounts about private schools detailed above:

I wouldn't want to send them to a school where there's any sort of selection really. Where it's only a certain type of person, whether that's only girls, or only people that have passed their Eleven-plus or only people from a certain religion. I think, well, we live in a community full of lots of different people, so why on earth would you want to separate out groups for your child's education? Part of growing up is mixing with people from wherever.

As Rebecca described, the outcome of the Eleven-plus is often seen as a moment which 'affects the rest of your life'. It was certainly something that framed several accounts of parents' choices. At times, experience of the Eleven-plus was credited for producing different attitudes in a couple toward the choices available. Meredith, who lived in Cheadle Hulme, explained that:

My husband wouldn't agree, but I would like for him to have the option in Stockport of like - some sort of state grammar school. But there isn't so, there we go. 


\section{Choice, what choice?}

Why would your husband not agree with you?

I think because he failed the Eleven-plus [laughter]. So he thinks it's a waste of time, anyway, but I don't know.

However, it is not only those who had failed the Eleven-plus who opposed the system of selection. Several of those who voiced opposition to grammar schools had themselves passed the Eleven-plus and attended grammar schools, but they still rejected the system. It was almost universally taken for granted that children would need tutoring to pass the exam. Many parents objected to this need for tutoring to pass the exam and also worried that a child who had been tutored to pass might struggle once they were in the school. Harrison, a white homemaker, living in Chorlton (and also discussed in Chapter 2), was concerned that, if he went to grammar school, his son might not flourish without a lot of support. As someone who had gone to grammar school himself he also had reservations about 'the old stuffiness about it, being a grammar school' so he was relieved that his son was interested only in going to the local comprehensive. Sara, a white student who lived on the Chorlton-Trafford border, characterised her objections as both political and personal:

I object to them on political principle. And personal principle, 'cause I went to a grammar school and I ... I mean it was, you know, years and years ago, but I hated it, I hated everything about it, so for me I wouldn't want her to go to that school. [...] All they banged on about was results and education and this, that and the other. And I came out with, with very little because they were only focused on academia, academia, academia, so for me, I'm just thinking, ooh I don't want, you know, I don't want that for my child.

This objection follows a Bernstein-type distinction between instrumental and expressive education cultures (Bernstein I97I) in which, in the former, academic or formal school knowledge is given priority, as opposed to, in the latter, a focus on values and character. Interestingly, Sara thought that the particular primary school her children went to was characterised by this discourse of opposition to grammar schooling, which distinguished it from other schools in Chorlton:

I think at a lot of other schools it's a bit of, some of the other schools in Chorlton they're a bit of, 'oh my God what school?' They don't want to send their children to Parkside High [...] they want them to go to Blessingham Grammar and dah, dah ... you know. [...] I mean 


\section{All in the mix}

especially at our school I think, you know, it, it's a bit frowned upon for people wanting to send their children to the grammar school, there is, because there's a political motivation there, it's like, why send them to a grammar school?

This reminds us that the school from which the Chorlton participants were drawn, as discussed in Chapter 2, represents only one (potentially self-selecting) section of the area. Interviews with parents whose children went to other schools in Chorlton might have thrown up different experiences and different accounts of Chorlton itself. It also suggests that some of the discursive and affective contexts or habitus that parents operate in and relate to are small and may vary considerably from others which are geographically relatively close. At the same time, it also demonstrates the extent to which the respondents themselves had an awareness of how discourses around schooling circulate and differ from each other.

As we have seen in the case of Cliff (above), some parents we interviewed also drew on previous experiences with older children. Serena, an African-Caribbean nurse whose daughter went to school in Chorlton, had an older daughter, now in her twenties, who she felt had been blighted by failing the Eleven-plus:

I wish I'd never let her take the Elven-plus because she failed it [...]. It damaged her self-esteem and she didn't do so well at school and I think she carried that on with her even though I encouraged her, I helped her and it took a lot she then felt that, that she wasn't intelligent enough and I don't like kids to go by this intelligence. [...] It took her ages, her self-esteem was terrible until she went to college [...] and it started to pick up really slowly. [...] Her self-esteem it took ages, about ten years for her to get that back.

Several interviewees had got private tutoring for their children who had taken the Eleven-plus. For those whose children failed, it had been a difficult experience. Tej from Chorlton explained that it had been her son who really wanted to try for the exam, influenced by his friends who were also taking the test. When he failed 'he was devastated [...] I must admit. I was quite surprised about how upset he was'. In the following section focused on the experience of Natalie, we shall see a very similar account of parental surprise at how strongly their children had taken success or failure at the Eleven-plus to heart. However, other parents told of children who did not want to engage with tutoring and the Eleven-plus exam, who had managed 


\section{Choice, what choice?}

to drag their heels enough to put their parents off the idea of grammar school. Although we consider later in this chapter the gendered nature of decision-making over schooling, we do not discuss at length the balance of generational decision-making power between parents and children. This was largely because the parents interviewed almost overwhelmingly suggested that children were consulted but the final decision was steered by the parent. However, it is clear that some children had more power than others to influence the process, and non-engagement with tutoring for the Eleven-plus is one example of this. Alia, a British Pakistani homemaker who lived in Cheadle Hulme, had been to grammar school herself and both she and her husband thought that it would be good for her son to go to a grammar school. She had also been encouraged by the school to consider it:

But if you want to try for grammar school, you have to prepare a year beforehand. He wasn't interested in trying, so basically the decision [was made]. You know, you can't do it at the last minute, you have to prepare a year beforehand. I mean, I would have liked him to go, but I wasn't going to push him.

Similarly, Kelly's daughter was opposed applying to grammar school:

She refused to do the entrance test for that because she said it was discriminatory and she didn't agree with it [...] because it's a test of intelligence and she thought it wasn't fair to just skim off the brightest children and put them in one school together. [...] So I thought, 'fine, if she's made that decision [laughs] that's her choice. I can't argue with that'.

In contrast, Samantha, a nurse living in Cheadle Hulme whose elder daughter had passed the test to go to a highly regarded grammar school, decided in the end not to send her daughter there. Samantha also did not like the fact that the school was only for girls and she was confident that she 'would have done equally well at a local school'. This confidence about one's child's education was not particularly common among the respondents and is not fostered by the affective context in which school choice operates which appears to be driven by anxiety. As we saw in the discussion of the impact of the Eleven-plus on the respondents' own educational biographies as well as their general approach to choice, navigating the question and mechanics of school choice was at times an emotional process for the respondents. In the following section, we consider the example of someone who 


\section{All in the mix}

presented herself very clearly as an 'active chooser' who took a range of measures to exercise choice. Natalie gave a striking account of her anxieties over schooling and the steps she took to achieve her desired outcomes which illustrates how the focus on professional middle-class respondents in much of the literature misses the levels of concern and effort displayed by those who are less securely middleclass. The section also considers some of the affectual processes that choosing and applying for schools involved.

\section{Natalie: 'I know my child'}

Natalie, a white part-time office worker from Cheadle Hulme, took a very different position from those who accepted the limited choices available and embraced the idea of a 'local school'. For Natalie, the process of taking control of the schooling of her daughter had begun when she was considering primary school. The family lived very near to the school that her husband Chris (a paint sprayer) had been to as a child and it seemed as if everyone (including family and friends) had taken it for granted that her daughter Grace would attend that school. Natalie presents her struggle to resist the idea that you should go to the nearest school and to feel some control over the education of her children:

I actually suddenly thought, well, why, when it comes to going to school do I as a parent not really have that much say in where my child goes? Why should that be? So I said to Chris: 'No. I'm not going to take that. I want to look at the schools within the area and I want to make the right decision that I think it is right for Grace.'

This moment set the tone for the account that Natalie gave, where her narration of the decision-making and application process was told in the first person singular. When asked directly who made the decision, Natalie responded:

Me! Well no, that's unfair. I've initially made my preferences [...]. Chris's [...] gone along with [my choices]. He, I'm sure, would say he knows I'm making the right decision.

Natalie went on to explain how her daughter had not been accepted at her first choice of primary school which presented her with a dilemma described in a dramatic narrative: 


\section{Choice, what choice?}

I only got initially an offer of a place at one school which was our local school here. You then had a two-week window with which to either accept or decline the place [...] and I left it right till the death 'cause I really was quite reluctant - I knew I didn't have a choice but I was quite reluctant to accept the place we'd been offered because it wasn't my first choice as a parent.

At the eleventh hour, Natalie found out that her daughter, who had been put on a waiting list for her preferred school, had got into it (we shall see in the next chapter what Natalie was looking for in a school). Although her husband seemed to be happy with her choices, the decision to go against the local school was questioned by a friend and fellow mother:

She said, 'I think you're being really, really unfair sending Grace to a school that isn't her catchment school'. So I said: 'Why? [...] if that's the best option for her, why am I wrong in doing that?'

The other mother thought that Natalie's daughter would miss out on making friends. Natalie explained that she had responded by comparing choosing schools to her friend selecting a day care nursery for her child. This also involved asserting her rights as a citizen and consumer:

I said, so why shouldn't I have that choice over where I send my child to school? Just because I'm not paying doesn't mean somebody's got the right to tell me automatically: your child will go there. I should have a say in that. That should be part of my decision - I know my child, Stockport council have not got a clue. [...] I know my child and I know what's the right decision.

When asked about when she had started thinking about secondary school for her daughter, Natalie joked: 'when I started? In reception! I was like that.' Natalie gives an account of the information gathering and considerations she took into account in order to make the right choice for her daughter. Unlike some of the respondents in Perrier's study (Perrier 20I2), Natalie does not seem to worry about presenting herself as the 'pushy mother'. She cheerfully concludes, 'I'm a bit of a control freak at the end of the day'. Nonetheless, she also emphasised at various points in the interview how stressful she found the process:

It's always been at the back of my mind, it's such a huge step and probably I started - in all seriousness, I did probably start thinking about 


\section{All in the mix}

it when Grace got into year 3, when she moved up to the junior side of the school.

Honestly, I've found as a parent it is mind-blowing. It absolutely - it ties you in knots, it really - you know, you think one thing, then you think another.

It was the hardest decision I have ever had to make [...] if you get this wrong, potentially, this is the rest of Grace's life. [...] [it is] huge [I've been] petrified.

Natalie champions a neo-liberal market-based approach to schooling, where the individual parent has the most knowledge about the child and should have the right to have the decision-making power over their education. She was frustrated by what she saw as a lack of power over her daughters' educational choices and resisted the logic of local-as-best. However, whilst Natalie asserted her desire to choose, the process had an impact not only on herself but also on her daughter. Having consulted the teachers about whether they thought Grace had the ability, Natalie paid for nearly a year of weekly tutoring for her daughter. Initially in the interview she presented Grace as relaxed about the process of choosing schools and sitting the Eleven-plus. However, she also admitted that she herself had not predicted the impact on her daughter: 'She was absolutely devastated to have failed the exam at the end of the day [...] heartbroken. I was really surprised at her reaction to it. [...] hindsight is a wonderful thing.'

We see a hint of a regret in this account - that although Natalie solidly defends her views and actions, perhaps with 'hindsight' she would have behaved differently. In this more detailed example, we can see how what are often presented as middle-class anxieties and practices over school choice are also shared by working-class or less securely middle-class parents, albeit with a potentially narrower range of options. Whilst Natalie was able to pay for her daughter to have one hour of tutoring each week, this was the limit to her ability to buy education. Although she had considered private schooling, if she wanted to pursue this option, she would have been reliant on her daughter achieving a bursary which was very competitive.

In terms of the stress involved in making decisions around schooling, Natalie was not alone in feeling a heavy weight of responsibility. Sharon, a white civil servant also living in Cheadle Hulme, explained: 


\section{Choice, what choice?}

It's absolutely awful because you just, it doesn't matter how much research you think you've done, you know you're never a hundred per cent sure as to whether you're making the right choice.

In this account, the responsibility of making 'the right choice' is what weighs particularly heavily. While this anxiety was undoubtedly real, it was also perhaps part of the performance of being a parent. To be a good parent is to choose and perhaps also to worry about one's own acts of choosing, as Ball found in his study of parents choosing schools:

Their failure to be rational, to be an ideal consumer, to live up to the expectations of the consuming subject discursively embedded in guides and tables leaves them with a sense of not being good parents.

(Ball 2003: IO2)

The nature of the anxiety is likely to differ depending on the context in which choice is taking place, shaped by classed and racialised practices and concerns as well as the locally available options and the prevalent discourses surrounding schooling in the social group. Worry was described by many as an inevitable part of parenting. Worrying was so ingrained in the performance of parenthood that it was also something that could also be joked about. When asked when she started to think about secondary choices for her son, Fiona from Chorlton responded: 'I don't know it's always been on the horizon really. [...] I'm already worrying about him being forty [Laughs].' As Michael, whose son also went to the Chorlton primary and had explained that he didn't play much part in choosing schools, summed it up:

Everything is anxious with children no matter what. Whether it's schools, or anything. [...] So yeah, you worry, you gotta give them the support, that's the main thing. He is got the support, so, yeah, you know, I don't worry about it too much, but yeah you do worry about it a bit.

As we saw in the example of Natalie, there was often a gendered division in how parents divided the labour over the task of negotiating school choice, with mothers - in the vast majority of cases - taking the most prominent role. The next section will consider the different ways in which the process of selecting schools plays out through the gendered relations of the family. Despite changes in family forms, and with some exceptions, we can see the continuation of the dominance 


\section{All in the mix}

of a traditional gendered division of labour in the accounts of families making choices, where the various labours involved in overseeing the education of children are left to the mothers.

\section{Shall I be mother? Gender and the negotiation of school choices}

Whilst children were often consulted about their preferences for high schools, of the parents interviewed few said that they let their children choose which secondary school to go to. It was the mothers who took the main role in seeking out information about schools and therefore played the major role in the decision-making around schooling (Stambach and David 2005). The information was accessed through official sources of information about schools (such as Ofsted reports and school results tables which are published every year) and more informal social networks of friends and parents of older children. These latter networks remain largely gendered (Ball 2003). The gendering of social networks can be seen in the following exchange between Ken and Fran from Chorlton:

Fran: I think more that I talked to the mums and stuff because I was picking the children up from school at the time and asking them you know how their kids did.

Ken: Yeah, yeah that was - I was working till late and Fran was working earlier enough half the time to go to the school so she was you know, she was talking with the mums, mums and dads.

Fran: Yeah I think, it is quite interesting because as a comparison I've got a friend that is a mutual friend and they're a couple and I talk to Sarah quite a lot about choices of school and I just wonder did you ever talk to Alan about it?

Ken: I think once or twice but not as much as you, I didn't.

Whilst most women felt they did most of the labour (or 'groundwork' as Annette called it), they appeared accepting of and even happy with this division of labour. This might be partly an inevitable result, as Emily explained, of an already gendered division of labour which meant that women were better placed to make the decision:

So I did the playground duties and you build up a social network around the school. So I have a set of friends that I have for friends, but I also have a set of friends that evolve round the school. So we had that input with each other and there's lots of talk about lots of different things either round the table drinking coffee or in the school environment 


\section{Choice, what choice?}

that the men don't necessarily have a lot of input with. So I think when it comes to making decisions about education - and again, you know, you might hear lots of different sides to this - but I think that probably with the woman, the mother is probably the better person to make the decision anyway. ${ }^{7}$

Here Emily presents her role in networking as akin to a job (in the phrase 'playground duties') but seems to be happy that this has given her superior information and decision-making capacity on the question of her children's schooling. There were also several cases where the mother was the one who made the decision with little consultation with or involvement of the father, even though he was present in the family. In the case of Meredith, her husband was 'quite happy for him to go wherever'. It seems that some fathers, rather than taking the role of the anxious parent, performed the confident 'laid-back dad'. As one father said, 'I think he'll do fine wherever he goes'. In other cases, particularly with some of the ethnic-minority respondents in Whalley Range, the father was sidelined in the decision because he did not have good enough English to engage with the schools, or because he had less knowledge of the British education system than his wife (although in the case of Samer, quoted earlier, he played the major role partly because his English was better than his wife's). Sabah explained:

I think because my husband is from Pakistan and my English is better than his, I'll do all the running around mainly [...] so when it comes to a decision like that, I think you'd, I'd have to [make it].

Leyla tried to more explicitly exclude her husband from the decision

I wasn't listening to what he said. Because he didn't do it. He left school at sixteen and just worked for his brother. He regrets it all now [...] he knows I went to uni, so they are going to uni. And I think he just leaves me $[. .$.$] he doesn't interfere.$

Leyla went on to explain that she thought her husband and his family's views in favour of separate or Islamic education were 'extreme' so she wanted to resist his input.

For those single parents in the sample, it was the mother as primary carer who played the most important role in decision-making over education, although sometimes in consultation with the father. In contrast, for Sharon, it was important to keep as much distance as possible from her daughter's father: 


\section{All in the mix}

He'd like to know more I think, but I - I try to, we had quite a violent ... he was quite violent towards me and that's one of the other reasons why we left the area we lived in before and came here. So, I tried to have as, as little contact as possible and he does show an interest. Yes, he tries to more as she's getting older, but I try to have as little to do with him as possible.

There are structural reasons why women are more involved in childcare than men and this was largely responsible for the mothers' greater role in gathering and assessing information and making the decisions about school choice. Nonetheless, for some women there was a concerted attempt to ensure that they were the primary decision-maker. One exception to this gendered division of labour over educational choices, as well as over childcare, was Harrison, who was the primary carer for his children while his wife worked full-time. This meant that he was also there to do the informal 'groundwork' that the mothers described:

Yes, I will be in the playground asking a lot of mothers. And quite a few fathers as well, because Chorlton is very much like that. But asking parents what they're doing, what they've put down for their school. And finding out [information].

Whilst Harrison got the most of the information about the schools and the likelihood of their son getting into them, he presented a model of shared decision-making which suggested more equal involvement of both parents than was described by most of the mothers:

I think we tend to - I suppose, like any relationship we kind of thrash things out with a bit of talking, forgetting about, talking, argument, forget about it, talking until we kind of get there. But it depends [...] it's more about your character and what's important to you. We have slightly different ideas on education.

Harrison also showed how anxiety around school choice was not limited to mothers. He had explained how he had thought his son's primary school was a 'feeder' school (implying automatic entry to the secondary school). This not only proved not to be the case, but the option or implicit requirement to put down three choices made him question his chances of getting a place for his son in the most local school. His use of the term 'vulnerable' to describe the impact of uncertainty over choosing schools was particularly striking. He summed up his experience of choosing at the end of the interview: 


\section{Choice, what choice?}

I just wanted to get over that fact that it was very stressful. Even though I didn't think it would be, the information was mixed and I didn't feel particularly supported from, as I said, everybody telling us - acting like a feeder school, and using the word feeder school but then when it came down to the forms there was no mention of it being that and [...] you'd better not [only put down one school] just in case. I think it was more the shock of that that threw me [...] Yeah, and just suddenly I felt very vulnerable.

In reality, Harrison lived near enough to be certain of his son getting a place, but he described the conflicting advice he got from other parents about whether he should 'just in case' put down other school options. Rebecca, also from Chorlton, described these conversations with other parents as contributing to what she called a 'collective' stress:

There's the kind of collective stress like other parents start to get really kind of, you know, concerned and start asking and you know, yes. [...] everyone starts to, you know, be talking to each other and where are you going to send them and then I think that kind of starts to rub off on the children as well because they realise that maybe some of their friends won't be going to the same school as them. And they start to get a bit upset about that.

This stress was something that Rebecca did not think was inherent to parenting, but was perhaps produced by the way in which the system was structured and the idea that there were 'worse' schools that needed to be avoided:

I just think if all schools provided a good basic standard of education then it shouldn't matter which school your child goes to. They should all be of a certain standard and children ought to be able to - you know, every child ought to be able to do well in any school.

This group anxiety led some people to opt out of socialising with other parents as a way to insulate themselves against the pressure. As mothers tended to be more involved in these networks which centred on children, they were more likely perhaps to feel the pressure:

I try not to have an opinion on it just, I just again it's, you'll hear the mums having a good whinge in the playground so, I try to sit in my car now because they, there's at least something that they're moaning about and I think oh shut up, because not everything's perfect all the time, it can't be can it? (Sharon) 


\section{All in the mix}

Some parents presented themselves as not one of 'those' worrying parents and here we can hear anxieties about being seen as pushy parents, as discussed in Perrier's work (Perrier 20I2). This can be seen in the embrace by Molly from Chorlton of being a 'relaxed parent':

It's not caused any hassle for us, but I could imagine it's caused a lot of anxiety for other people that perhaps might have been better left undone, I don't really know. It's nice to have the choice but I think if you've got parents who are anxious - we're quite relaxed - but if you've got parents who are anxious about these things, I could imagine it causing a lot of problems.

Molly's more relaxed attitude might also be shaped by the fact that this was her third child going through the system. How parents positioned themselves in terms of styles of 'choosing' could potentially have quite profound effects. Fiona, also living in Chorlton, explained how the politics of education could impact on friendships: 'And they're people who are best friends, so suddenly when it comes to education, they're poles apart. [...] it's a bit like the elephant in the room that nobody mentions.' Byrne (2006b) found a similar sense that school choice could be a point of tension between friends.

\section{Conclusion}

This chapter has explored parents' experiences of making choices about their children's secondary schooling in what they often regarded as a very limited field of potential options. A sense of limited choice - sometimes exacerbated by an awareness that those with greater financial resources would have more choice - often produced high levels of anxiety for their children and their futures. Navigating the educational system at this moment in their children's lives involved engaging with a range of options which were not equally available. Weighing up schools also involves deciding what you want in a complex field of potential choices which are not equally obtainable. There is a confusing array of different types of schools and also of entry criteria which potentially make decisions more fraught. We have argued that these choices need to be understood as relational and affective. Furthermore, this chapter has continued to show how parents' discussions of schooling and school choice are often areaspecific and shaped in part by the areas in which they lived. Chapter 2, 'Imagining place', explored how living in a particular area was 


\section{Choice, what choice?}

often understood relationally, where people consider the extent to which they feel like one of the people who would be expected to live in the area and whether they like being with other people who live there (in ways which are frequently classed or raced). The choices are assessed in relational terms as parents consider what the impact of other children in the school will be on their own children's education and social development. There are more or less desirable children and, by implication, more or less desirable parents whose attitudes are often felt to lie behind the behaviours of their children. This chapter has shown how it is assumed that more selective schools would be populated by those more desirable children. The following chapters will explore further how the assessments made by parents are classed and racialised. It was frequently assumed that private schooling would logically have more of these better, more disciplined children - at least partially through an exclusionary logic. For some Muslim parents, a religious education was particularly important, but for others there was an appreciation that their children might benefit from being educated with other children who were not Muslim (and some felt that non-Muslim children could also benefit from being educated with their children). In the case of private schools and grammar schools which select their intake on the basis of educational achievement, it was assumed by most parents that there was a benefit to attending schools which had children whose parents were regarded as committed to education and who were often assumed to be more disciplined. However, parents also worried that their children's (and possibly their own) lack of cultural capital might be exposed in the context of private schooling. Could their children feel comfortable in a school where the lifestyle of the other children - what they ate, what they did on their holidays - was so different from their own? Other parents, particularly those living in Chorlton, also raised more ethical concerns about private schooling while not necessarily questioning assumptions about superiority.

In addition, we have seen how, in some cases, the choice of school also reflects on the parents' sense of themselves in relation to other parents. Thus, school choice involves navigating a complex field of affect which is influenced by ideas of parental responsibility and the 'good' parent; and by long-term and short-term future happiness of children; and is shaped by the parents' own memories of and emotions about their own schooling. In particular, the discussions of state selective education in the form of grammar schools in this chapter 


\section{All in the mix}

also revealed how navigating questions of school choice can stir up emotional responses of parents which are in part driven by their own memories of education. In this context, the Eleven-plus was frequently remembered as a pivotal moment on which academic success or failure was determined, with important implications for the future. The views of parents on selective state education were often framed by an explanation of their own, or their partner's or even their older children's, experience of going through this process of academic sorting. For some parents, this reflection on the system of state and private selection, both of which relied on financial resources, also raised questions of ethics and social justice. By focusing on Natalie's account of her experience of choosing schools for her daughter, we have shown how this can be an emotionally taxing process for both mother (or parents) and child.

The chapter also discussed the way in which parents' engagements in the processes of choosing schools were narrated as gendered, with the majority of parents (of either gender) describing mothers as more engaged, and better positioned, to do the labour involved in choosing schools and generally steering the process. This was often because it rested on a gendered involvement in parenting, with mothers more integrated in parenting networks which were an important source of information on secondary schools. There were however some exceptions where fathers - particularly if they had been more present at the school pick-up times - took a leading role. Whatever their role in information-gathering, almost all of those interviewed for this research expressed feelings of anxiety around the process of choosing school, to a greater or lesser extent. This anxiety was often felt to be exacerbated by the expression of other parents' worries about schooling. Chapter 4 will explore in greater depth these emotions around school choice and the ways in which they are often shaped by racialised and classed fears which often determine who are considered to be undesirable children who should be avoided.

\section{Notes}

I Around 6.5 per cent of the total number of school children in the UK are in private or independent education (with around 5 per cent of those overseas students): www.isc.co.uk/research.

2 Of course there may have been many children living in Chorlton who attended and were planning on continuing attending private schools, but 


\section{Choice, what choice?}

they are excluded from the sample which contacted parents through a state-funded primary school. However, nationally, pupils often move from the state to the private sector after primary school (see ISC annual census 20I7: www.isc.co.uk/research/annual-census/ first accessed 2I December 20I7).

3 See Byrne, (2006b) for a discussion of school choice and its impact on friendship groups.

4 Grammar schools in this context are those state-funded schools which remained selective on educational ability despite the move to non-selective comprehensive schools in the I960s and I970s. Grammar schools have a skewed socio-economic intake, with in 2016 fewer than 3 per cent of students in grammar schools eligible for FSM (compared to the I7 per cent of children eligible for FSM in the grammar school areas): https://fullfact. org/education/grammar-schools-and-social-mobility-whats-evidence/, last accessed 4 January 20I8).

5 Although, confusingly for many parents, they did have schools with 'grammar' in their titles (these were either private schools or, in one case, an academy).

6 The Eleven-plus exam governs admission to grammar schools and some other selective secondary schools. It includes tests of mental arithmetic, writing and general problem-solving.

7 See Byrne (2006b) for a discussion of the distinction between long-term friends and 'mothering' friends. 


\section{4 \\ Schooling fears}

\section{Introduction}

The previous chapter discussed how some parents found the process of choosing schools very stressful. These stresses were expressed by parents from a variety of backgrounds - in terms of both class and ethnicity - and in all areas of the study. Parents in part put this stress down to the frustration at the experience of being given the responsibility to make a choice yet finding that there were only one or two schools to choose between. At the same time, many parents had exercised a choice in terms of where they chose to live - either before or after having children. As we saw, for parents in Chorlton who had not been born or grown up there, the decision to move to the area may not explicitly have been influenced by schooling considerations, but it is likely that the local schools were a factor in them staying in the area. Many presented this as a happy chance. Yet, in many ways, the reasons for moving to the area were the same as those for staying enough 'people like us' - which produced the elective belonging that Savage et al. (2005) described. By contrast, some parents in Cheadle Hulme had moved into the area in order to fall within the likely catchment areas of schools they saw as more desirable. However, many parents do not have the means - either financial or in the form of knowledge or cultural capital - to exercise choice through relocation. The parents from Whalley Range, for example, had frequently not chosen the area in such a conscious fashion as other parents in the study and some had not realised the significance of where they located to in terms of their children's education.

Whatever the reason parents had come to be in the areas they lived in, and whichever schools their children were likely to be given places in, a sense of stress and anxiety about the move to high school was common. When considering the experience of applying 


\section{Schooling fears}

for school places, it is worth remembering that sending children to school (both primary and secondary) potentially promotes many worries and anxieties which go beyond the question of the frustrations of being required to make a choice and then feeling that the options are limited. For many parents, the move from primary to secondary school is seen as a particularly significant step in their child's development which represents their growing up and potentially away from the care of their family. It marks a milestone in their child's development of independence. Schools are an important part of children's social development. Thus parents consider not only their children's formal education - what qualifications they will gain - but also how they will be shaped in other ways. This is at heart a relational process, in terms of how the children will respond to and be shaped by those they meet at school. It is here that race and class can feature in potentially prompting anxieties - or reassurances - and the ways in which this plays out will also differ according to different class positions and experiences of racialisation. The idea that parents often want to send their children to schools that are populated by 'people like us' is well established in the literature (Ball 2003, Croft 2004, Devine 2004). White middle-class parents who are sending their children to state schools do not necessarily expect all the students at the school to be 'people like us' - rather it is a question of 'enough' people like us. Here the question of 'mix' becomes critical (Byrne 2006a, 2006b). The mix is not necessarily solely about 'people like us'. For example, Reay et al. (20II) have shown how some white middle-class parents also seek a 'cosmopolitan' mix. In this mix, the interrelations between race and class are critical. Reay et al. found that, for middle-class white parents, ethnic mix was valued not just for its provision of cosmopolitan capital but also because ethnic others provided a protective layer insulating them from the white working class.

However the literature on 'people like us', while revealing important ways in which parents approach school choice, often focuses on the white middle class - leaving the experiences of non-white parents (from a range of class positions) and white working-class parents largely unresearched. This chapter will argue that race, class and gender are undercurrents running through the interviews with a wide variety of parents. Many parents may not consciously be thinking - or at least talking - about racial and class differences when they consider what they want from schools. However, in 


\section{All in the mix}

many cases it is possible to see that race and class structure their understanding of what constitutes a good school or a school to be avoided, and in particular what kind of environment their children will be happy in as well as achieve academically. For a wide variety of parents - in terms of both class position and racial identity the anxieties they mention about their children moving on to high school are either explicitly or implicitly classed. The following chapter explores the different attitudes that parents had towards a multicultural mix (understood as multi-ethnic) which shows a range of responses - including both fears and desires. This chapter focuses on parental expressions of anxiety around schooling which were, perhaps surprisingly, not generally focused on academic success, but circulated more often on fears of a classed other or what might be described as an 'underclass'.

This chapter will argue that, whilst arguments for increasing parents' role in choosing schools for their children often rest on the idea of a rational agent, in fact, as we saw in Chapter 3, this is an emotional process. Parents' views of the schools they consider, and their sense of what is right for their child, both in the here-and-now of attending school and in their future ${ }^{1}$ lives as adults, are both considered and emotional. As Sara Ahmed (2004a: I95-6) has pointed out, emotions and reason should not be seen as inherently opposed: 'emotional responses to others also work as forms of judgement'. Parents have a range of different emotional responses to choosing schools for their children. These include fears for the future; fears of others; anxiety about the choices and what is the right thing to do; and hope and desire for what they want in schools and education. As we saw in Chapter 3, these fears are also shaped by their own experiences of schooling, as well as the nature of prevalent 'school talk' in the local area, particularly surrounding local schools. Many of these emotions are racialised and classed, shaping what parents and carers want - and don't want - for their children. Whilst emotions around race, class and schooling are highly interrelated and mutually constituted, in this chapter we will focus largely on the classed nature of these concerns. As we shall see, a key way in which parents consider potential schools is relational - in terms of worrying about whom their child will mix with socially and what impact that interaction will have on their futures. School is not regarded as solely about obtaining qualifications, but also as affecting the sort of adult the children will become. Parents' responses to what they see as diversity in the school 


\section{Schooling fears}

population (in terms of race, class, ethnicity and religion) shape how they narrate both their hopes and fears about secondary schooling for their children.

The emotional aspect of choosing schools can be seen in the various ways that schools seek to appeal to parents and children, through open days, glossy brochures featuring always-happy children and other forms of advertising. Schools frequently display their GCSE results or positive quotes from the Ofsted reports about the environment or pastoral care in the school. Courtney (20I5: 8I4) argues that 'in a sense, though, all schools are required to act in a corporate way: their characteristics understood and performed through branding'. This branding, which indicates the ways in which state education is being drawn into and constructed as a market, often seeks to reassure as well as to impress. As mentioned in the Introduction, one of the schools in the study area had the tag line 'Successful, creative, happy' with an increasing font size, so that 'Happy' was written in letters twice as large as 'successful'. Sara Ahmed, in her book The Promise of Happiness (Ahmed 2010), reminds us of the need to be attentive to the work done by claims about happiness and the ideal of happiness as a point of human existence. Ahmed argues that 'happiness as a word is both mobile and promiscuous; it can be articulated lightly, can appear anywhere, even everywhere' and in this way risks being empty of meaning (Ahmed 20I0: 20I). She also lays out the aspirational nature of happiness: 'happiness evokes a point that lies elsewhere, just over the horizon, in the very mode of aspiring for something' (2010: 204). It is perhaps not surprising that the school, in its branding, attempts to tap into this affective register which speaks to parents' concerns about their children's happiness as well as their well-being.

School uniforms also represent a form of branding, and have an affective impact for parents, as we will see in this chapter where uniforms, their 'smartness' and the extent to which they are enforced can serve as important markers of the quality of schools for many parents. As we saw in the Introduction, another way in which schools 'sell' themselves to prospective parents and children is through open evenings. In the study areas, we saw how schools devote serious effort and resources into putting on a good 'show' for potential parents and children which are designed to reassure and impress. Open evenings give parents and children the chance to go inside the school, hear a talk by the headteacher, be guided around the school 


\section{All in the mix}

by a current pupil, go into classrooms and get some feel for what it is like to be a pupil in the school. They are clearly occasions when the school presents its best face, with selected children asked to act as guides, teachers on hand to answer questions and often exciting activities for children to participate in. These can include treasurehunt-style quizzes, flash-bang science experiments and displays of artwork, and children performing music. Free food and drink are often provided and children may leave school with give-aways such as sports bags, key rings, pencil and ruler sets all branded with the school logo. During the school choice peak season of September and October, when most school open evenings are held, the media frequently provide guidance to parents on how to get the best out of open evenings and what to look for in a school. These caution parents not to be fooled by the perfect face that schools may project on such visits, but the articles also acknowledge the emotional element of choosing schools. On the BBC website, there is a ten-point guide to choosing schools with the tenth recommendation: 'Remember listen to your instincts'. ${ }^{2}$

This chapter will explore how the parents in the study spoke about their experience of choosing schools for their children and, in particular, the ways in which their narratives emphasised fear and anxiety. The chapter will argue that these anxieties are often centred on classed fears which are at times also gendered and racialised (the nature of racialised fears and desires will be discussed in more detail in the following chapter). The chapter will begin with exploring the relative weight given to academic considerations versus those concerned with the child's happiness and issues with child development. It will argue that, for some, particularly middle-class parents who are confident about their children's academic abilities, questions of academic success (and the kind of official reports and statistics which might serve as a guide to this) appear to be sidelined in their narratives of decision-making. The chapter will consider the non-academic issues that are stressed by many parents and the ways in which these become expressed as fears around threats to their children from other students in the school, around bullying but also a form of classed contamination which is also gendered and racialised. In these discussions, discipline and dress become key markers. The following section explores what the parents consider to be at stake in making these decisions over their children's schooling. 


\section{Schooling fears}

\section{Choosing schools, choosing futures}

For many parents the decision of which secondary school to send their children to is framed as a decision that may decide some critical aspects of the future. Thus, even if parents were confident that their children would get admission to the school they chose, the decision could feel as if it had very high stakes. As Fran explained:

I want my child - my children - to do well and I want them to get, you know I want them to do well and I want them to get their GCSEs and I want them to get their A Levels and I want them to go to university if that's what they want at the end of the day. (Fran, white midwife, Chorlton)

However, Fran's account is relatively unusual for its explicit reference to academic qualifications. When parents discussed the factors that mattered to them in looking for secondary schools for their children, there was surprisingly little reference made - without prompting - to either qualifications in themselves or the kind of career aspirations that they had for their children. This might be because these were taken so much for granted that they did not need to be mentioned or could be referred to merely in passing. However, the taken-for-grantedness of these assumptions may be easier for some to display than others, depending on their own qualifications and life experience. In the case of Melanie and Steve, a beauty therapist and delivery driver respectively, the aspirations for the educational future of their daughter were spelled out more carefully, perhaps reflecting the way in which this was an unchartered path for them as neither of them had had further education. In this interview, in contrast with many others, GCSE results in the school were the 'most important thing' (Melanie) and were a consideration that both of them referred to repeatedly through the interview. They had already been paying for private tutoring at a reduced rate from a friend - 'we're dead mean, we make them both have a tutor'. In the following extract, they spelt out why qualifications were so important to them:

Steve: Well look at it at the moment, let's be realistic about all these people that have been to school, university [...]. And people now that are coming out of university it's, it's very hard for people to get a job isn't it in this day and age, so we want to make sure that they can. In our own mind, I don't think it, I think it'd be cruel of us if we didn't give him 


\section{All in the mix}

every opportunity that we can, we'd be lazy to sit back and think, oh it doesn't really matter.

Melanie: We worry about that. I don't want my kids to go and work in Morrison's for the rest of their lives, I want -

Steve: No, no they can if they want to, but we want to give them as much opportunity that, they've got a broad, a big wide horizon hopefully.

Melanie: There's nothing wrong with wanting more, I don't think.

Steve: No, so we try to do the best we can really.

Melanie: And then it's up them what they do with it isn't it?

Thus pushing for educational choices for the child is seen as a critical part of active (rather than 'cruel' or 'lazy') parenting. This is framed as particularly important in the current economic and social context. Steve shows an awareness of qualification inflation - whereby, as more people acquire university degrees, employers increasingly require degrees from potential employees and those without the qualifications are locked out of employment. At the same time, Melanie expresses a defensiveness about this type of aspiration - which is perhaps because she is consciously seeking class mobility for their daughter: 'there's nothing wrong with wanting more'. It is not clear what this defensive response is aimed at. It could spring out of a fear that they will be seen as showing a rejection of their own social position, or that they are putting too much focus on future potential against present happiness (Reay I998). It could also reflect the slightly different positions that they take between themselves. The notion of 'laziness' was also implicit in what some parents wanted to avoid in their children. Annette stressed that what she wanted was that her children should be pushed to achieve the best they could.

I want a school that's going to stretch the child so that they, you know, they reach their full potential, whatever that potential might be. I mean the potential of one child - one of my children might not be as great as another, but you still want them to do the best they possibly can. And I also want them to value good behaviour and, you know, expect that of all the pupils that go there. So I think it's really behaviour and the quality of teaching. (Annette, white, Cheadle Hulme, pre-school teacher)

As we saw in Chapter 3, some parents also discussed differences in the academic ability of their children, and the potential tensions that these differences created in the process of choosing schools. Here the focus rests more on schools helping them to reach their 'full potential' which is expressed as an individualised desire, 


\section{Schooling fears}

without any sense of social justice that sometimes underpins these assumptions.

Whilst choosing school may seem like a heavy responsibility to many, some parents did acknowledge that the support their children get at home may be just as significant as the school they go to. Jas, by his own admission, did not play a huge role in the education of his son. He wasn't very engaged in the decision of which school his son should go to - and he also admitted that his ex-wife was the one who supported his son in his homework. As we saw in Chapter 3, this was a common pattern between father and mothers - even when they were living together. Jas was however unusual in not expressing any serious parental anxiety about the decisions around schooling: 'I'm not really too fussed. I think he'll do well in any school he goes to.' He went on to argue something less often acknowledged by parents:

I am a firm believer that if somebody has got the ability to do well at school, they will do well at school really, even if it is a poor performing school, I think it depends on the parents pushing the child. (Jas, South Asian, regional manager)

Jas was unusual in explicitly arguing that home life was more significant than school context. Michael, also from Chorlton, put it slightly differently:

I just think schools are there to do certain things, but they won't provide everything. And now the parents have got to provide, you know, hell of a lot more of what they had to provide when I was a kid. So I think the schools are important to give him a structure and a grounding, but it's only half of the story really.

Other parents downplayed the importance for them of the schools' exam results per se. Kelly (a white teacher living in Chorlton) said that:

We're not, we've never been massively concerned with like exam results and things. If we looked at an Ofsted report we'd be looking at things like behaviour and sort of pastoral care more than exam results.

Kelly was not necessarily saying that she didn't think exam results were important for her children but rather that this was not an important criterion in assessing a school. Kelly went on to admit that this lack of concern for academic results may be 'because they're doing okay, we've not had a problem with any of them yet [laughs] so far it's 


\section{All in the mix}

been fine'. The laugh perhaps suggests an unexpressed anxiety about academic achievement. The downplaying of academic results often went along with the suggestion that Ofsted reports were a limited source of information. Kelly continued by explaining her attitude to Ofsted:

I've never been a parent going: 'my child must achieve, achieve, achieve, we must go to a school that has high Ofsted reports and SATs results and all that'. Because my children - I've worked very hard for my children to be sociable and confident, because I was very shy as a child myself and I felt it held me back [...] Ofsted reports are pretty boring, aren't they, and it usually just ends up with something like they're satisfactory, satisfactory, oh but the children don't like the toilets very much.

Here we see again how many attitudes to schooling are formed through a consideration of the parents' own experience (see Chapter 3). This can shape a desire that their child or children should have the same kind of opportunities, or alternatively that they should not suffer the same experiences. This attitude to official reports and assessment accords with the findings of Ball (2003) where 'hot' information gathered from local knowledge was preferred to the formal 'cold' information provided by Ofsted or the promotional material provided by schools. This position on Ofsted was common among the interviewees and is also present in popular discussions. For example, an article in The Guardian in September 2014 proclaims that Ofsted reports 'have all the value of wet toilet paper'. ${ }^{3}$ Ofsted (and published league tables) were regarded as giving insufficient information about things that matter. There was also a strong sense that the statistics, reported in league tables, could be manipulated. As Emma put it:

I'm not going to talk about league tables because I don't believe in them one iota. I work in an environment where you can fiddle figures to make them look however you want to make them look. So I don't lay a lot of weight to league tables. (Emma, Cheadle, white, primary school teacher)

Apart from the possibility of figures being fixed, there appeared to be a discourse, particularly strongly featuring in Chorlton, that the competent parent had better sources of information than Ofsted. Perhaps somewhat surprisingly for parents who generally expressed high levels of concern over the education of their children, it was quite common for parents to claim never to have read Ofsted reports. 


\section{Schooling fears}

For some this may spring from a lack of knowledge or access. But for others it appeared to be presented as a badge of pride. By claiming that they knew about, but disregarded, the reports, we would suggest that some parents were positioning themselves as invested in an approach to education that went beyond the quantification that the reports represented. ${ }^{4}$ Rejecting the importance of Ofsted reports could be a means for parents to present themselves as another kind of expert in this context with the 'logic and taste' (Ball 2003: 59) required of them to make choices. As we can see from Emma, for some there was also a professional competence being expressed, that they knew that the information in Ofsted reports could be 'gamed' and should therefore be disregarded.

For many respondents, as suggested by the literature on the importance of 'hot' information (Ball 2003, Croft 2004), the opinions of 'people like us' were more important than the dry Ofsted reports. Terri, a white health visitor living in Chorlton, explained:

I think you'd get that feeling from the other parents whose children have already gone, they've made a decision to send their children there, they have similar views on education, so I think that influences me more than maybe an Ofsted report would.

She went on to summarise these 'similar views' as:

What they want for their children, you know they want the children to be safe, they want them to be educated well and pushed and, you know to achieve and they expectations probably that they might go to college or university or, you know that sort of [thing].

These views as described by Terri of wanting children to be safe and secure might be safely assumed to be universal for parents and carers. However the classed nature of the desire (and the question of whose opinion would be valued) is indicated by the reference to aspiration, of children being pushed (perhaps both by the school and by the parents themselves) and wanting their children to go on to further education. This nonchalance around consulting Ofsted directly was perhaps also enabled for some by the fact that they could get the same information from others, as Sara explained: 'you don't need to, in my circles you don't need to read Ofsted reports because people tell you [laughs]'.

A notable exception to this claimed disregard for statistics was the case of Samer, a chemical engineer, who, along with his son, knew all 


\section{All in the mix}

the potential schools' GCSE results from memory. He also was one of the male interviewees who was most engaged with, and worried about the process of school choice (see Chapter 3 for more discussion of parental choosing and gender). As an immigrant to Britain and as an Iraqi feeling isolated from his Pakistani neighbours, he and his family struggled to get clear information about the schooling choices, and the exam results gave him a basis for comparing schools. Despite his high level of education, his relatively low social and cultural capital in Britain also made him less able to decode the 'talk' around school choice. As a result, Samer put great emphasis on the 'facts' and solidity provided by the tables of exam results.

This section has shown how many parents are relying on considerations which potentially complicate the process of school choice. Rather than focusing on more cut-and-dried measures of the best exam results or official assessments in the form of Ofsted, parents are looking for a more holistic range of markers of what might be the right school for their children, which speak to the affective nature of schooling and school choice. The following section focuses more directly on the affective and shows how negotiating school choice often produces a range of fears and anxieties in parents which coalesce around a classed, raced and gendered other.

\section{Choosing schools: what's fear got to do with it?}

This section will discuss how parents expressed fear, anxiety and worry about their children's future experience of schooling. These fears were the most common sentiments expressed by parents in their discussion of secondary schooling. In particular, the behaviour of (other) children in the school and the related question of discipline cropped up frequently in the interviews. Behaviour and discipline were important from the perspective of children's safety and happiness - as Fiona explained:

You want them to be safe, you know, this place is awash with scare stories about children having knives pulled on them and things stolen and bullied and, you know [...] some children have been in situations where they've been in really frightening situations because you've just got a real mix of people there, haven't you? (Fiona, Chorlton, white, freelance project manager)

Here we see the question of 'mix' representing possible dangers although what kind of 'mix' is potentially dangerous is not explained. 


\section{Schooling fears}

Through much of this chapter, we see fears, desires and aspirations around schooling which centre on questions of mix and exposure to difference. As we shall see, there can be a 'good' or 'bad' mix (Byrne 2006a), but what is being imagined is often left vague, as in the account given by Fiona. We will argue that differences of race, class, ethnicity and religion can be at the heart of these notions of mix, even when they are not very clearly articulated. Thus analysis of the data requires attention to what is assumed or left unsaid as much as what is said (Byrne 2006b). With exposure come possibilities also of contagion, and some parents were concerned about how their children might be influenced, and how this might change their behaviour and even personalities. The issue at stake, mostly unvoiced, appeared often to be 'what will my child end up like?' Halima, a fulltime parent, living in Chorlton, who was hoping to pursue university education once her children were older, was one of the few to actually spell this fear out:

I would be so mortified that she went to high school and within a few weeks her character was completely changed, her personality had changed completely, that what I know of how she is has changed completely because of being in an environment with girls, a few girls that were swearing or were shouting or were being disrespectful to the teacher. (Halima, Pakistani, homemaker)

Change is inevitable as children grow and, for Halima at least, this prospect caused anxiety. The fact that going to high school coincides with children entering adolescence may particularly heighten concerns around character change and the influence of peers. Halima expresses fears associated with a lack of control over her daughter's development and the potential negative influence of the 'wrong' kind of mix. In her interview, Jessica repeatedly said that her children's happiness was at the centre of her thinking - 'I want my children happy'. This focus on happiness meant that her son's response to the schools was an important factor guiding her decision around choice of school. But she did also have an eye to concerns about academic success:

I think the main factor was my son and what he wanted to do, I think, and where he wanted to go. Because it's him that's going to the school not me. I want the best for him but I think a lot of getting the best out of him is if he's happy. If he's not going to be happy somewhere there's no point even if it's the best school in the whole country, if he's not 


\section{All in the mix}

going to be happy there he's not going to do well at the school. (Jessica, Cheadle Hulme, white childminder)

Parents felt that much of their children's future academic and potential working future is shaped by the choices they make in school now. School has a critical role in shaping the social mobility - or reproducing the social position - of their children. In addition, the aspirations they have for their children also help to construct the way they see themselves (and others see them) as parents and as a family. We saw in the previous chapter how school choice is often discussed with friends and can at times become a fraught issue (see also Byrne 2006b). Yet, for many of the parents interviewed, the most immediate anxieties they had about potential schools was the nature of the experience that their children were going to have in the next few years. Transition to high school means putting your child into a very different landscape: 'I'm absolutely petrified. She's going from a school now of 240 children, potentially to a school of I500 children. That in itself is just mind-blowing' (Natalie, white, office worker). As Fiona explained, much of the concern was about the emotional wellbeing of their children and the loss of control that parents have over their children once they are in school:

And also, you know, you're sending them there for the majority of the hours in their day and you don't want them to be miserable do you? You wouldn't be sending them somewhere they're terrified or learning nothing or vegetating or just feeling upset. (Fiona, Chorlton, white, freelance project manager)

These parents were talking about children who were, after all, already in school full-time. However the shift from primary to high school is seen as an additional step away from the world of the family, as Halima suggested:

And the thing is, it's just that jump, because you know your children are so - when they're at primary school they're so innocent, in the way that you want to protect them, they're so young and everything, and you protect them from certain things and seeing really horrible things. But then when they go to high school, they're totally exposed to people and crazy children. It's such a big school as well, from having been in a small school to going to somewhere where there's eight to nine hundred students, very overwhelming. And I think that really is daunting for the child and daunting for the parents as well, because how are they going to fit - you know, they have to adjust. (Halima, British Pakistani, homemaker) 


\section{Schooling fears}

This fear of the numbers of children involved at high school is understandable in terms of thinking of a child navigating more crowded contexts. However, at the same time the idea that they will be 'exposed to [...] crazy children' is an interesting - and quite strongly expressed - fear. It perhaps reflects the shift from a relatively knowable space of the local primary school to the more unknowable space of high school. We would suggest that this unknowability arises in part from the different relationship which primary and secondary schools tend to have with parents. Primary schools and primary school teachers often have a fairly close relationship with parents whom they might see on a twice-daily basis, at drop-off and pick-up times. At secondary level, children make their own way to and from school or at least between a waiting car and school. Parents may only rarely engage directly with secondary schools and therefore have a more distant relationship. In addition, once their children go to high school, parents will also have only limited contact with other parents whose children go to the same school. Thus, for parents, some of the known features of state primary school arise from its relationship to a relatively constrained catchment area. This geographical space is relatively well defined and has known classed and racialised characteristics. Primary schools may have a sense of belonging to a known 'local' which a secondary school may not. In secondary schools with higher numbers of children, children are coming from a wider area which may not be seen as 'local' in the same way.

At the same time, this sense of fear around the impact of 'crazy' children may also reflect anxieties around the idea of adolescents and their potential to be 'crazy' and dangerous. For Halima, it was important that, post-puberty, her children were in single-sex schools:

if you go to secondary school and all that free mixing environment where you're going through puberty and your hormones are all over the place, it's better for us as Muslims [to have single-sex education].

Apart from concerns around developing sexualities, an important feature of the fears that parents have about high school is the spectre of the bully (interestingly, while several parents raised the question of bullying, no parent worried that their child might bully others). The fear of bullying was tied to questions of 'mix' (which will be discussed further below). Fiona explained that Chorlton was 'awash with scare stories' which told how 


\section{All in the mix}

Some children have been [...] in really frightening situations because you've just got a real mix of people there, haven't you? [...] just age groups and some people have kind of got a more aggressive lifestyle than others. I don't want to put it down to money or anything like that. I just think it's, you know, you've either got a more aggressive personality or you find yourself in a situation where you, you know, you can either be a bully or be bullied. And the bigger the school, I suppose statistically there's more chance of that happening and statistically there's more places within the school where you can end up finding yourself feeling vulnerable. (Fiona, Chorlton, white, freelance project manager)

Here we see a hesitation to describe the 'aggressive lifestyles' which may lie behind bullying. Fiona chooses her words carefully and explicitly denies the idea that this might be down to class or 'money'. It may also be shaped by racialised discourses around 'hyper masculinity' (Williams et al. 2008). In Fiona's account, both the parents and children seem to be feeling 'vulnerable'. Certainly the language of fear was common among parents. This can be seen in Sharon's desire to keep her daughter safe at home:

If I had my ultimate choice I would wrap her up in cotton wool and teach her at home. [...] Because I'm just terrified of her going to these big schools and the things that gone on in them and you know. My worst fear, and I don't know why because it never happened to me personally but $[. . .$.$] my worse fear is the bullying point of view. But that$ is the thing that I'm most afraid of. (Sharon, white, Cheadle Hulme, civil servant)

Thus, for many parents, their children's emotional experience of secondary school is understandably a high priority. In Cheadle Hulme, one of the local secondary schools was on a split site which was connected by an underpass. This, for several parents, was the focus of much concern. Jen described children having to go 'crawling under the road' and Meredith, a white unemployed homemaker, also raised the subway as one of her concerns:

Boundary Road High again has had the same reports but it's on two sites, it's on two campuses and they have to use a subway and a pelican crossing which I'm not happy about and a friend of a friend is a teacher there and she says that the subways become a no go area for teachers because they're scared of the pupils. Because of gangs under there so I'm not - I don't want my son to go there. 


\section{Schooling fears}

The idea of a 'no go' area is reminiscent of media treatment of highly deprived (and often perceived as racialised) areas which present 'no go' areas for the police. ${ }^{5}$ This particular physical feature of the school was the focus of many concerns which parents had about the school in Cheadle Hulme, which were exacerbated by the subway not being included in the open evening tours. Sara, a white student, whose daughter was at school in Chorlton, explained how some of her choices (and the choices she saw around her) were driven by fear:

there's a level of fear ... this is my opinion, I think there's a level of fear, isn't there? That you want your child to be secure and comfortable and safe, and your level, your barometer of fear goes up, so, so I think in terms of your circumstances, in terms of how you are. [...] I suppose my level of fear is, is quite minimum compared to some people, but I do have it.

Sara explained that some of her friends had looked at the choice of schools in Manchester and decided to move to the Lake District: 'that's extreme'. Nor had she tried to take the grammar school route as an attempt to get her children into a school with more 'people like her'.

While this section has examined how the process of choosing schools can be seen as both emotional and relational, in the next section we will explore how parents tried to get a better sense of the school populations with a particular focus on discipline and behaviour.

\section{Discipline, behaviour and ability: markers of class, race and gender?}

Apart from considering officially available reports and canvassing the opinion of other parents and carers, parents had various ways of getting a picture of what behaviour was like at the schools they were considering. One of these was through observing the children as they left school and their general behaviour on the streets. Although class and race or ethnicity are not frequently referred to in these accounts, given the visual and embodied nature of both class and race it is likely that both impacted on how parents saw the school populations. In an earlier study of parents of primary-school-age children, Byrne (2006a, 2006b) found it common for white parents to over-visualise ethnic minorities present in schools when giving estimates of the ethnic make-up of their children's schools. In this research, we have found that these visualisations often demonstrate the intersections of 


\section{All in the mix}

class, gender and race (Byrne 20I5). Rachel, a student nurse living in Cheadle Hulme, explained what she looked for:

When I'm driving, or I see them and I say they look a bit more [...] I see the children from Boundary Road High, I said they look a bit more respectable, a bit, they look like their school is very strict and in their policies and things. I don't know that, I've not researched it, but [I] look. Just when I see the children come from Poplar High School, some of them, not all, some of them skirts are a bit shorter, make-up on, hair dyed different colours, and I know children like to experiment but, in my eyes, I moved to Cheadle Hulme because I want them to have a straight education, not be swayed by anything.

Rachel had a strong discourse of working-class social mobility (as was discussed in the previous chapter) and desire for her children to have a better class position than her own. Here she is describing the kind of class work that Bev Skeggs explored in the workings of working-class respectability, where working-class respondents make a concerted effort not to risk being cast out of respectability (Skeggs I997). Here respectability is visible and can be read off the clothing and comportment of children. Rachel's account also reminds us how discourses of class respectability are highly gendered - another interviewee spoke about disliking 'number one haircuts and jewellery'. ${ }^{6}$ Melanie, also from Cheadle Hulme, and who, as we saw in Chapter 2, had experienced being judged for being a young working-class mother, also had a strong account of an underclass, which included a fear of contagion:

That's the sort of people you want your children around, that's sort of how you want your children to grow up and be like, you know I don't want my daughter to end up in a council flat when she's sixteen with two children on benefits for the rest of her life, and if that makes you a snob, then who cares, I don't want that. (Melanie, Cheadle Hulme, white, beauty therapist)

Melanie was one of the few parents to say that class influenced her choice of school, and there is a discourse of gendered respectability similar to that given by Rachel. While these were accounts given by working-class respondents who were particularly wary of being cast out of respectability, other respondents also referred to markers of class and particularly the undesirable working class in their discussions of what they were concerned about in thinking about high schools. In these accounts, visual markers and forms of embodied 


\section{Schooling fears}

and abjected cultural capital are particularly important. The figure of the 'benefit scrounger' is an increasingly stigmatised figure (Tyler 2013a). The unemployed are assumed to be less interested in education. Samantha explains why she wouldn't have been happy for her children to go to a school where she used to live:

I think they're good schools but I think the area, the ... the population that they cover is there's higher rates of unemployment and there's higher ... you know the results are generally lower quite a bit lower.

(Samantha, Cheadle Hulme, white, nurse)

The pauses are particularly expressive in this account, signifying that an uncomfortable idea is about to be broached, which is a common response to talking about class and race (Byrne 2006b). In the following account, Mark, a white social worker from Cheadle Hulme, explains his understanding of class and shows how the notion of 'working class' has been reduced to households dependent on benefits and dominated by single parents. Earning money and a 'successful' nuclear family are the markers of respectability:

I would say working to middle class is saying both parents who are working, not where by unfortunately one parent - if it's a one-parent family then the one parent can't work because they've got the children to look after and they're having to claim off the state. I would say the majority of people at Cheadle Hulme, the majority of the children I would say, have got both mum and dad at home and they come from a nice family background rather than the parents being split up. And that's what I mean by middle class, I would say.

He goes on to elaborate what are for him signifiers of "nice family background' which seems to be associated with middle-classness. Mark describes taking children on holiday and eating a good diet:

You try and give them good food like fresh vegetables and pasta and meat and - whereas low - you know, if somebody's got a low income coming in they might be on egg and chips a couple of times a week and, you know what I mean?

This account echoes that of Melanie in Chapter 3 where she sets up the contrast between eating sushi and pizza and chips. It demonstrates both the classed nature of food practices and consumption and the extent to which people are aware of how food makes distinction (Bourdieu I994, Wills et al. 20II). For others, the focus was more on behaviour and appearance than food. 


\section{All in the mix}

Marion, a white grandmother, who lived in Whalley Range and worked as a hospital cleaner, was a carer for her grandchildren. She wanted the school to be somewhere where her grandson would be happy but also where he would be kept out of trouble by giving him a firm direction. Marion wanted her grandson to do better at school than she (or his father, who had never learnt to write) had done, but she was less concerned about exam results. Her grandson had struggled with academic work, but improved through one-to-one intervention at primary school. Her goal was for her grandson to join the army and she thought results were less significant than physical fitness. But she did want a school to give him a sense of direction:

He needs secondary school to sit him down [and say], 'Right Peter, you can't do what you want [...] you need to help yourself' ... 'cause it's harder when you get to secondary school. [I want them to] sit him down and say, 'Right Peter, you sit there and you listen.'

It is worth noting that Marion was looking for a school that would provide the strict boundaries and behaviour requirements for her grandson, rather than having the more common concern that other children's behaviour should be kept in check.

Talking about appearance rather than behaviour, Cindy suggested that her experience as a social worker made her value strict discipline and conventional notions of respectability:

I like the fact that Sasha cannot wear make-up, that she can't wear earrings, that she, do you know what I mean, she just goes to school like that. I say: 'at weekends you can do what you want, Sasha', but, you know what I mean, in school and I - I don't know, I just think some of the other schools that I work with, I don't like a lot of the stuff that happens in the schools. (Cindy, Whalley Range, white, social work manager)

It was certainly common for 'smart' uniforms to be a key marker for a good school. Indeed, one of the high schools in the research area had large banners up on the school's external fence to advertising that it gave a free blazer to every new child, suggesting that it recognised the symbolic value of the uniform. In the following account, Sam describes how a school in Chorlton had been transformed in recent years:

Seven years ago it didn't have a good reputation. The uniform policy was quite poor, they just wore casual uniform and since then they've 


\section{Schooling fears}

got a new headteacher that's changed the school quite a bit. The results have improved. And the appearance of the children has gone up. And the ethos of the school I think is genuinely better so people we've spoken to have a better feel for that school now. (Samantha, Cheadle Hulme, white nurse)

In this account, Sam directly relates the ethos of the school to the uniform. Similarly Annette, a white pre-school teacher living in Cheadle Hulme, describes what she looks for when she drives by a high school at the end of the school day:

Just looking whether they look like louts or whether they [...] You know, if they look like, you know, if they look very rough and whether they look very smart and stuff, I suppose.

Class is underlying much of this talk around uniforms - it is discernible in terms such as 'louts' and 'rough' versus 'smart' and 'strict'. However, class itself was very rarely explicitly mentioned. It is clear that, for some parents, talk of class was taboo. To some extent, this contrasts with what was said about racial, ethnic or multicultural mix, as we discuss in Chapter 5. When asked directly about whether the class make-up of a school was important to her, Serena tried to accommodate our interest in class as 'sociologists', but otherwise was opposed to talking about it:

And I don't think we should actually talk - I don't even think we should be look - I know, I know you know not, I'm not a sociologist and that to look at class. Um, Well I think if you're doing it in that type of manner, in - in a sociological way, and you'll, yes look at it, but if you're doing it as a parent, even if you look, I don't think you should be looking at class and things like that as a parent. Because I think once you don't have those sort of view, you bring up children who, who, who value themselves. (Serena, African-Caribbean nurse)

For Serena, talking, and even thinking, about class are likely to have an impact on her children - perhaps that they will see themselves as less worthy because they have a working-class background. We see a similar reluctance to name class with Jen as she tries to explain why her parents had moved areas so she didn't have to go to a particular school:

I suppose Woodley School, the people they had at the time, I suppose it's for, it's, gosh, how can I say this, it's, I suppose it's the people that go there you want, you want people that are sort of, that are going to go 


\section{All in the mix}

and make the most of the school and not be disruptive and so perhaps get the support from home and whether you imagine people in a certain area will give more support. Uh huh, yeah. It's getting social now isn't it? [Laughs]. (Jen, white shopworker, Cheadle Hulme)

We can see her real hesitation in naming the problem as associated with class. This contrasts, as we shall see in the following chapter, with the ways that racial, ethnic and religious difference are often spoken of. Ann, a white accountant from Chorlton, was one interviewee who was more openly considering questions of class, with the assumption that working-class children would be less successful academically: 'I mean, at Parkfield High, you're never going to get the best results in the world because of its catchment area. But it does do well, I think, in both groups really doesn't it?' Ann described 'two sets of kids' at the local school. Here classed (as well as possibly raced) markers may be inferred through reference to those who do well at school and those who need to be 'controlled':

There's a two-tiered system and there's two sets of children and there's the kids that do well at the school and there's the kids that don't do well at the school and they're like two different societies and these kids never mix with these kids, at all, ever. They don't socially mix, they don't do anything and I think probably - I think probably that's where education is going really, is that they're - they're intense with the children that can do well or they see the potential of and the other children, they control them. It's behavioural control and I think there's a lot of that in schools basically, you know the kids that can get on and do well they'll teach and the other ones are controlled.

Whilst Ann is suggesting that academic ability is what divides these children who 'do well' from those who don't, she nonetheless also raises questions more related to classed habitus by referring to the two 'societies' never 'mixing' and the role of behaviour as the clear marker of difference. In this quotation, Ann does present this as a problem - that some children appear to be disregarded by schools in favour of those who will 'do well'. However there may also be an element of reassurance that her children will be kept away from those who need to be controlled. Her husband Cliff added later in the interview:

I suppose I'd like to think that we have a school where the middle-class high achievers aren't dragged down by the fact that there are people from poor backgrounds and that the people from poor backgrounds might be helped by having that mix. 


\section{Schooling fears}

Whilst he is supporting the idea of a mix, in this account only the middle-class children will be 'high achievers' and those from poorer backgrounds appear not to contribute to the others but are constructed only as potential recipients from their middle-class peers. At the same time, for Cliff, there is a risk that middle-class children might be 'dragged down' by their poorer peers. Many of the parents expressed hesitation around their child or children mixing with a classed other. Ken, a white courier whose children went to Longford School in Chorlton, also characterised Chorlton as divided by class:

Well it's very much the two-tier thing that we said - there's this end of Chorlton where it's all middle-class and there's the other end of Chorlton near the school where there's a huge ... council estate and it's definitely a two-tier feel to it.

He went on to discuss with his wife a conversation he'd had with another parent who already had children at the high school, and was critical of the kind of class talk that this parent produced:

Ken: What was it he said, he said something quite poignant about class didn't he [...]?

Fran: Yeah he said she's doing all right because she's ... [laugh]

Ken: Because she's middle class or something.

Fran: No it wasn't like that. It was just like she's in the top group so at least she's getting...

Ken: Yeah, it was about - she's separated from the rabble or whatever you know? The half of the school that are just you know left to rot. (Ken and Fran, white courier and midwife)

The abandonment of the half who were seen to be failing was presented as 'poignant', but at the same time it appeared that separation from 'the rabble' was also reassuring because it didn't impede middle-class or brighter learning. Similarly, in Cheadle Hulme, Bea explained how she guided her children in avoiding the "wrong crowd':

Stephanie knows who not to mix with; she chooses her friends and when they're growing up like I'll say to Ben I don't want you playing with him any more, he's - you know, I just don't want you playing with him and he's started to say 'yes' or 'no mum, I know what you mean'. And you sort of guide them don't you but if they get in with the wrong crowd you can - do you know what I mean? You try and nurture them the best way and the people that you want them to be friendly with. 


\section{All in the mix}

It is unclear from this account what might constitute the "wrong crowd'. Nonetheless, the discourse of contagion favours the safety of separation. Similarly, Michael explained his satisfaction that his son's friends tended to be of a type (he later described his son's friends as 'very middle-class'):

but his friends they are all a certain type really; he hasn't got many that don't fit with the [mould]. [...] I try my best to get him away from the scum [laughs].

Carla: Scum being?

[Laugh] I don't know, ah he knows. You know, I think you make a decision when you think the kids are right for each other, it's not based on anything.

Michael's laughter here would indicate perhaps that he knows that he is using particularly hostile class language, in the concept of 'scum' and then also backtracks on the idea of class altogether: 'it's not based on anything'. However, the classed narrative is continued through his interview as he characterises Chorlton as a 'funny area':

I think, it's funny, Chorlton is a funny area, 'cause there is a load of rough next there and there is a load of people who are really posh and rich. [...] It is a good area for Manchester generally, compared to a lot of other areas, so, but it is a strange mix really. I think of, you know, I don't know, Chorlton people, [...] I think some will have a shock when they get the kids in Parkside High. [...] they will have a shock some, some will be all right but a lot, uh-uh, they won't, when they go to Chorlton High. [laughs].

In this account, there are apparent contradictions about the area of Chorlton, where the 'rough' and 'posh' are in relatively close proximity. Nonetheless, when Michael refers to 'Chorlton people', he is referring to the middle classes who might be shocked by the make-up of the high school. Kelly, a white primary school teacher living in Chorlton, demonstrates the interplay between race and class in talk around diversity where cultural difference, when it applies to a racialised or ethnic difference is celebrated (this is discussed in Chapter 5). Yet her response to class difference is more equivocal:

There's a really good mix at the school. Lots of different backgrounds, lots of different races, lots of different languages spoken there, lots of different, you know, sort of home lives they've come from, different kinds of families and it's sort of well celebrated there. The children grow up very tolerant of people's differences. But I suppose a lot of 


\section{Schooling fears}

people in Chorlton are sort of teachers or social workers or you know those sorts of professions and well ... I think when you have your kids first of all you can be a bit snobby about wanting them to have friends whose parents you like which tells, it doesn't sound very nice now [laughs] but you ... I think you want your children to have friends to choose from that are going to be nice people to play with.

It would appear that, for Kelly, the markers of who is not 'nice' (and not to be 'celebrated') would be shaped more by class than ethnicity or religion. These findings echo Reay et al.'s research which found, in their research on white middle-class parents choosing inner-city high schools, that a 'mix of ethnicities was far more likely to be sought out and celebrated than a mix of social classes' (Reay et al. 20II: 74; see also Harries 20I7). It is notable that educational policy on diversity tends not to refer to class differences or 'working-classness' as something that might be celebrated and may also impact on how parents view such differences. This is not to say, of course, that ethnic minorities are not working-class and that working-class ethnic-minority children would not be viewed ambivalently by white and ethnic-minority respondents alike.

Despite this general trend across parents in both Cheadle Hulme and Chorlton, for one of the parents, class and race were equally part of the mix that was desired. Rebecca explained what she liked about the local high school:

There's things that I like about Parkside High which is that it's really mixed, it has children from lots of very different kinds of backgrounds and it seems to bring them together in a really positive way [...] although it wasn't the reason I chose that school, it's something that's really strong. ... there's something about kids that come from there that feel like that confident in being themselves and not just going with the crowd. (Rebecca, white, local government officer, Chorlton)

Rebecca then went on to explain the impact she felt going to Parkside High had had on her eldest daughter who was now at university and who maintained good friendships with her school friends:

And they are a really mixed group. Some of them are at university, some are working and done different things with their lives, but they're still really good friends, a mixed group class-wise and ethnicity-wise. But the people that she sees at university are a very narrow group of people who've mostly come from private schools, mostly come from very narrow social backgrounds. 


\section{All in the mix}

This was a rare example of a white middle-class respondent who felt that there was something positive to gain from her children growing up in a class mix. This is somewhat different from the sense given by Cliff, earlier, that middle-class children represent a contribution to a school whilst working-class children posed a risk. As we shall see in Chapter 5, this sentiment was more common when parents were considering a multicultural mix, as marked by ethnic difference.

\section{Conclusion}

This chapter has explored some of the emotions stirred up in the process of choosing schools and the ways in which these feature questions of class and contagion, and how these fears are also often gendered. These anxieties and responses demonstrate how parents view schooling as an intensely relational process. When they are interviewed at the moment of making decisions around school choice, the focus is much less on the likelihood of their children achieving success through formal qualifications than on their fears for the well-being of the children. Rather than express aspirations for their children, it was much more common for parents to express a range of anxieties about who their children will be spending their days with. In Chapter 3, we saw how some parents worried that their children might have a difficult time in private education if their lack of cultural and material resources became a reason for exclusion from friendships and activities. In this chapter the fear is the opposite - not exclusion, but inclusion and contamination, where friendships might lead their children off the correct path. Fears about other children included questions such as: will they be bullies; will they be teaching their children 'bad ways' in terms of dress, behaviour, lifestyle, work ethic? In order to assess these possibilities, directly observing the everyday behaviour and dress of current students was an important route to judging the social make-up of the school, as well as asking parents with children already at the school. Open days could tell parents about the school facilities and the approach of the teachers, but watching children on an ordinary school day could reveal more about the children who are likely to be surrounding your child. The chapter has shown how class, gender and to a lesser extent race (which will be discussed in the following chapter) feature in parents' accounts of stigmatised groups who will be potentially detrimental to their children. Those who appear to be members of an underclass ('the 


\section{Schooling fears}

rabble' or 'scum') might be bullies and they might also lead children away from the path to respectability. As many parents expressed a discomfort or unwillingness to talk in terms of class, reservations were sometimes expressed in coded ways. Thus questions of class and gender would be indicated through wearing the wrong clothes and having the wrong aspirations and lifestyles. In these accounts, notions of discipline and general adherence to rules around uniform are used as shorthand for markers of respectability.

In the case of talking about these fears, there were less clear differences on the basis of area in the way people talked about class. Similar fears were expressed in Chorlton, Cheadle Hulme and, to a much lesser extent, Whalley Range. Ethnic-minority respondents shared these fears, but perhaps a more limited sense. Whilst in all of the study areas parents expressed fears of contagion from what might be called an educational underclass, the following chapter focuses on parents' responses to ideas of a multicultural mix. Although we do see from some interviewees a celebration of ethnic mix as found by Reay et al. (20II), we argue that it is important to be attentive to the local contexts in which such 'celebrations' take place. Once we do this, we can track how different discourse of multiculture circulate in different contexts and see how these differences are expressive of different fears about the other.

\section{Notes}

I See Reay (1998) for a discussion about the potential classed shape of these different responses to present happiness as opposed to future happiness.

2 www.bbc.co.uk/schools/parents/open_days, accessed 6 October 2017.

3 www.theguardian.com/education/20I4/Sep23/choosingsecondaryschoolteachers-guide-for-parents, accessed 6 October 2017.

4 In fact, Ofsted reports cover more than academic results. They also report on pastoral care, behaviour and the general learning and cultural environment of the school.

5 See, for instance the controversies around Donald Trump declaring that Europe has 'no-go zones' because of the presence of Muslim radicals: www.theguardian.com/us-news/20I5/dec/08/the-met-blasts-donald-trump -for-london-police-in-fear-muslims-claim, first accessed ıo January 2018.

6 'Number one haircut' refers to the shortest guard attachment on hair clippers which produces a short cut of hair, which, like shaved heads, is sometimes associated with working-class 'skinheads'. 


\section{5 \\ Evaluating the mix: negotiating with multiculture}

\section{Introduction}

The previous chapters have discussed the ways in which parents' and carers' discussion of school choice were infused with concerns about their children's emotions and also how talking about school choice also frequently raised emotional responses. Chapter 4 focused in particular on ideas of threat and contamination which were produced when thinking of high schools and the presence of classed others. This 'underclass' was imagined as gendered, identified by both behaviour in and around the school and through dress and appearance. The classed other is seen as posing a potential threat to both the respondents' children's happiness and educational achievement. As we also saw in Chapter 3, the assumed source of the problem with unruly children is bad parenting. In this chapter, the focus is placed more specifically on the parents' discussion of ethnic diversity, arguing that parents were more likely to consider diversity in general as something related to race or ethnicity rather than class, and this kind of diversity is often welcomed. However, what ethnic diversity is and what risks it may be seen to pose vary by area, with some parents in Cheadle Hulme expressing reservations about both ethnic and religious difference which they saw as potentially threatening, particularly when accompanied by 'political correctness'. As we will explore below, in the UK schools have been a key site for the implementation and debate over multicultural policies and it is perhaps unsurprising that they also serve as a site for anxieties about multiculturalism. The chapter considers how many parents desire a 'good mix' in the schools and talk about ethnic diversity in positive ways. Thus, schools can be an important site for the kind of everyday conviviality (Gilroy 2004, Valluvan 20I6; Rzepnikowska-Phillips 20I7) which many parents view in a positive light and seek cross-cultural 


\section{Evaluating the mix}

interactions and 'exposure' (Byrne 2006b; 2009) for their children. However, as this chapter will show, there are often limits to the exposure to difference or 'mix' that is desired. Some white parents fear 'too much' of an ethnic mix, or an 'over-exposure' which would mean that their children were no longer in a context where white children are the majority. At the same time, ethnic-minority parents also fear 'not enough' of a racial or religious mix which could leave their children more vulnerable to racism (Weekes-Bernard 2007, Rollock et al. 20I5). What is notable about this complex situation of desires and fears around multicultural mix is the paucity of language for talking about diversity. As the chapter will explore, the single term 'good mix' is used to describe schools which differ very markedly in terms of the ethnic make-up of their student population. Thus we argue that there is no shared language around multiculturalism and no consensus on what multiculturalism might (literally or metaphorically) look like in the everyday context of a school. As there is no vocabulary to calibrate degrees of 'mixedness', it appears that what constitutes a good mix is largely in the eyes of the beholder. It is also worth noting the caveat raised by Reay et al. (20II: 50) about the use of the term 'mix': 'it can be a misleading term since in practice it may not actually refer to social mixing per se but rather to the social backdrop, the context for living'. Thus the degrees of real encounter (Wilson 20I7) and conviviality desired may also vary markedly.

As argued in Chapter I, this book is distinct from much of the literature on school choice and ethnicity because it is able to consider the choice talk of both white and ethnic-minority parents across a range of class positions and in different geographic areas where the ethnic make-up of both the relevant primary and secondary schools and the wider areas are known. ${ }^{1}$ With an approach which includes ethnic as well as class diversity in three areas, we are able to see how class, race and place all shape parents' responses to ethnic difference. In particular, the chapter will argue that there are broad, area- or school-specific discourses circulating around the question of multiculture which also serve to point up the complex intersections, and layering, of race and class. Generally all the interviewees thought that educating children in a 'diverse' context with a mix of children from different ethnic backgrounds was a positive element of the primary schools their children attended, and of the high schools they wanted their children to go to. At the same time, parents living in the different study areas had markedly different ideas of what a multicultural mix or diversity 


\section{All in the mix}

looked like. Multiculturalism appears to be a widespread affective discourse conveying particular emotional landscapes and responses to difference. Yet we will argue that it is lived and felt differently in particular spatial contexts (Nayak 20I0). For those white respondents living in the areas with the lowest ethnic mix, alongside a general approval of a good 'mix' there were also fearful discourses circulating around the consequences of having 'too much' diversity for their children. Thus we will explore different degrees of comfort around ethnic mix and varied levels of attachment to a whiteness that can be put at risk in situations which are 'too' multicultural. At the same time, for the ethnic-minority parents, the possibility of 'not enough' racial or religious mix could leave their children more vulnerable to racism.

Thus, this chapter will demonstrate how parents of children in the school in Chorlton, and to a certain extent Whalley Range, had a particular range of responses to ideas of cultural difference which differ from those of the Cheadle Hulme school, where the talk tended to be more fearful and tentative in its embrace of mix. The relaxed approach of the parents in Whalley Range and Chorlton might be expected from the fact that they all appeared happy with their children's current primary schools which had high levels of ethnic, religious and, to a certain extent, class diversity. Many of them stressed the 'comfortable', 'friendly' or 'nice' atmosphere they found in the schools their children already attended. This orientation towards multiculture or everyday conviviality (Gilroy 2004) is shared by white and non-white respondents and of people in different class positions in these areas to a large degree, but with some significant differences. In the case of the parents from the Chorlton school, it is also accompanied by a sense of a liberal and sometimes 'alternative' lifestyle which has classed characteristics, also shared by white and ethnic-minority respondents. Whereas, for the non-white parents of both areas, there was an element of what Reay and Lucey (2003), considering children's approaches to school choice, call 'ethnic choosing' or what we have characterised as 'safety in numbers'. This chapter will briefly consider the relationship of policies of multiculturalism in the UK education sector which perhaps go some way in explaining how parents have an, albeit limited, vocabulary to express a valuing of ethnic - as opposed to class - mix. It will then explore the ways in which, in Chorlton, an espousal of multiculturalism and a high value placed on diversity often coincided with a broader range of what were seen as lifestyle or ethical concerns including, for example, vegetarianism 


\section{Evaluating the mix}

and openness to same-sex relationships. The chapter will also explore how diversity also included a sense of proportion or balance and the ways in which the mix might not be right. The chapter will then explore how, for ethnic-minority parents, the nature of the mix might be particularly urgent as the dominance of white pupils at a school might expose their children to experiences of racism and hostility. The final sections of the chapter will consider the accounts of those white parents living in Cheadle Hulme who express serious reservations about 'too much' diversity and multicultural mix. Here the discourse of embracing difference espoused by both middle and working class in Chorlton is rendered much less enthusiastically. Instead, a sense of fear creeps in to accounts of ethnic diversity. Although the parents in Cheadle Hulme are living in areas with much lower levels of ethnic diversity and the schools their children go to are also much less ethnically diverse, they at times gave quite resentful and embattled accounts about the impact of 'political correctness' which suggest a sense of whiteness under threat.

\section{Multiculturalism and diversity in education}

Anne Phillips (2007: 3) argues that in the early twenty-first century 'Multiculturalism became the scapegoat for an extraordinary array of political and social evils, a supposedly misguided approach to cultural diversity that encouraged men to beat their wives, parents to abuse their children and communities to erupt in racial violence' - and she could have added the threat of terrorism. Multiculturalism has also been held responsible for breaking up what are nostalgically imagined to be cohesive communities and has become what Sara Ahmed calls 'an unhappy term' (Ahmed 2004b: I22). Multiculturalism is also positioned as one of the causes of a 'crisis' of national identity in Britain and/or England (Byrne 2007, 20I4b). Trevor Phillips (the chair of the then Commission for Racial Equality in the UK) controversially declared the failure of 'multiculturalist' policies in $2004 .^{2}$ These policy discussions around multiculturalism also need to be understood in the context of a post 9/II 'war on terror' and also as shaped by responses to the disturbances in Britain in 200I which focused on a perceived rise in segregation (particularly in cities of northern England with large Muslim populations) (Cantle 200I; see Phillips et al. (2008) for the counter-argument). Recent debates around multiculturalism have tended to have an increased attention 


\section{All in the mix}

to religious difference (particularly Islam), alongside the older focus on racial or ethnic difference.

In February 20II, David Cameron, the Conservative Prime Minister of the coalition government launched a 'war on state multiculturalism' ${ }^{3}$ which he blamed for encouraging separatism and therefore being responsible for the radicalisation that can lead to terrorism. David Cameron has also focused on definitions of Britishness set in the context of a declared 'crisis' of national identity. In his 2006 Party Conference speech, Cameron declared that 'every child in our country, wherever they come from, must know and deeply understand what it means to be British'. ${ }^{4}$ Sara Ahmed argues that 'this nostalgic vision of a world "staying put" involves nostalgia for whiteness, for a community of white people happily living with other white people' (Ahmed 20IO: I2I). The nostalgia can also be seen in some of the campaigning around the 2016 Brexit referendum, where imperial fantasies of national sovereignty and control of borders seemed to have a strong purchase on some voters. Thus, although it is frequently unspecified, 'diversity' is generally considered to be a positive attribute of British society and within education. Yet, at the same time, there has been a distinct 'turn' in terms of government policy towards religious, ethnic and racial difference. This turn, which draws to a close the era first initiated by Roy Jenkins in the I960s, has an affective register which often produces ideas of wounded and vulnerable whiteness and contradicts some of the positive more convivial associations with multiculturalism. Roy Jenkins, as the Labour government's Home Secretary, argued for a policy move away from an assimilationist approach which sought to assist (and require) migrants to relinquish cultural difference in the quest to become British. Jenkins favoured an understanding of 'equal opportunity accompanied by cultural diversity in an atmosphere of mutual tolerance' (Grillo 2007).

In the context of education, in the I980s, there began to be a focus on schools in white areas as well as inner-city multicultural areas to promote respect and tolerance for other ethnic groups and religions (Tomlinson 2008: 83). The Swann Report of I985, Education for All, argued for cultural pluralism and opened the door for a range of multicultural policies from schools and LEAs (Rattansi I992, Tomlinson 2008). As Tomlinson argues, '[t]he Swann Committee took the view that the aims of a multicultural anti-racist curriculum were synonymous with a good education designed to produce decent, tolerant and knowledgeable citizens' (Tomlinson 2008: 93). This approach 


\section{Evaluating the mix}

has been criticised, both by those who worry about the 'dilution' of British culture and by those who oppose multiculturalism from an anti-racist perspective (Tomlinson 2008). Nonetheless, schools have played an important role in the politics of multiculturalism where they have generally been seen as a site both of tension and risk around culture and diversity but also as a possible solution to racialised prejudice and inequalities. As Rattansi argued, 'the basic educational prescription [of multiculturalism] is the sympathetic teaching of "other cultures" in order to dispel the ignorance which is seen to be at the root of prejudice and intolerance' (Rattansi 1992: 24). Nonetheless, many anti-racists criticised the multiculturalist approach for failing to address racist structures and ideologies and assuming that a 'dose' of 'other cultures' - often read as religion (Yuval-Davis I992: 283) would cure ignorance and thereby end racism (Hesse 2000). This is not to say that 'multiculturalism' consists of a coherent political or policy discourse: as Stuart Hall (2000) argues, it should properly be understood in the plural. Lentin describes it rather as 'a patchwork of initiatives, rhetoric and aspirations' (Lentin and Titley 20II: 2). Nonetheless, despite its relatively modest ambitions and partial implementation, it seems clear that we are facing what Derek McGhee describes as the 'systematic dismantling of multiculturalism as the organising rhetoric of public policies' (McGhee 2005).

The discourse within education has shifted from multiculturalism to 'diversity' and with associations first to 'active citizenship' and then to 'British Values' (Yuval-Davis 2007, Byrne 20I4b). In this shift, schools are again central to the attempt to create a new form of citizenship based on the elusive 'common culture' of the nation in a reframing of cultural debates within a 'reinvigorated nationalist discourse' (Alexander 2007). Parents are unlikely to be aware of these policy debates, but we would argue that they still have an impact on schools as spaces and on ideas of education. Schools as spaces are marked as multicultural by the posters in receptions and other areas saying 'welcome' in multiple languages. But they have become in recent years a site of resurgent nationalism as signalled by the return of the Union Jack in displays of British values. The following section will consider the accounts of parents whose children went to school in Chorlton who generally have a positive response to the idea that their children will go to schools which have a 'good' ethnic mix, or at least are in a context where to question multiculturalism would appear to be breaking a taboo. 


\section{All in the mix}

\section{Chorlton talk: 'enough of a mix'}

You wouldn't have somebody in Chorlton saying, 'I don't' ... 'I want my children to go to a school where people have nice families and that they are white, and nice middle [class]' ... [...] that might be what they felt, but you wouldn't openly say it. (Sara)

Sara, a white student, whose daughter goes to school in Chorlton, tries to explain that there is a kind of 'Chorlton talk' around diversity which, she suggests, enforces certain silences. The sensitivity of the issue is perhaps expressed in her false start - she tries to first say what might not be desired (otherness) but fails and switches to an alternative, positive phrasing of the issue. The hesitancy in this quotation alerts us to the difficulties of interview-based research on questions of ethnicity - as well as class and gender and other social divisions - that respondents may tailor what they say to what they think is acceptable. This requires greater attention both to silences and to what is not said (Byrne 2006b, Harries 20I4, 20I7). Nonetheless, it can sometimes be surprising what people do feel able to say in an interview context about ethnicity (and about class as we saw in the previous chapter), as the chapter will demonstrate. Furthermore, we argue that what people feel is appropriate to say differs in this research in part according to the areas they live in. Much of the talk around school choice happens most intensely in local spaces (Wilson 20I4) - in homes, at the school gate - and we found that parents in different areas did tend to produce distinct area-specific discourses around ethnic mix (more so than around class, as was discussed in Chapter 4).

Certainly, what we heard most frequently in the interviews with respondents whose parents attended the school in Chorlton was a positive response to diversity, but one which also had a broad approach to the notion of difference, often encompassing questions of 'ethical approach' (to child-rearing or, for example, vegetarianism) as well as questions of sexuality and cultural difference. This might be considered to in part reflect what Ghassan Hage (I998: 129) refers to as 'ethnic surplus value' where ethnic diversity is something to be consumed. At the same time, the embedding of an idea of ethnic diversity with other kinds of difference is something that is under-explored in the literature. Thus, in this context, racialised or religious differences are understood as embedded within a range of different 'lifestyles' or 'cultures', which we would argue are also classed. Which differences 


\section{Evaluating the mix}

matter at a particular moment is therefore also likely to shift according to a range of considerations and the geographic location which is being considered. As we shall see, understanding people's responses to 'multiculture' is hampered when exactly the same language is used by people describing very different situations (Ball et al. 2002, Byrne 2006a).

Fran (a white midwife) had lived in Chorlton for almost twenty years and had moved there as a student. As with many of those interviewed in Chorlton, as we saw in Chapter 2, Fran appreciated Chorlton as a place of diversity where there was an 'alternative culture', including people with similar ethics - in Fran's case vegetarianism was particularly important. In considering which primary school to send her children to, this question of diversity and ethics was extended to a notion of ethnic mix. She explained why she had chosen Longford Primary:

Well, I think because we're not religious, we didn't want any sort of Christian school or anything like that. We wanted a school that had a good mix of different kinds of kids, so Longford School is quite a mix of like different cultures. There's Asian kids, Afro-Caribbean kids, Chinese kids, there's loads of different kids and there's quite a lot of gay parents as well, so we wanted the kids to get a really good idea of difference basically.

In this account, diversity is tied to the visible racialised differences, as well as the perhaps less visible issue of sexuality, but not class. This kind of diversity is something positive which Fran says she actively sought. However, there were limits to what would be a desirable diversity. Fran went on to explain that, when they were choosing primary schools for their first child, the question of ethnic mix was very important:

We'd heard that it [a potential alternative school] was predominantly an Asian school so thought it might be quite difficult for a white child to fit into a really predominantly Asian kind of culture. And Longford has like so many different cultures, I just thought it'd be better for the kids if they had a really good mix of children and not just one predominant like White, Asian, whatever in that school. (Fran, white, midwife).

The primary school that Fran's children went to had just over 50 per cent white children whereas the school she ruled out had just over two-thirds from Pakistani backgrounds. So she was reflecting on a 


\section{All in the mix}

quantitative difference and, although happy for her child to be in a school which only just had a majority white context, there were limits to how she felt about a non-white context, especially when it was not 'different' enough.

This desire for diversity, with an acceptance of limits to the desire, was not only expressed by white respondents. Jas and Tej (British Asian managerial employees) also lived and Chorlton and they together explained how they chose Longford Primary School:

Jas: Tej spoke with other parents and they thought Longford was a good cosmopolitan school.

$[\ldots]$

Tej: We found it was more of a community school. You know. ... the mix, the parents were quite similar to what we wanted to be involved with, you know. It is quite relaxed, like there is no uniform. Children are from all different backgrounds ... there is a good network, the parents' ethics are quite good.

Jas and Tej were comparing Longford School with the one (also considered by Fran) that their son initially went to. They characterised the school as '90 per cent Asian', 5 thus overestimating the Asian presence in the school. Jas and Tej were both Sikhs with ancestry from India and the school they were referring to would have had children from predominantly Pakistani Muslim backgrounds, so religion as much as ethnic origin is likely to make up a significant part of the mix that matters for them (as it may have done for Fran). For Jas and Tej, as much as for Fran, the diversity represented by 'cosmopolitan' Chorlton is an important part of their elective belonging in the area (Savage et al. 2005). In contrast to the desire expressed by many parents quoted in Chapter 4 for smart uniforms at high school, for Jas and Tej the no-uniform policy of the primary school was symbolic of its relaxed, cosmopolitan approach. This may partially mark a distinction between what is desirable for a primary school as compared to a secondary school.

Other parents in Chorlton also qualified their approach to a 'mixed' school by suggesting there was a point at which their child became too much of a minority, which might be characterised by class, race or religion or a complicated combination of them all:

I supposed that might have influenced me in thinking are there, is she going to have other children who, you know that she's going to have similar things in common with, lifestyles and backgrounds as well as 


\section{Evaluating the mix}

other people. So more of a mix, so it's not about, erm, I just want, I would like her to go where there's a mix of children. ... I don't want her to go to school where it's all white children, but I wouldn't want her to go to a school where it's all predominantly Asian children either, just because I think, you know it's nice for there to be a mix. [...] you want them to have friends and have things in common [...] I just want her to go somewhere where there's a good choice of people she can be friends with, and that sounds awful if [it] makes me sound like I don't want her to be friends with Asian people, it's not that, it's about [...] you know, if I was black and I was choosing a school where there wasn't a very big ethnic mix, that's exactly the same. I think it's having the mix that's really nice, and really nice at that school. (Terri, health visitor, white, Chorlton)

Wrapped up in the expressed desire for 'mix' may be different concerns and experiences: it is a complex affective terrain, and there are potential risks in the encounter with difference (Wilson 20I7). It carries risk that children may not find friends - or perhaps the right kinds of friends who, in Terri's words 'have similar things in common with, lifestyles and other backgrounds'. As Ball et al. (20II: 4) argue: '[i]n relation to friendships, mix is an arena of social risks as well as a form of social learning in relation to identities of different sorts'. It is clear that describing these desires is difficult for Terri, presenting the possibility that she would be read as prejudiced and racist. Even representing one's desires and choices presents risks and dilemmas. It seems clear that, for Terri, not enough of the right kind of children would present a social risk for her daughter. However, getting the mix right can present benefits for children. For many of those interviewed, the desire for a multicultural mix was presented pragmatically as gaining 'real life' experience for their children. This could be regarded as the same kind of desire for social and cultural capital that Reay et al. (20II) found in their study on white middleclass parents. The parents in Reay's study who had gone 'against the grain' of school choice by selecting inner-city comprehensives for their children frequently felt that their children were gaining an essential attribute for success in modern times which was to be comfortable with people from a whole range of ethnic backgrounds. However, in the context of this research, it is interesting to note that it is a desire shared also by non-white parents. As Serena, a nurse whose parents migrated to Manchester from the Caribbean, and whose children went to the Chorlton primary school, argued: 


\section{All in the mix}

Children nowadays need to know everybody, before they make up their mind about a certain class of people or a certain ethnicity of people, they need to know everybody, and I think that our children now that are growing up are more, are much more, are much better in communicating with different types of people, than say [we] were or you know people were a couple of years ago or before.

Serena is unusual in explicitly mentioning class as well as ethnicity which, as we saw in Chapter 4, was something many parents avoided, even where it might be implied (this can be seen in the following quotation from Kelly, a white teacher whose child went to Longford Primary in Chorlton: 'We want our children to grow up knowing there's lots of different kinds of people around and they're all ... it's all good'). Alongside raising questions of class, Serena also reflects a common sentiment in the research: that their children's generation will need to be much more comfortable with diversity than their parents are. The next section will focus on the experiences of ethnicminority parents and show how, although they commonly asserted the same positivity around diversity in schools, their school choices were also framed by a need to consider the risks to their children posed by being outnumbered in white schools - or consigned to lowachieving 'sink' schools.

\section{The safer choice}

For ethnic-minority parents, the desire for diversity of multicultural mix may be focused more on the undesirability of a situation of overwhelming whiteness - rather than the overwhelming otherness which usually is imagined by the white respondents. As Ball et al. (2OII) argue: 'within the processes of school choice, the social mix of particular schools can serve, in parent's accounts, as a surrogate indicator for other things - white privilege or school policies that are sensitive to diversity, anti-racism or the possibility of racism and perspectives and practices which are conducive or not to minority ethnic achievement'. For Nasreen, a translator who had come to Britain from Bangladesh as a child and lived in Whalley Range, this caution about all-white contexts arose from her own experience of schooling in the UK:

Obviously diversity means a lot because I was - I went to a school where it was all white. And there was a lot of racial abuse so - which 


\section{Evaluating the mix}

is something that I do not wish for my daughter. So if there is a school where it's quite diverse hopefully she won't get that.

Thus diversity offers a sense of protection from racism and avoiding the vulnerability of being the only non-white pupil in a class. Alongside this desire for security, Nasreen does express the more general desire for a cosmopolitan outlook for her daughter, as suggested by many white parents: 'all you wish for your child [is] to grow up aware of other cultures and religions. And not just cultures and religions, different experiences of lifestyle.' Similarly, Stan, a Chinese migrant living in Cheadle Hulme, mentioned that the primary school was 'not mature' in its approach to ethnic difference, and he was attracted to Poplar High School because of its multicultural mix.

Samer, a migrant from Iraq, had relocated to Whalley Range from another area in Manchester because of his (and more particularly his wife's) experiences of racism. So he was also attentive to the racial make-up of the school his son would go to. This included trying to avoid schools which were either too white or too black as well as finding it difficult to navigate a mostly Pakistani local community. He repeatedly told his son that he would need twice the level of qualifications to achieve alongside white candidates in the job market - and then quickly apologised for suggesting that Britain was racist: 'I'm sorry, you don't mind me saying that, no?' Bethan Harries (20I4) discusses the silencing of discussions of race in an imagined multicultural and post-race society. We can see the hesitation in naming, describing and resisting racism in regard to schooling and education from some of the interviewees for this research, which is perhaps not surprising given the dominance of discourses around diversity, multiculturalism and education. Whilst celebrations of diversity are clearly important, they can also make the description of less positive experiences difficult to express. ${ }^{6}$ Concern about racism and the potential for diversity to offer more 'safety' was explained by Sabah, a British Pakistani nursery worker:

even though I'm not racist or anything [like] that, you think about your child if he's going to be the only Asian in the whole school, how is he going to, how are other children going to react to him? And then you think about that, I sometimes, ... It might be fine you just, it's your worries at the back of your mind I think. I think yeah you do opt for the safer choice. I think as parents we do go for the safer choice. So where 


\section{All in the mix}

we see that ... you know the way it is diverse and it's got a lot of mixture of children.

Weekes-Bernard (2007) and Rollock et al. (2015) have explored how concerns about racism are a significant consideration for many ethnic-minority parents. This perhaps goes beyond what Archer (20I0: 453), discussing the experiences of minority-ethnic parents, describes as 'niggling insecurity' and a 'background hum of discomfort when discussing their children's education'. Serena, cited above, who felt it was good for her children to be educated in a diverse context, was nonetheless concerned to ensure that her daughter studied in a class where there would be enough black girls to build her selfesteem: 'you have to be proud to be black'. We would argue that this is a different sentiment from the white parents concerned that their children might not be in a white-majority context as the other parents were considering questions of feeling comfortable, rather than the necessary context for building self-esteem in a society where racist stereotypes about black women persist.

The ethnic-minority parents in both Chorlton and Whalley Range were generally (like the white parents) pleased with the primary schools that their children were in. Fauzia, a Bangladeshi full-time parent who had been in Britain since she was fifteen, described how she particularly valued the approach of her children's primary school:

[The school] is multicultural and is very friendly atmosphere and lots of different kinds of things happen there [...] And we have lots of different cultural things there, picnics and wood fair [craft event]. And lots of other activities for parents to get involved with.

Here we have a sense also of how schools can create a sense of community that includes not only the children but also their parents. Having had this experience at the primary level, when Fauzia explained why she preferred one grammar school over another (despite the fact that it was generally less well regarded), the lack of ethnic diversity was a key issue:

When I went to West Street Grammar for open day, I felt like less - more like white based, most people are white. And when I go to Blessingham Grammar, there's lots of mixed children there, lots of Asian, Arabs and lots of blacks and all kinds there. That's why I feel the same feeling as St Catherine's [current primary school] as at Blessingham Grammar. 


\section{Evaluating the mix}

For Fauzia, whiteness is something that needs to be diluted in order for her to feel a sense of security for her children, and this desire for diversity is distinct from those white parents who are seeking exposure to difference for their children. Rachel, who lived in Cheadle Hulme, was white with mixed-race children. She said that she was specifically choosing the less 'white' high school for her daughter. This was because her daughter had faced problems of racism at the primary school. What we can see here is that the nature of the 'mix' matters to these parents because of the effect it will have on their children's experience. It is a desire for 'people like us' - but of a very different kind from the desire considered by most of the literature on school choice. In addition, it is important to note how talking about 'mix' includes consideration of religious difference as well as racialised differences. This is particularly important in the current context where Muslim experience of racism is increasing in general and often peaks in times where there have been terrorist attacks. ${ }^{7}$

Nonetheless, concerns about mix from some non-white parents could also include prejudice and stereotyping. Samer, as mentioned above, explained that, in the case of primary school, he had rejected one which he worried had 'too many black' children, particularly as his son was 'soft'. This demonstrates how stereotypes and prejudices may be shared across racial lines. In fact, Samer had felt isolated by other Muslims in Whalley Range through language differences and his son had experienced problems with 'other Asians'. In addition, finding a school with 'enough' mixture was not always a strong preference. Helen, a teaching assistant of African-Caribbean origin, said she was not worried about the local schools because they were a good mix, but at the same time she argued that:

If I was living in a very white area, where there are mainly white families, mainly white children, I would still be choosing the best schools for that area. So I wouldn't look for the school that had more black people than white people.

For some parents from ethnic-minority backgrounds, there was also a sense that other (white or Christian) children would benefit from 'mixing' with their children. Halima sent her first child to an Islamic school but her other children have gone to Longford Primary School in Chorlton: 'I must admit I've changed my views since then'. She likes the way all faiths are introduced to the children: 'These are my children, they practise their religion but they don't practise how 


\title{
All in the mix
}

you've been - how the TV portrays Muslims, extreme Muslims.' This was therefore, for Halima, a distinct contribution to society that she was making in showing white British children that the portrayal of Muslims in the media was not accurate. However, the politics of being Muslim in Britain may also have other pressures, and the respondents point to the importance of not seeing Muslims in Britain, or even Pakistani Muslims in Britain, as an undifferentiated group. There are many differences in experiences and perspectives which are shaped by class, education and generation. Runa explained that, because she is a 'liberal' Muslim, she likes her daughter going to school in an area with fewer Muslims, so that she will not be judged by other Muslims for her practices. She also wanted her daughter to have a wide variety of friends rather than just Asian Muslims. This was a view shared by Saira, a migrant from Pakistan living in Cheadle Hulme, who felt distanced from other Pakistanis by class and by different practices of religious observance (such as dress and diet):

\begin{abstract}
A lot of Asians I notice sometimes they don't mix with other people [...] here there's a good mixture of people and the majority of my children's friends are - are English people. [... ] I didn't want to be in a place where there was not a good mixture of people. [...] If I wanted to stick to all Asians then I should - might as well stayed in Pakistan [laughing] and the thing is for my kids to have more mixed sort of upbringing and be aware of other cultures, religions and to respect each other and work in a very multicultural society. I think it should be a good mixture.
\end{abstract}

Here Saira shows an engagement with the multicultural discourses common in British education, and in some ways there appear to be more commonalities between Saira and the white middle-class parents of Reay's study where cosmopolitan knowledge is something to be acquired. But for Saira, this also involves a process of negotiation with the 'community' to which she is assumed (by others) to belong. She marks the distance between herself and those other 'Asians' through a discourse of an appreciation of 'mixing':

\begin{abstract}
A lot of Asians that moved here many years ago, they came from small towns and some of them might not have been educated. Although their kids got educated and stuff, but they didn't let their kids mix with other people. They didn't want to lose their identity, their culture, religion and all that ... [they are] living in a time capsule.
\end{abstract}

Similarly, Noreen, originally from Pakistan (where she had been a teacher) but who had arrived from Belgium only three months before 


\section{Evaluating the mix}

the interview, explained that she had avoided one primary school because it was too Asian. In contrast, the school her children went to had:

Some Iraqi people, some Arabic. Some was Africans, some Chinese and then it's most of multiculture that's good. I prefer that. Because then my children also, they know other cultures, other religion also they have to know because they live here. And for that I think it will better ... the multicultural.

At the same time, she was also concerned that the high school her daughter went to should not be too white as she was worried about racism from both fellow students and potentially the teachers. Thus a mix represented potential enrichment for her daughter's education (she already spoke four languages and with this proficiency she managed to pass a specialised language test for a local academy). In addition, a sufficient mix was also read as a signal that there was less likely to be racism within the school.

This section has demonstrated how the many ethnic minorities share an affective register with their white counterparts in Chorlton and Whalley Range where diversity and multicultural mix are deemed to be a positive part of schooling. However, for some, the espousal of mix is also shaped by a fear that, in more white contexts, their children may suffer racism and exclusion. Thus the mix provides more than cosmopolitan exposure but also provides a refuge from prejudice. The following section will explore the accounts of some of the white parents of children in Cheadle Hulme who, whilst they shared a discourse of viewing 'mix' and diversity positively, at the same time produced fearful accounts of whiteness being lost or supplanted.

\section{Questioning multiculture}

An interesting issue which arises out of this research is that we lack a highly developed vocabulary for describing diversity. Thus, in all three areas, which are quite distinct from each other in terms of both the residential population and the make-up of the schools, very similar phrases are used. So Cheadle Hulme, Chorlton and Whalley Range are all described as areas with 'a good mix', 'very diverse' and 'very multicultural' by different respondents, as are the different schools which their children attended. But what 'diverse' or 'mixed' means will vary in each case. It is often difficult to read off 


\section{All in the mix}

from people's description of the 'mix' what that actually means in demographic terms. Thus terms such as 'very diverse' and 'good mix' were used to describe schools in which there were 76 per cent white pupils (in Cheadle Hulme); 5I per cent white pupils (in Chorlton); and II per cent white pupils (in Whalley Range). However, whilst the parents from the Cheadle school, which was notably whiter in terms of residence and school intake than Chorlton or Whalley Range, did express a desire for ' $m i x$ ', there were also more explicit expressions of fear and a risk of something lost. This outlines perhaps what might be seen by these parents as the limits to the 'tolerance' or the risk of the embrace of difference. Much of the fear expressed is framed around religious as much as ethnic difference, although it is clear that the two are mutually constituted. We would argue that there is a different discursive and affective conceptualisation of difference in operation among the white parents of the school in Cheadle Hulme. Thus, where Sara, quoted at the beginning of the chapter, suggested that there are things that are almost unsayable in Chorlton, they were expressed more freely by parents in the Cheadle Hulme school. What appears to be under threat is a sense of Christian culture. However, it would be mistaken to see this as a straightforward replacement of ethnicity or race by religion. Often, the desire for Christianity (or conversely the fear of or concern about the Muslim) is coupled with ethnic or racialised descriptors. For instance, Natalie, a white office worker, explains why she likes Ashover Primary School in Cheadle Hulme (she is one of the few white interviewees from Cheadle Hulme to bring up questions of racialised difference without prompting):

because of its ethics. ... It was quite a Christian background actually, although there were children from other denominations that came to the school, it was a predominantly white Christian background that the children came from which I actually quite liked. I'm not an overly religious person.

Although a desire for a 'predominantly white Christian background' appears to be sayable in the Cheadle Hulme context in a way that it might not be in Chorlton, there remain other restrictions on what is acceptable to say, at least without care. So, as Natalie goes on to explain how the demographic nature of Cheadle Hulme has changed since the building in the area of a mosque about which she and her husband 'weren't overly happy', she says, 'I have to be careful what I say here'. Natalie also explains some of the limits to easy mixing 


\section{Evaluating the mix}

which she has experienced: 'And you - to a certain extent you're still segregated 'cause we don't know and you do tend to put up barriers. You do become defensive with what you don't know.' This segregation also translates into concerns about schooling:

The only thing that concerns me over ethnic backgrounds that go into secondary school is - and you do get it - is to a certain extent gang culture because again, because there is still a barrier and there's always going to be a barrier [...] a lot of the time you'll get the Asian children sticking together and the white children sticking together. It causes tension. ${ }^{8}$

Natalie expresses some discomfort in talking about ethnic and religious difference and worries about her own ignorance. Sharon, a white civil servant also from Cheadle Hulme, had a positive discourse about 'Asian' families investing in their children's education. However, she appeared confused in her terminology:

I think a lot of Asian families tend to invest more in their children than well you know, they might be white Asian family, I don't - you know I don't know what, but ... I - I just know an Asian person from the colour of their, you know from they look like it's, but I - I - I - I don't know whether they are white Asian or whether they're not, but I just feel as a culture, I feel that they invest more in their children.

Sharon appears here to be confusing Asian with Muslim (or alternatively a British Asian person has been rendered white) which again suggests that 'diversity' talk is something she is a bit uncomfortable with, or unused to. This confusion also points to the intertwining of religion and ethnicity in her perspective. Sharon also overvisualises the non-white presences in her children's primary school, stating that it is now 'majority' Asian (although it is 76 per cent white and South Asians make up only a small proportion of the minority group). ${ }^{9}$ Sharon draws on familiar discourse which is anti-multiculturalism or the trope of 'political correctness':

There's been a lot of ill-feeling in the past few years ... with parents that celebrate a lot of the Asian holidays and stuff but we're not allowed to celebrate any of ours because it's classed as racist. We're not allowed to celebrate St George's Day and ... they stopped two children sending Christmas cards out and there's been a lot of stuff like that. [...] There are a lot of subjects that white British children are not allowed to learn about because the other pupils' parents say it goes against their religion for them to learn about it and so they suffer in that respect. 


\section{All in the mix}

This narrative was shared by Melanie, a white beauty therapist also from Cheadle Hulme. Again, however, Melanie feels she has to choose her words carefully: we don't know what word she wants to say, but it appears to be unsayable:

Carla: How would you characterise the ethnic make-up of the school?

Melanie: I don't think it's that, it sounds, it's a shocking word to say. ... Right. This is the honest truth, I think there are quite a few Pakistanis at the school, which is fine, which is great you know. I'm not a racist in the slightest, I don't really care as long as it doesn't affect me, if they're a nice person and it doesn't really matter does it what colour your skin is, [...] what country they're from I don't care. What we do care about is things like the school, like everything, the whole world has gone politically correct and I think our school is quite a, like we have a racist [incident] book for example, so if a white child does anything to a Pakistani child then us as a parent and the child sign the racist book. Now in my eyes it should work both ways, but it doesn't so, I think things like that annoy you. Things like, oh we're going to stop the Christmas nativity because of that, well hang on a minute we're in England, you know, things like oh the kids have to go off and visit the mosque, they have to take their shoes and socks off and they have to like do reading from the Quran and they have to respect it.

Melanie builds up quite a head of steam in her account against 'political correctness' which she feels is responsible for both unequal treatment and significant changes in the school culture. The school administrator confirmed that neither Christmas nor nativity plays had been stopped in the school and said, 'Although we're a multiracial school, Christmas is quite a big deal here'. ${ }^{10}$ What this illustrates is the power of media scares around the 'banning of Christmas' in the face of religious-minority sensibilities, as well as the existence of mistrust around religious differences. ${ }^{11}$ Here we see a discourse of tolerance which suggests it is at least provisional, and Melanie would seem to have quite a high level of discomfort around discussing religious difference, which remains entangled with race.

In the interviews of parents from Cheadle Hulme, as well as evidence of discomfort about what was seen as a changing racial make-up of the area, there was also some discussion of white flight. Annabel had moved from Burnage, an area with a more South Asian population, to Cheadle Hulme. The reason that she gave for this move was wanting to avoid single-sex secondary schools which had been 'a big discussion with the white parents' (although she also 


\section{Evaluating the mix}

acknowledged that some Asian parents did not want single-sex education). Annabel said: 'It's not a problem for me, I mean, the way schools teach religions and how to accept other children of different nationalities.' Nonetheless she was happier in the school in Cheadle Hulme where the majority of the children were 'white British' and more middle-class:

I think it's good. I think because the children will be among children that are like themselves. And although it's good for them to mix with children from other classes and other ethnic backgrounds, you just gravitate towards people that are similar to you, don't you? And they're obviously going to have more chance of making good friends among children that have a similar background ... It's nice for them to be among more white children.

This is a response to diversity and multiculture clearly different from the general view expressed by those interviewed in Chorlton and Whalley Range. The 'naturalness' of 'gravitating towards your own' wins out against any embrace of difference. Difference also brings with it inconvenience. Annabel explains how she felt that in Burnage her children's social networks and capital were limited. She used the example of afternoon tea invitations which were not reciprocated by her children's friends, because 'children from big Asian families, who obviously live a different life, it's difficult, coming home for tea, it's difficult because these children cannot' and how vegetarian food had to be provided 'because of halal meats'.

\section{Conclusion}

Richard Hacker has argued that multiculturalism as a concept is 'given only a taken-for-granted common sense meaning, impoverished both theoretically and in terms of concrete lived experience. It is a concept innocent of class' (quoted in May 2002: I29). The material of this chapter would suggest that multiculturalism and responses to multiculturalism do need to be understood as both classed and located in place. In addition, multiculture in terms of racialised or cultural difference is best understood within the context of a whole range of differences that people encounter in the everyday, including differences of class, religion and what some respondents in this study characterised as 'ethical' differences in approaches to child-rearing and consumption. Despite policy-level declarations of the end of 


\section{All in the mix}

multiculturalism, in the everyday, individuals and communities, such as those created by a school, continue to negotiate cultural difference in a variety of ways. The everyday context of schools is also shaped by the emphasis on parental choice in schools. As Alexander (2007: iii) notes, there is a potential contradiction between the idea that schools can both be the site of multicultural citizenship and the exercise of choice. It raises questions of who should 'shoulder the burden of integration' and who is granted 'the privilege of individual choice'.

This chapter has explored how attitudes towards and experiences of multiculture can both impact on choice and produce different ways of talking about it. So, for some parents, the perceived ethnic, religious and social make-up of school populations will impact on how they view different schools. Parents make school choices in particular contexts, reflecting both the choices available and the experience of primary schools and local areas which also shapes how parents become used to talking about difference. The sense of ease with, and embrace of, multiculture varies among different groups of parents. So, for those in Whalley Range and Chorlton schools, who are already used to high levels of ethnic diversity in primary schooling, there is a sense that convivial mixing can be achieved and is desirable. However, this ease of mixing is tempered by concerns about class difference. In interviews with parents living in Cheadle Hulme, there is more of a tendency to view ethnic difference as naturalised and presenting an unbridgeable distance. At least part of this difference in responses comes from a different class habitus. Thus for the more professional middle classes in Chorlton, many of them working in the public sector, a 'liberal' and convivial attitude is part of their class habitus (Bourdieu I99I). What is interesting is how this language is also shared by some ethnic minorities and migrants from a variety of class positions. For the white working-class and middle-class parents living in Cheadle Hulme, there is more hesitation in both talking about and perhaps living with difference. These differences point to the need to study everyday multiculture in its context, where it is lived, and to be alive to the other differences that matter. It also suggests the need to understand the limits of language in describing experience. The chapter has shown how there is a marked paucity of language with which to express these negotiations with diversity. The same terms might be used by different people to describe very different situations. Social agreement is clearly lacking on what constitutes a 'mix' or 'diversity'. This poses the risk that parents, schools and policy-makers may well 


\section{Evaluating the mix}

be failing to communicate well with each other about difference and schooling. It is also important to track how cultural difference can contain ideas of both racialised or ethnic difference and religious difference which are mutually constructed and sometimes difficult to unpack. Whilst ethnic-minority interviewees often shared an affective relationship to difference as a positive and important resource for the next generation, the benefit of a 'good mix' was also one of protection from racism and stereotype. Finding schools which were sufficiently mixed represented for them the hope that their children could easily fit in and be part of that mix, rather than isolated and vulnerable in a sea of whiteness.

\section{Notes}

I See Chapter 2 for a fuller discussion of the areas and schools.

2 www.guardian.co.uk/society/2004/may/28/equality.raceintheuk, accessed 4 July 20 II.

3 www.independent.co.uk/news/uk/politics/cameron-my-war-on-muticult uralism-2205074.html, accessed 4 March $201 \mathrm{II}$.

44 October 2006: http://news.bbc.co.uk/I/hi/uk_politics/54077I4.stm, accessed 4 March 20II.

5 In Britain, the term 'Asian' generally refers to those who come (or whose ancestors came) from the South Asian subcontinent.

6 It should also be acknowledged that the fact that both the researchers on this project were white may have also had a silencing effect on some of the interviewees.

7 See, for example, https://tellmamauk.org/constructed-threat-identityintolerance-impact-anti-muslim-hatred-tell-mama-annual-report-20I6/, accessed 3 July 2017.

8 In Chorlton, too, some respondents expressed concern about gang culture, some of which was associated with racialised groups, but others explicitly said that the 'gangs' went across racialised groups. This fear of gangs also has a gendered element, in that it was more likely to be brought up of boys rather than girls. It links into the debates around 'boys in crisis' which are also ethnicised in particular ways: Archer(2003).

9 See Byrne (2006b) for discussion of white over-visualisation of racialised groups.

Io Telephone conversation.

II See Gillborn (2009) for a discussion of the creation of white victimhood in the media, with specific reference to education. 


\section{Conclusions}

A friend waiting for the decision on her son's application to high school explained to Bridget how this was a particularly stressful time. At the same time, she hoped it was also the end of her major responsibility for his education. She'd decided on his primary school and now his high school, but the rest, she hoped, would be down to him. Navigating a path through the schooling system for one's child is perhaps inevitably an emotional process. For the child it can be an anxious time, representing a big step: going to a much larger school; moving from being in the oldest class in the school to the youngest; often having to travel further and without parents. For a parent, it can bring up their own experiences - for good or ill - of schooling, the successes and failures of other children in the family, and often involves discussions not only with the child's other parent but also with wider members of families and friends. These conversations can be difficult in themselves. Sharon, quoted in Chapter 3, explained how she had started to stay in her car to pick up her children from primary school, rather than get out and be drawn into conversations about schools with other parents. Discussions about school choice can be fraught because they are in some senses deeply political concerned with questions of equity and opportunity - and are also often shaped by economic wealth (the ability to live in the 'right' area, to buy in tutoring or to buy a private education). They are also deeply personal. Parents may fear that a wrong step at this stage in a child's education may have lasting ramifications on their future life. It may set the parameters of the opportunities the child has in the future and it may also play a significant role in determining how they grow up, how happy they are at school and in the future and what character they develop. At the same time, education policy over the last thirty to forty years has also constructed parents as consumers who choose 


\section{Conclusions}

the schools their children will attend. As we have seen in this book, this injunction to choose ramps up the anxiety, particularly for those parents who feel their choices are too limited - or that they have to make a choice where all of the available options are undesirable. In this creation of the choosing parent, we are faced with the neurotic citizen that Isin (2004) suggests is created by a neo-liberal model of the operation of the market and the ideal of the rational consumer. The perfectly choosing parent becomes impossible to perform effectively for the majority, and thus anxiety and worry are a normalised part of the display of parenthood for all but a few. To be a good parent is to worry. Whilst it is often assumed that worrying about education is a middle-class, particularly metropolitan London-based activity, this book traces the ways in which anxiety and concerns are displayed across a much wider range of classed, gendered and racialised positions. Thus many parents worry. At the same time, how they worry and what they worry about may be very different and shaped by a range of social relations and positions, including race, class, gender and religion. What they worry about can also reveal the ways in which class and race are experienced and understood in the everyday. Because, as we have seen, a major issue they worry about is the mix of pupils their children will encounter in school and what implications this will have for their learning, development and socialisation.

This book has sought to explore the accounts of parents going through the process of choosing secondary schools for their children whilst paying particular attention to how these accounts are raced, classed and gendered. We have argued that the moment when a parent is considering secondary schooling is a productive time to consider how they talk about or use discourses that are raced, classed and gendered. This is because of the relational and social nature of schooling which places children in a community and hub of relations which can raise questions about race, ethnic and religious difference, class and gender. Thinking about potential schools not only involves considering the standards of teaching and the subjects and facilities on offer but also frequently includes the assessment of the other children (and their parents) in the schools. The other children in school are critical both as potential friends of your child who are likely to play an important role in both the happiness and sense of belonging of your child but also be a major influence on them. The other children could be friends or bullies, affirming, disruptive or transformative. In 


\section{All in the mix}

Bourdieusian terms, the other children in the school will be an important part (alongside the school itself) of the way in which education endows social and cultural capital. From this education, children will learn ways of being and cultural tastes, and potentially be embedded in social networks which can be critical to social mobility or the maintenance of classed distinctions. We have argued that these processes are raced as much as they are classed and are also shaped by gender.

Through conducting semi-structured interviews with parents in three different areas of Manchester who were in the process of applying to secondary schools, the book has considered the ways in which race and class talk is explicitly or implicitly present in their narratives about school choice. This gives us insight not just to the racialisation and classed nature of school choice and parenting, but also how people narrate their belonging to areas and other sources of community, such as schools. It also opens a window on to some of the ways in which people regard classed and raced others in relation to themselves. The political and ethical nature of school choice is suggested by the book How Not to Be a Hypocrite: School Choice for the Morally Perplexed (Swift 2003) which is explicitly addressed to middle-class readers (also implicitly assumed to be white) who believe in equality of opportunities and the importance of good education for all, but do not want to send their children to the local school because they regard the education offered by those schools as in some ways undesirable (or or because they score low in 'local status hierarchies' Greany and Higham 20I8). There has been considerable sociological research on the question of school choice, particularly focused on the same (white middle-class) group hailed by Swift in How Not to Be a Hypocrite. However, All in the mix examines the experiences of a wider range of social and ethnic or religious groups. Thus we can see the ways in which people from different class and economic positions, from different racialised positions and with different legal status in Britain, respond to questions around school choice. In the book, we have considered the choice-talk of both white and ethnic-minority parents across a range of class positions. There is a risk that only speaking to white middle-class parents gives a sense of exceptionality to their experience. It can create school choice and the strategies and emotions which surround it as a singularly white middle-class experience. However, as we have seen, anxieties around choosing schools and concerns about the classed and racialised make-up of the school body are shared by parents from varied class and racialised positions. 


\section{Conclusions}

Worrying about your child's schooling is something shared, although expressed in different ways and with different targets of anxiety and responses to them, by parents who are both working-class and middle-class. It is also shared by both working-class and middleclass ethnic minorities, although with an additional set of concerns which are shaped by fears of their children experiencing racism from schools that are too white. White working-class parents also worry that, in some schools, their children may not fit in because of class and economic differences.

Thus we have seen how almost all the parents in the study responded to the state injunction to choose their children's schools with a sense of concern and responsibility about making the right choice. As discussed in Chapter 3, for many - but not all - parents, the process of schooling was also gendered and largely mother-led. Mothers often spent more time in and around school and were better able to access informal networks of information. However, it was clear from the interviews with fathers that the experience of stress and anxiety over school choice was also often experienced by men as well as women. Thus worrying about schooling choice is fairly ubiquitous, even whilst it is shaped by differences of class, race and gender. All parents are also making choices in a context of a reduction in the number of secondary schools (presenting therefore less choice in one sense) and a shifting terrain of different kinds of schools, with the introduction of academies and free schools, the continuation of various forms of selective state schooling. Parental choice is powerful in shaping schools: Greany and Higham (2018: 52) found that schools are increasingly competing for students and engage in a range of strategies to appeal to parents and to move up the local status hierarchies. They also found that, in the context of the policy of academisation, these processes also impacted on inequalities in state schooling, with the increased clustering of FSM-eligible children in schools which were marked less well by Ofsted (Greany and Higham 2018: 58). Whilst parental choice, among other processes, has a negative social impact, at the same time it can also be difficult for individuals. The responsibility to choose almost universally produced expressions of anxieties from parents. Those who were least likely to express worries about the process of choosing schools were characterised not by their class, location or ethnic heritage but by having an 'old hand' status, having already navigated the question of high school choice with older children. Having gone through the process with an older 


\section{All in the mix}

child also often provides the security of an assured place through the preference given to siblings by most state schools (with the exception of selective grammar schools).

It is important to remember that school choice is an inherently local affair as choices are shaped by the realistic prospects of getting admission to and managing the logistics of travelling to specific schools. In order to capture the located nature of school choice, the study was conducted in three distinct although relatively nearby areas. This enables us to consider the accounts of parents in the context of the places in which the decisions are made and where the ethnic make-up of both the relevant primary and secondary schools and the wider areas is known. Thus parents' accounts can be understood in the context of the very local dynamics in which they are operating. Drawing on this localised approach, we have shown how choices are shaped by narratives which circulate in different areas about schools and about the politics of schooling which include distinct approaches to the idea of what makes a 'good mix' and what are the risks and opportunities presented by social mixing. This located study also enables us to see the relationship between an area's reputation and local schools - which indicates the ways in which schools can become a marker of an area and vice versa. This was reflected in the ways in which the parents themselves also narrated their own position, particularly in ways which they were classed. So we found that respondents often described themselves as being typical of a particular area. In Chorlton, some liberal middle classes felt that they characterised Chorlton, whilst in Cheadle Hulme, several respondents saw themselves as being a middling kind of person, as Cheadle Hulme was a middling kind of quiet area. Thus our understanding of accounts around school choice are enriched when we know about the places about which people are talking and how they view themselves in relation to those places. This understanding is critical to shaping some of the dynamics of discourses around class and racialised or ethnic difference.

As we have seen, the different areas of the study had distinctive demographic characteristics which varied in terms of class composition, ethnic, religious and national make-up. The sample of parents we interviewed largely reflected that of the schools in terms of their ethnic and class mix (acknowledging, as we did, that FSM are a poor measure of class but the only one available in the context of schools). Looking at the accounts of the parents in the context of the areas 


\section{Conclusions}

where respondents were living revealed that the parents in the different areas also had come to live in the sample areas through different routes and across different temporalities. Cheadle Hulme was the area with the largest proportion of white British residents with more working-class and lower-middle-class respondents. It also had a larger number of parents who reported that they had moved into the area (from relatively local areas) specifically to be nearer more desirable schools. Here we see that it is not exclusively the professional middle classes who exercise choice through moving into areas which have what they regard as better schools. Furthermore, from the accounts of parents from Cheadle Hulme, the class composition of the schools they are anxious to avoid is also critical. In many cases, parents in Cheadle Hulme had been born in or relatively near Cheadle Hulme, had often moved out as young adults and then returned once they had had children. This return was shaped sometimes by a desire to be nearer family, but also to move to 'quiet' Cheadle Hulme and away from areas which they characterised as 'rough'. In narratives of undesirable areas, problem schools were particularly identified by the behaviour of the parents as they dropped their children off and picked them up from school. Concerns around language, behaviour and dress indicated concerns around classed notions of respectability (Skeggs 1997). In the case of parents in Cheadle Hulme, the 'rougher' areas they had lived in were often areas of higher levels of economic deprivation with largely white residents. However, for some, discussing the dangers of rough areas summoned up racialised images of the inner city with gangs and a more diverse ethnic mix. As we shall see, Cheadle Hulme, the whitest area in the study, was also the area where the question of ethnic and racialised difference was viewed with most concern and as a potential source of threat.

In Chorlton, also largely white but with more established middleclass parents, the idea of moving to an area with a view to the schools was much less present than in Cheadle Hulme and there were fewer anxieties expressed about ideas of respectability (although these were also present). Rather, Chorlton was seen as a natural destination for a particular kind of liberal middle-class graduate and as an area defined by lifestyle and consumption opportunities, particularly bars and restaurants. The respondents had often moved to Chorlton as young adults post-university. They then stayed once they had children and thus could fully espouse the idea of going to a local school as they felt confident (enough) that there would be sufficient people 'like us' in 


\section{All in the mix}

the schools whilst, at the same time, embracing some ideas of multicultural and class difference. Their choices had, to a certain extent, already been made before they had had children. Finally the much more ethnically mixed and more economically precarious parents in Whalley Range were less able to produce a coherent narrative of choosing the area as a place to live. It was an area where they had ended up, often as a result of migration and, for some, as part of a flight from other areas of Manchester where they had experienced racism. Nonetheless, they also had a sense of affective belonging to the area, characterising it as a friendly area where they felt safe and which served their religious needs as it had both mosques and Asian, halal food shops.

The ways in which the parents talked about school choice also reflected some of these personal narratives of geographical mobility, as well as their concerns about education and the classed and raced composition of the local schools. What they largely shared was a narrative of school choice being difficult and somewhat unsatisfactory with too few 'real' available choices. What made a choice 'real' depended on a range of factors, including location (in terms of how possible it was to get their children there), affordability (related to private schooling and the tuition costs often entailed by trying to access selective grammar schooling) and the existence of schools which raised too many fears about racial, class and religious difference. Many of the discussions about selective education focused on ethical issues concerning equity. In the context of non-religious private schools, it was only the parents in Cheadle Hulme who considered them seriously. For these parents, the cost of private schooling was prohibitive, but they also had worries about putting their children in environments where they would have a too severe 'fish-out-of-water' experience and where they might face exclusion on the basis of being different and not rich or middle-class enough. Some of the Muslim parents in Whalley Range and Chorlton did have experience of sending their children to Islamic private schools, although those we spoke to had largely sent older children to Islamic schools and were not considering it for their current year 6 child. Some of these parents had a slightly different account of the question of 'fish-out-of-water' where they, on reflection, considered that it was good that their own children would get used to being in a non-Muslim context and also that it was important for mainstream schools to have their children in them because they would then foster an understanding of Islam in other 


\section{Conclusions}

children. Here we saw how some ethnic-minority parents are very conscious of what they bring to the mix, as much as what they get out of it. This tended not to be considered by white parents in the study. In general, as we saw also in Chapter 5, the ethnic-minority parents did suggest that the embracing of multiculturalism was important for all children. However, this came with the proviso that there should be enough difference to ensure that their children would not face the kind of racism that was risked in an overwhelmingly white context.

The framing given to accounts by the parents' own experiences of schooling was perhaps most evident in the discussions around grammar schooling. As we discussed in Chapter 3, state selective education, in the form of grammar schooling, was available because of the presence of grammar schooling in neighbouring boroughs. For those parents who had experienced the Eleven-plus in their own childhoods and had either passed or failed this critical test, their success or failure and the subsequent effect it had on their schooling was a strong part of their narratives. This was also a topic on which overtly political or ethical questions were most often raised, where some suggested that education with a whole community, rather than a selected educationally elite section, was part of a rich educational experience. Some parents however had wanted their children to apply for grammar schools and paid for at least a year of tutoring, whilst others had done this with their older children (although not the current year 6 child). None of the children in the sample had been successful in getting into grammar school, however, so the responses were dominated by accounts of children's disappointment (the levels of which the parents sometimes said they were surprised by) and also knocks on their children's levels of confidence. These accounts demonstrate some of the risks of selective education for those who are not successful in getting into grammar schools. Chapter 4 considered directly the nature of some of the emotions around schooling which are related to the social and relational nature of education. In the interviews with parents, they were more likely to talk about their children's happiness and security than about straightforward academic achievement. These are things that schools also sought to reassure parents about in ordered open evenings, with school slogans stressing concern for the children's happiness and the presentation of strict uniform rules. It was in this nexus between happiness and security that we argued that choosing schools for their children often produced in parents fearful emotions that were centred on ideas of the 'wrong' kind of children 


\section{All in the mix}

in a way which was racialised and classed. In the context of worrying about children's comfort and the security of a new school environment, class was particularly present in parents' accounts, even if it was rarely directly mentioned. The wrong kind of children (coming from the wrong kind of families) were indicated in references to being exposed to 'crazy children' or those with an 'aggressive lifestyle' or 'aggressive personality', or perhaps who were involved in gangs. As mentioned above, parents often observed schools at the end of the day and were put off particularly if they saw unruly behaviour by parents, or if the appearance of the children was particularly classed and gendered in ways which signalled notions of a repudiated working class. This again circulated around parents' notions of respectability and the risks of their children being influenced by those who appeared to have no regard for respectability or who were seen as an underclass. We argued that this was one explanation for the focus on school uniforms as a marker for a good school. This was in contrast to some primary school contexts where a policy of no uniform was taken as a positive sign of a liberal approach suggesting a more expressive educational culture (Bernstein I97I).

Whilst this book has tracked how parents share anxieties around the process of choosing secondary schools for their children, this is not to say that they do not want to have a say in where their children go to school. What parents generally want is more choice - a sense that the schools their children attend will not be determined largely by where they live. Parents often felt that this limited them to one - or perhaps two - schools. However, as we have seen, this limited choice was often a result of some potential local schools already having been ruled out of consideration. This process of elimination was often directed by the social and ethnic mix of the schools in question. Here we have an inherent tension in a state education policy focused on parental choice which, through processes of parental selection, produce and reproduce inequalities and elements of social and ethnic segregation. As we have seen, where class (or more specifically questions of working class or underclass) appeared in the accounts, either directly mentioned or implicitly referred to, it was generally seen in a negative light, in ways that were largely shared across the different areas. The repudiated working class were not considered to have anything positive to add to the mix and were almost always characterised in negative terms as a risk to children's education. However, as we saw in Chapter 5, ideas of cultural and 


\section{Conclusions}

racial difference could be framed more positively through drawing on ideas of multiculturalism as a positive learning environment for children. Here difference was often narrated as a positive, convivial, experience for children which would equip them to live in a more diverse world. However, discourses around cultural, ethnic and racial differences were discernibly different in the different areas, reflecting the ethnic composition of those different places. Parents in Whalley Range and Chorlton were generally positive about the higher levels of ethnic mix in both the area and the primary schools which children were attending. These parents therefore also embraced notions of ethnic mix in high schools - with some differences between them. A small number of parents in Chorlton had in fact avoided the primary schools in Whalley Range and other neighbouring areas for their children as they were considered not mixed enough, with a majority of ethnic-minority pupils. These considerations may also have led parents to avoid some high schools in the area - such as, for example, the girls-only high school which had larger numbers of Muslim pupils, which was more popular among the Whalley Range than the Chorlton parents.

In the whiter Cheadle Hulme in contrast to Whalley Range and Chorlton, although many said they appreciated diversity, some also expressed fearfulness about the risks of 'too much' difference, particularly when it came to religious difference and the presence of Muslim children in schools. This was despite the fact that white children were in a much larger majority than in the Chorlton primary and high schools. Some parents in Cheadle Hulme rehearsed popular narratives of the kind of 'political correctness gone mad' variety where too much attention was given by schools to racist incidents and respect for other (particularly Muslim) religious sensibilities although this was denied by the schools (for example, the claim that nativity plays were no longer put on). Thus, in-depth interviews in three different locations revealed that, although all parents expressed some positivity around ideas of multicultural mix, there were significant differences in the feelings behind these broad generalisations. Whilst none expressed strong anti-immigrant or racist attitudes and all were able to agree that the fact of their children having been exposed to difference was a positive element of schooling, for some parents in Cheadle Hulme it was possible to feel an awkwardness and discomfort in using the language of racialised and ethnic difference. There was also a possibility that too much difference (or not enough 


\section{All in the mix}

white Christian influence) could be seen as a threat to their children and their education.

We also saw that, in all areas, a different kind of threat was considered by ethnic-minority and migrant parents in the study. Many ethnic-minority parents also considered the impact on their children in contexts which were too white as they feared that their children might experience racism. For these parents, sufficient ethnic and religious mix was regarded as a vital protection against racism, discrimination and the impact of being the 'only black child' or the 'only Muslim child' in the class. Thus, for ethnic-minority parents, a good mix suggested the possibility of avoiding these situations, and some also expressed concerns that their children's education should include positive attitudes about and role models for their children. In this way, this chapter in particular demonstrates the importance of interviewing parents in a known local context. Here we have parents using subtly different discourses around mix and multiculture which are better understood when analysed in their specific context. What this reveals more generally is that we have a very undifferentiated language for talking about ethnic and religious diversity. Thus, almost all the parents said that they were living in a fairly mixed area and their children were going to schools which had high levels of cultural diversity, despite the fact that the ethnic mix in their areas and schools varied widely. Schools where the large majority of children come from ethnic minorities are described with the very same language as schools where ethnic minorities form a small majority or where white British are in the large majority. This raises important questions at both research and policy levels for how we approach questions of multiculturalism and social mix. It points to the importance of establishing that we know exactly what is being referred to in discussions of mix, multiculturalism or diversity. It is clear that, when the focus is all on the 'mix', one person's diversity may, literally, look like another's monoculture. 


\section{Appendix: Participants}

Respondents from Chorlton

\begin{tabular}{|c|c|c|c|c|c|}
\hline & $\begin{array}{l}\text { Country } \\
\text { of birth }\end{array}$ & $\begin{array}{l}\text { Ethnic } \\
\text { origin }\end{array}$ & Age & $\begin{array}{l}\text { Married } \\
\text { status }\end{array}$ & $\begin{array}{l}\text { Employment and } \\
\text { highest level of } \\
\text { education }\end{array}$ \\
\hline Ann and Cliff & Britain & White & $\begin{array}{l}\text { Ann: } 48 \\
\text { Cliff: } 50\end{array}$ & Married & $\begin{array}{l}\text { Ann: Accountant } \\
\text { (University BA) } \\
\text { Cliff: NHS manager } \\
\text { (University BA) }\end{array}$ \\
\hline Cindy & Britain & White & 45 & Married & $\begin{array}{l}\text { Social work } \\
\text { manager } \\
\text { (University BA) }\end{array}$ \\
\hline Fiona & Britain & White & 43 & Married & $\begin{array}{l}\text { Freelance project } \\
\text { manager } \\
\text { (University) }\end{array}$ \\
\hline Halima & Britain & $\begin{array}{l}\text { South } \\
\text { Asian / } \\
\text { Pakistani }\end{array}$ & 40 & Married & $\begin{array}{l}\text { Homemaker } \\
\text { (A levels) }\end{array}$ \\
\hline Harrison & Britain & White & 43 & Married & $\begin{array}{l}\text { Homemaker } \\
\text { (formerly university } \\
\text { lecturer and in } \\
\text { advertising) } \\
\text { (University BA) }\end{array}$ \\
\hline Jas and Tej & Britain & South Asian & $\begin{array}{l}\text { Jas: } 42 \\
\text { Tej: } 4 \mathrm{I}\end{array}$ & Divorced & $\begin{array}{l}\text { Managers } \\
\text { (University BA) }\end{array}$ \\
\hline Jasmine & Britain & South Asian & 39 & Divorced & $\begin{array}{l}\text { Family support and } \\
\text { outreach worker } \\
\text { (A levels) }\end{array}$ \\
\hline Kelly & Britain & White & 40 & Married & $\begin{array}{l}\text { Primary school } \\
\text { teacher } \\
\text { (University BA) }\end{array}$ \\
\hline Ken and Fran & Britain & White & Both 43 & Married & $\begin{array}{l}\text { Ken: courier; } \\
\text { College } \\
\text { Fran: midwife; } \\
\text { (University BA) }\end{array}$ \\
\hline
\end{tabular}




\section{Appendix: Participants}

\begin{tabular}{|c|c|c|c|c|c|}
\hline & $\begin{array}{l}\text { Country } \\
\text { of birth }\end{array}$ & $\begin{array}{l}\text { Ethnic } \\
\text { origin }\end{array}$ & Age & $\begin{array}{l}\text { Married } \\
\text { status }\end{array}$ & $\begin{array}{l}\text { Employment and } \\
\text { highest level of } \\
\text { education }\end{array}$ \\
\hline Michael & Britain & White & 53 & Married & $\begin{array}{l}\text { Commercial } \\
\text { Manager } \\
\text { (University BA) }\end{array}$ \\
\hline Molly & Britain & White & 44 & Married & $\begin{array}{l}\text { Research technician } \\
\text { (FE college) }\end{array}$ \\
\hline Rebecca & Britain & White & 42 & Married & $\begin{array}{l}\text { Local government } \\
\text { officer (A level) }\end{array}$ \\
\hline Sabah & Britain & South Asian & 34 & Married & $\begin{array}{l}\text { Primary school } \\
\text { nursery play worker } \\
\text { (FE college) }\end{array}$ \\
\hline Samer & Iraq & $\begin{array}{l}\text { Middle } \\
\text { Eastern }\end{array}$ & 45 & Married & $\begin{array}{l}\text { Chemical engineer } \\
\text { (PhD) }\end{array}$ \\
\hline Sara & Britain & White & 45 & Married & $\begin{array}{l}\text { Student (formerly } \\
\text { social worker) } \\
\text { (University BA) }\end{array}$ \\
\hline Terri & Britain & White & 38 & Married & $\begin{array}{l}\text { Health visitor } \\
\text { (University BA) }\end{array}$ \\
\hline
\end{tabular}

\section{Respondents from Cheadle Hulme}

\begin{tabular}{|c|c|c|c|c|c|}
\hline & $\begin{array}{l}\text { Country } \\
\text { of birth }\end{array}$ & $\begin{array}{l}\text { Ethnic } \\
\text { origin }\end{array}$ & Age & $\begin{array}{l}\text { Married } \\
\text { status }\end{array}$ & $\begin{array}{l}\text { Employment and } \\
\text { highest level of } \\
\text { education }\end{array}$ \\
\hline Alia & Britain & South Asian & $4 \mathrm{I}$ & Married & $\begin{array}{l}\text { Homemaker } \\
\text { (FE college) }\end{array}$ \\
\hline Annabel & Britain & White & 43 & Married & $\begin{array}{l}\text { Business woman } \\
\text { (FE college) }\end{array}$ \\
\hline Annette & Britain & White & 45 & Married & $\begin{array}{l}\text { Pre-school teacher } \\
\text { (A levels) }\end{array}$ \\
\hline Bea and Mark & Britain & White & $\begin{array}{l}\text { Bea: } 45 \\
\text { Mark: } \\
47\end{array}$ & Married & $\begin{array}{l}\text { Bea: hairdresser } \\
\text { Mark: driver } \\
\text { (Qualifications not } \\
\text { given) }\end{array}$ \\
\hline Emily & Britain & White & 37 & Married & $\begin{array}{l}\text { Local council worker } \\
\text { (A level) }\end{array}$ \\
\hline Emma & Britain & White & 43 & Divorced & $\begin{array}{l}\text { Secondary school } \\
\text { teacher } \\
\text { (University BA) }\end{array}$ \\
\hline Jen & Britain & White & 46 & Married & $\begin{array}{l}\text { Shopworker } \\
\text { (Qualifications not } \\
\text { given) }\end{array}$ \\
\hline
\end{tabular}


Appendix: Participants

\begin{tabular}{|c|c|c|c|c|c|}
\hline & $\begin{array}{l}\text { Country } \\
\text { of birth }\end{array}$ & $\begin{array}{l}\text { Ethnic } \\
\text { origin }\end{array}$ & Age & $\begin{array}{l}\text { Married } \\
\text { status }\end{array}$ & $\begin{array}{l}\text { Employment and } \\
\text { highest level of } \\
\text { education }\end{array}$ \\
\hline Jessica & Britain & White & 40 & Married & $\begin{array}{l}\text { Childminder } \\
\text { (O levels) }\end{array}$ \\
\hline $\begin{array}{l}\text { Melanie and } \\
\text { Steve }\end{array}$ & Britain & White & $\begin{array}{l}\text { Melanie: } \\
29 \\
\text { Steve: } \\
30\end{array}$ & Married & $\begin{array}{l}\text { Melanie: beauty } \\
\text { therapist } \\
\text { (GCSEs) } \\
\text { Steve: delivery } \\
\text { driver } \\
\text { (GCSEs) }\end{array}$ \\
\hline Meredith & Britain & White & 33 & Married & $\begin{array}{l}\text { Homemaker } \\
\text { (GCSEs) }\end{array}$ \\
\hline Natalie & Britain & White & 37 & Married & $\begin{array}{l}\text { Office worker } \\
\text { (A levels) }\end{array}$ \\
\hline Rachel & Britain & White & 27 & Single & $\begin{array}{l}\text { Student Nurse } \\
\text { (A levels) }\end{array}$ \\
\hline Runa & Britain & South Asian & 38 & Divorced & $\begin{array}{l}\text { Unemployed } \\
\text { (previously worked } \\
\text { in admin) } \\
\text { (University BA) }\end{array}$ \\
\hline Saira & Pakistan & South Asian & 39 & Married & $\begin{array}{l}\text { Works at the } \\
\text { airport } \\
\text { (High school) }\end{array}$ \\
\hline Samantha & Britain & White & 44 & Married & $\begin{array}{l}\text { Nurse } \\
\text { (University BA) }\end{array}$ \\
\hline Sharon & Britain & White & 39 & Widow & $\begin{array}{l}\text { Civil servant } \\
\text { (FE college) }\end{array}$ \\
\hline Stan & China & Asian & 46 & Married & $\begin{array}{l}\text { Waiter } \\
\text { (High school) }\end{array}$ \\
\hline
\end{tabular}

\section{Respondents from Whalley Range}

\begin{tabular}{|c|c|c|c|c|c|}
\hline & $\begin{array}{l}\text { Country } \\
\text { of birth }\end{array}$ & $\begin{array}{l}\text { Ethnic } \\
\text { origin }\end{array}$ & Age & $\begin{array}{l}\text { Married } \\
\text { status }\end{array}$ & $\begin{array}{l}\text { Employment and } \\
\text { highest level of } \\
\text { education }\end{array}$ \\
\hline Fauzia & Bangladesh & South Asian & 39 & $\begin{array}{l}\text { Married } \\
\text { (husband } \\
\text { often } \\
\text { abroad) }\end{array}$ & $\begin{array}{l}\text { Homemaker } \\
\text { (High school) }\end{array}$ \\
\hline Helen & Britain & $\begin{array}{l}\text { African } \\
\text { Caribbean }\end{array}$ & 36 & Married & $\begin{array}{l}\text { Teaching assistant } \\
\text { (A levels) }\end{array}$ \\
\hline Leyla & Somali & African & 34 & Married & $\begin{array}{l}\text { Homemaker } \\
\text { (High school) }\end{array}$ \\
\hline
\end{tabular}




\section{Appendix: Participants}

\begin{tabular}{|c|c|c|c|c|c|}
\hline & $\begin{array}{l}\text { Country } \\
\text { of birth }\end{array}$ & $\begin{array}{l}\text { Ethnic } \\
\text { origin }\end{array}$ & Age & $\begin{array}{l}\text { Married } \\
\text { status }\end{array}$ & $\begin{array}{l}\text { Employment and } \\
\text { highest level of } \\
\text { education }\end{array}$ \\
\hline $\begin{array}{l}\text { Marion } \\
\text { (grandmother } \\
\text { and guardian) }\end{array}$ & Britain & White & 54 & Married & $\begin{array}{l}\text { Domestic worker } \\
\text { (O levels) }\end{array}$ \\
\hline Nasreen & Britain & South Asian & 33 & Married & $\begin{array}{l}\text { Translator } \\
\text { (FE college) }\end{array}$ \\
\hline Nighat & Tanzania & South Asian & 42 & Married & $\begin{array}{l}\text { Homemaker } \\
\text { (High School) }\end{array}$ \\
\hline Noreen & Pakistan & South Asian & $4 \mathrm{I}$ & $\begin{array}{l}\text { Married } \\
\text { (husband } \\
\text { abroad) }\end{array}$ & $\begin{array}{l}\text { Homemaker } \\
\text { (formerly teacher in } \\
\text { Pakistan) } \\
\text { (High school) }\end{array}$ \\
\hline Nusrat & Pakistan & South Asian & 50 & Separated & $\begin{array}{l}\text { Homemaker } \\
\text { (High school) }\end{array}$ \\
\hline Pam & Britain & $\begin{array}{l}\text { African } \\
\text { Caribbean }\end{array}$ & 40 & Separated & $\begin{array}{l}\text { Midwife } \\
\text { (University BA) }\end{array}$ \\
\hline Sadia & Libya & $\begin{array}{l}\text { Middle } \\
\text { Eastern }\end{array}$ & 42 & Divorced & $\begin{array}{l}\text { Teacher in a } \\
\text { mosque } \\
\text { (High school) }\end{array}$ \\
\hline Serena & Britain & $\begin{array}{l}\text { African } \\
\text { Caribbean }\end{array}$ & 46 & Married & $\begin{array}{l}\text { Nurse } \\
\text { (University BA) }\end{array}$ \\
\hline Shahida & Pakistan & South Asian & 37 & $\begin{array}{l}\text { Married } \\
\text { (husband } \\
\text { abroad) }\end{array}$ & $\begin{array}{l}\text { Homemaker } \\
\text { (High school) }\end{array}$ \\
\hline Simal & Turkey & Turkish & 44 & Married & $\begin{array}{l}\text { Homemaker } \\
\text { (High school) }\end{array}$ \\
\hline Winnie & Ghana & $\begin{array}{l}\text { Black } \\
\text { African }\end{array}$ & 46 & Married & $\begin{array}{l}\text { Fashion designer } \\
\text { (University BA) }\end{array}$ \\
\hline
\end{tabular}




\section{References}

Adams, M. (2006). "Hybridizing habitus and reflexivity: towards an understanding of the contemporary identity." Sociology 4O(3): 5II-28.

Ahmed, S. (2002). Racialized bodies. In Real Bodies. A Sociological Introduction, ed. M. Evans and E. Lee. Basingstoke, Palgrave: 46-63.

Ahmed, S. (2004a). “Affective economies.” Social Text 2(22): II7-39.

Ahmed, S. (2004b). "Declarations of whiteness: the non-performativity of anti-racism." Borderlands ejournal 3(2): I-59.

Ahmed, S. (2006). Queer Phenomenology: Orientations, Objects, Others. Durham and London, Duke University Press.

Ahmed, S. (2010). The Promise of Happiness. Durham and London, Duke University Press.

Alexander, C. (2007). Introduction. In School Choice and Ethnic Segregation. Educational Decision-making among Black and Minority Ethnic Parents, ed. D. Weekes-Bernard. London, Runnymede Trust: i-iii.

Allen, R., S. Burgess and L. McKenna (20I4). School performance and parental choice of school: secondary data analysis. In Department for Education Report. London: Department for Education: I-77.

Anderson, B. (2005). "Practices of judgment and domestic geographies of affect." Social \& Cultural Geography 5(6): 645-59.

Archer, L. (2003). Race, Masculinity and Schooling. Muslim Boys and Education. Maidenhead, Open University Press.

Archer, L. (20I0). "We raised it with the Head': the educational practices of minority ethnic, middle-class families." British Journal of Sociology of Education 3I(4): 449-69.

Archer, L. (2OII). "Constructing minority ethnic middle-class identity: an exploratory study with parents, pupils and young professionals." Sociology 45(I34): I34-5I.

Archer, L. and B. Francis (2007). Understanding Minority Ethnic Achievement. Race, Gender, Class and 'Success'. London and New York, Routledge.

Ball, S. (2008). "Some sociologies of education: a history of problems and places, and segments and gazes." The Sociological Review 56(4): 650-70. 


\section{References}

Ball, S., R. Bowe and S. Gewirtz (I995). "Circuits of schooling: a sociological exploration of parental choice in social class contexts." The Sociological Review 43(I): 52-78.

Ball, S. J. (2003). Class Strategies and the Education Market. The Middle Classes and Social Advantage. London and New York, Routledge.

Ball, S. J., D. Reay and M. David (2002). “'Ethnic Choosing': Minority ethnic students and higher education choice." Race, Ethnicity and Education 5(4): $333-57$.

Ball, S. J., N. Rollock, C. Vincent and D. Gilbourn (20II). "Social mix, schooling and intersectionality: identity and risk for Black middle class families.” Research Papers in Education XX: I-25.

Ball, S. J. and C. Vincent (2007). "Education, class fractions and the local rules of spacial relations." Urban Studies 44(7): II75-89.

Barker, B. (2010). The Pendulum Swings: Transforming School Reform. Stoke on Trent, Trentham Books.

Bécares, L., Nazroo, J., Jackson, J. and Heuvelman, H. (2012). “Ethnic density effects on health and experienced racism among Caribbean people in the US and England: a cross-national comparison." Social Scienca and Medicine 75(12): 2107-I5.

Benson, M. (20I4). "Trajectories of middle-class belonging: the dynamic of place attachment and classed identities." Urban Studies 5I(I4): 3097-II2.

Bernstein, B. (I97I). Class, Codes and Control. Volume 1: Theoretical Studies Towards a Sociology of Language. London and Boston, Routledge and Kegan Paul.

Boliver, V. and A. Swift (20IIa). "Comprehensive schools and social mobility." Renewal i9(2): 32-6.

Boliver, V. and A. Swift (20Irb). "Do comprehensive schools reduce social mobility." British Journal of Sociology 62(I): 89-IIo.

Bolton, P. (2012). Education: Historical statistics. Social and General Statistics. London, House of Commons: 20.

Bonnett, A. (2000). Anti-racism. London, Routledge.

Bottero, W. (2004). "Class identities and the identity of class." Sociology 38(5): 985-1003.

Bottero, W. (2005). Stratification: Social Division and Inequality. London, Routledge.

Bottero, W. (2009). Class in the 2Ist Century. In Who Cares about the White Working Class?, ed. K. P. Sveinsson. London, Runnymede: 7-I5.

Bourdieu, P. (I99I). Social space and the genesis of 'class'. In Language and Symbolic Power, ed. J. B. Thompson. Cambridge, Polity Press: 229-5I.

Bourdieu, P. (I994). Distinction. London, Routledge.

Bruegel, I. (2016). Social Capital, Diversity and Education Policy. London, London South Bank University. 


\section{References}

Burgess, S. and A. Briggs (2006). School assignment, school choice and social mobility. CMPO Working Paper Series 6. Bristol, University of Bristol.

Burgess, S., A. Briggs, B. McConnell and H. Slater (2006). School Choice in England: Background Facts. Bristol, Centre for Market and Public Organisation.

Burgess, S. and E. Greaves (2013). "Test scores, subjective assessment, and stereotyping of ethnic minorities." Journal of Labor Economics 3I(3): 535-76.

Burgess, S., E. Greaves, A. Vignoles and D. Wilson (20I5). "What parents want: school preferences and school choice." The Economic Journal I25(September): I262-89.

Burgess, S., C. Propper and D. Wilson (2007). The impact of school choice on sorting by ability and socio-economic factors in English secondary education. In Schools and the Equal Opportunity Problem, ed. L. Woessmann and P. E. Peterson, MIT Press: 273-92.

Burgess, S., D. Wilson and R. Lupton (2005). "Parallel lives? Ethnic segregation in schools and neighbourhoods." Urban Studies 42(7): 1027-56.

Butler, T. (I997). Gentrification and the Middle Classes. Aldershot, Ashgate.

Butler, T. and C. Hamnett (2OII). Ethnicity, Class and Aspiration. Understanding London's New East End. Bristol, The Policy Press.

Byrne, B. (2003). "Reciting the self: narrative representations of the self in qualitative interviews." Feminist Theory 4(I): 29-49.

Byrne, B. (2006a). "In search of a 'good mix'. 'Race', class, gender and practices of mothering." Sociology 40(6): IOOI-I7.

Byrne, B. (2006b). White Lives. The Interplay of 'Race', Class and Gender in Everyday Life. London and New York, Routledge.

Byrne, B. (2007). "England - whose England? Narratives of nostalgia, emptiness and evasion in imaginations of national identity." Sociological Review 55(3): 509-30.

Byrne, B. (2009). “Not just class': towards an understanding of the whiteness of middle-class schooling choice." Ethnic and Racial Studies 32(3): 424-4I.

Byrne, B. (20II). "Post-race? Nation, inheritance and the contradictory performativity of race in Barack Obama's 'A More Perfect Union' speech.” Thirdspace: A Journal of Feminist Theory and Culture IO(I): I-I6.

Byrne, B. (20I4a). Making Citizens: Public Rituals and Personal Journeys to Citizenship. Basingstoke, Palgrave Macmillan.

Byrne, B. (20I4b). Rhetoric and multiculturalism - David Cameron's 'King James' speech and the crisis of multiculturalism. In Rhetoric, Politics and Society, ed.J. Atkins, A. Finlayson, J. Martin and N. Turnbull. Basingstoke, Palgrave Macmillan: II9-32.

Byrne, B. (2OI5). "Rethinking intersectionality and whiteness at the borders of citizenship." Sociological Research Online 20(3): I-I2.

Byrne, B. and C. De Tona (20I2). “'Trying to find the extra choices': Migrant 


\section{References}

parents and secondary school choice in Greater Manchester." British Journal of Sociology of Education 33(I): 2I-39.

Cahill, K. and K. Hall (20I4). "Choosing schools: explorations in post-primary school choice in an urban Irish working class community." Irish Educational Studies 33(4): 383-97.

Cantle, T. (200I). The Cantle Report - Community Cohesion. A Report of the Independant Review Team. London, Home Office.

Courtney, S. J. (2015). "Mapping school types in England." Oxford Review of Education 4I(6): 799-8I8.

Croft, J. (2004). "Positive choice, no choice or total rejection: the perennial problem of school catchments, housing and neighbourhoods." Housing Studies I9(6): 927-45.

Crossley, N. (20I5). "Relational sociology and culture." International Review of Sociology 25(I): 65-85.

Cucchiara, M. B. and E. M. Horvat (20I4). "Choosing selves: the salience of parental identity in the school choice process." Journal of Education Policy 29(4): 486-509.

David, M. (I997). "Diversity, choice and gender." Oxford Review of Education 23(I): $77-87$.

De Certeau, M. (I984). The Practice of Everyday Life. Berkeley, University of California Press.

Devine, F. (2004). Class Practices. How Parents Help Their Children Get Good Jobs. Cambridge, Cambridge University Press.

Donald, J. and A. Rattansi, eds (I992). 'Race', Culture and Difference. London, Sage.

Exley, S. (20I2). "Making working-class parents think more like middle-class parents: choice advisers in English education." Journal of Education Policy 28(I): 77-94.

Fortier, A.-M. (2008). Multicultural Horizons: Diversity and the Limits of the Civil Nation. London, Routledge.

Fortier, A.-M. (2010). "Proximity by design? Affective citizenship and the management of unease." Citizenship Studies I4(I): I7-30.

Francis, B. and L. Archer (2005). "British-Chinese pupils' and parents' constructions of the value of education." British Educational Research Journal 3I(I): 89-IO8.

Francis, B., M. Mills and R. Lupton (20I7). "Towards social justice in education: contradictions and dilemmas." Journal of Education Policy 32(4): I-I8.

Gillborn, D. (2006). "Rethinking white supremacy. Who counts in 'WhiteWorld'." Ethnicities 6(3): 318-40.

Gillborn, D. (2009). Education: the numbers game and the construction of white racial victimhood. In Who Cares about the White Working Class, ed.

K. P. Sveinsson. London, Runnymede: $15-22$.

Gillborn, D., N. Rollock, C. Vincent and S. J. Ball (20I2). “You got a pass, 


\section{References}

so what more do you want?': Race, class and gender intersections in the educational experiences of the Black middle class." Race, Ethnicity and Education I5(I): I2I-39.

Gilroy, P. (2004). After Empire. Melancholia or Convivial Culture? Abingdon, Routledge.

Glick Schiller, N. and N. Salazar, B. (20I2). "Regimes of mobility across the globe." Journal of Ethnic and Migration Studies 39(2): I83-200.

Gorard, S. (2012). "Who is eligible for free school meals? Characterising free school meals as a measure of disadvantage in England." British Educational Research Journal 38(6): 1003-I7.

Gorard, S. (20I4). "The politics of the Academies Programme: natality and pluralism in education policy-making " Research Papers in Education 29(3): 268-84.

Greany, T. and R. Higham (2018) Hierarchy, Markets and Networks. Analysing the 'Self-improving School-led System' Agenda in England and the Implications for Schools. London, UCL Institute of Education Press.

Grillo, R. (2007). "An excess of alterity? Debating difference in a multicultural society." Ethnic and Racial Studies 30(6): 979-98.

Gunter, H. M., ed. (2012). The State and Education Policy: The Academies Programme. London, Bloomsbury.

Gunter, H. M. and R. McGinty (20I4). "The politics of the Academies Programme: natality and pluralism in education policy-making." Research Papers in Education 29(3): 300-I4.

Hage, G. (1998). White Nation. Fantasies of White Supremacy in a Multicultural Society. Melbourne and London, Pluto Press.

Hall, S. (2000). Conclusion: the multi-cultural question. In Un/settled Multiculturalisms: Diasoporas, Entanglements, 'Transruptions', ed. B. Hesse. London, Zed: 209-20.

Hancock, B. H. (2005). “Steppin' out of whiteness.” Ethnography 6(4): 427-6I. Harries, B. (20I4). "We need to talk about race." Sociology 48(6): IIO7-22.

Harries, B. (20I7). Talking Race in Young Adulthood: Race and Everyday LifeiIn Contemporary Britain. London, Routledge.

Harvey, D. (2008). “The right to the city." New Left Review 53(SeptemberOctober): $23-40$.

Hesse, B. (2000). Introduction. In Un/settled Multiculturalisms: Diasoporas, Entanglements, 'Transruptions', ed. B. Hesse. London, Zed.

Hewitt, R. (I986). White Talk Black Talk: Inter-racial Friendship and Communication amongst Adolescents. Cambridge, Cambridge University Press.

Isin, E. F. (2004). “The neurotic citizen." Citizenship Studies 8(3): 2I7-35.

Jackson, C. and M. Bisset (2005). "Gender and school choice: factors influencing parents when choosing single-sex or co-educational independent schools for their children." Cambridge Journal of Education 35(2): I95-2II. 


\section{References}

Johnston, R., D. Wilson and S. Burgess (2004). "School segregation in multiethnic England." Ethnicities 4(2): 237-65.

Jones, S. (I996). In the Blood. God, Genes and Destiny. London, Harper Collins.

Kerr, K., A. Dyson and C. Raffo (20I4). Education, Disadvantage and Place: Making the Local Matter. Chicago, University of Chicago Press.

Kirby, P. and Cullinane, C. (20I6) Class Differences: Ethnicity and Disadvantage. Research Brief I4. London, Sutton Trust.

Knowles, C. (2003). Race and Social Analysis. London, Sage.

Lareau, A. (2002). "Invisible inequality in Black families and white families." American Sociological Review 67(5): 747-76.

Lareau, A. (2003). Unequal Childhoods: Race, Class and Family Life. Berkeley, University of California Press.

Lareau, A. and E. McNamara Horvat (I999). "Moments of social inclusion and exclusion race, class, and cultural capital in family-school relationships." Sociology of Education 72(I): 37-53.

Lefebvre, H. (I99I). The Production of Space. Oxford, Blackwell.

Lentin, A. and G. Titley (20II). The Crises of Multiculturalism: Racism in a Neoliberal Age. London, Zed Books.

Long, R. (2015). Academies under the Labour government. In Library Note, Social Policy Section. London, House of Commons: I-5.

Lovell, T. (2000). Thinking feminism with and against Bourdieu. In Reading Bourdieu on Society and Culture, ed. B. Fowler. Oxford, Blackwell Publishers: $15-25$.

Lupton, R. (2OII). “No change there then!' (?): The onward march of school markets and competition." Journal of Educational Administration and History 43(4): 309-23.

Lupton, R. and S. Thomson (20I5). "Socio-economic inequalities in English schooling under the coalition government 2010-2015." London Review of Education I3(2): 4-20.

Mac an Ghaill, M. (I996). “'What about the boys?': schooling, class and crisis masculinity.” The Sociological Review 44(3): 38I-97.

Massey, D. (I994). Space, Place, Gender. Cambridge, Polity Press.

May, S. (2002). Multiculturalism. In A Companion to Racial and Ethnic Studies, ed. D. T. Goldberg and J. Solomos. Oxford, Blackwell: 124-44.

May, V. (2016). "What does the duration of belonging tell us about the temporal self." Time and Society 25(3): 634-5I.

McGhee, D. (2005). Intolerant Britain? Hate, Citizenship and Difference. Maidenhead, Open University Press.

Nayak, A. (20I0). "Race, affect, and emotion: young people, racism, and graffiti in the postcolonial English suburbs." Environment and Planning A 43(10): 2370-92.

Neely, B. and M. Samura (20II). "Social geographies of race: connecting race and space." Ethnic and Racial Studies 34(II): 1933-52. 


\section{References}

Paton, K., V. McCall and G. Mooney (20I6). "Place revisited: class, stigma and urban restructuring in the case of Glasgow's Commonwealth Games." Sociological Review Online 65(4): 578-94.

Perrier, M. (2012). "Middle-class mothers' moralities and 'concerted cultivation': class others, ambivalence and excess.” Sociology 47(4): 655-70.

Phillips, A. (2007). Multiculturalism without Culture. Princeton, Princeton University Press.

Phillips, D., L. Simpson and S. Ahmed (2008). Shifting geographies of minority ethnic settlement: remaking communities in Oldham and Rochdale. In Community Cohesion in Crisis: New Dimensions of Diversity and Difference, ed. J. Flint and D. Robinson. Bristol, The Policy Press: 8I-97.

Pickett, K. and L. Vanderbloemen (2015). Mind the Gap. Tackling Social and Educational Inequality, A Report for the Cambridge Primary Review Trust, CPRT Research Survey 4 (new series): I-33.

Power, S. (2004). "Comments on "How not to be a hypocrite: School choice for the morally perplexed'." Theory and Research in Education 2(I): 23-9.

Power, S., T. Edwards, G. Whitty and G. Wigfall (2003). Education and the Middle Class. Buckingham and Philadelphia, Open University Press.

Puwar, N. (2004). Space Invaders: Race, Gender and Bodies out of Place. London, Bloomsbury.

Rattansi, A. (1992). Changing the subject? Racism, culture and education. In 'Race', Culture and Difference, ed. J. Donald and A. Rattansi. London, Sage Publications: II-48.

Raveaud, M. and A. van Zanten (2007). "Choosing the local school: middle class parents' values and social and ethnic mix in London and Paris." Journal of Educational Policy 22(I): 107-24.

Rayner, S. M. (20I7). "Admissions policies and risks to equity and educational inclusion in the context of school reform in England." Management in Education 3I(I): 27-32.

Reay, D. (I998). "Classifying feminist research: exploring the psychological impact of social class on mothers' invovlement in children's schooling." Feminsim and Psychology 8(2): I55-7I.

Reay, D. (I999). "Linguistic capital and home-school relationships: mothers' interactions with their children's primary school teachers.” Acta Sociologica 42(2): $159-68$.

Reay, D. (2004). “It's all becoming a habitus': beyond the habitual use of habitus in educational research." British Journal of Educational Research 25(4): 43I-44.

Reay, D. (2007). “'A darker shade of pale?’. Whiteness, the middle classes and multi-ethnic inner city schooling.” Sociology 4I(6): IO4I-60.

Reay, D. (2008). Class out of place: the white middle classes and intersectionalities of class and 'race' in urban state schooling in England. In The Way 


\section{References}

Class Works: Readings on School, Family and the Economy, ed. L. Weis. New York, Routledge: 87-99.

Reay, D. (20I7). Miseducation: Inequality, Education and the Working Classes. Bristol, Policy Press.

Reay, D. and S. Ball (I997). “'Spoilt for Choice': the working classes and educational markets." Oxford Review of Education 23(I): 89-IOI.

Reay, D. and S. J. Ball (I998). “'Making their minds up': family dynamics of school choice.” British Educational Research Journal 24(4): 43I-48.

Reay, D., G. Crozier and D. James (20II). White Middle-class Identities and Urban Schooling. Basingstoke, Palgrave Macmillan.

Reay, D. and H. Lucey (2003). “The limits of 'choice': children and inner city schooling." Sociology 37(I): I2I-42.

Rollock, N., D. Gillborn, C. Vincent and S. Ball (20I5). The Colour of Class. The Educational Strategies of the Black Middle Classes. London, Routledge.

Rzepnikowska-Phillips, A. (20I7). "Convivality in the workplace: the case of Polish migrant women in Manchester and Barcelona." Central and Eastern European Migrant Review doi I0.I7467/ceemr.20I7.II.

Saporito, S. and A. Lareau (I999). "School selection as a process: the multiple dimensions of race in framing educational choice." Social Problems 46(3): 4I8-39.

Savage, M. (2015). Social Class in the 21st Century. London, Pelican.

Savage, M., G. Bagnall and B. Longhurst (2005). Globalization and Belonging. London, Sage.

Savage, M., J. Barlow, P. Dickens and T. Fielding (I992). Property, Bureaucracy and Culture. Middle Class Formation in Contemporary Britain. London, Routledge.

Sayer, A. (2005). The Moral Significance of Class. Cambridge, Cambridge University Press.

Simkins, T. (20I4). "School restructuring in England: new school configurations and new challenges." Management in Education 29(I): 4-8.

Skeggs, B. (I997). Formations and Class and Gender. Becoming Respectable. London, Sage.

Skeggs, B. (2004). Class, Self, Culture. London and New York, Routledge.

Skeggs, B. (2005). "The making of class and gender through visualising moral subject formation." Sociology 39(5): 956-82.

Smaje, C. (I997). "Not just a social construct: theorising race and ethnicity." Sociology 3I(2): 307-27.

Snee, H. and F. Devine (20I4). "Taking the next step: class, resources and educational choice across the generations." Journal of Youth Studies I7(8): 998-Iог3.

Stambach, A. and M. David (2005). "Feminist theory and educational policy: how gender has been 'involved' in family choice debates." Signs 30(2): I633-58. 


\section{References}

Swartz, D. (I997). Culture and Power. The Sociology of Pierre Bourdieu. Chicago, University of Chicago Press.

Swift, A. (2003). How Not to Be a Hypocrite: School Choice for the Morally Perplexed. London, Routledge.

Taylor, C. (200I). “The geography of choice and diversity in the 'new' secondary education market of England." Area 33(4): 368-8I.

Thrift, N. (2004). "Intensities of feeling: towards a spatial politics of affect." Geografiska Annaler 86(B): 57-78.

Tomlinson, S. (2008). Race and Education. Policy and Politics in Britain. Maidenhead, Open University Press.

Toth, K., K. Sylva and P. Sammons (20I5). Subject to Background. London, London Sutton Trust.

Troyna, B. and R. Hatcher (I992). Racism in Children's Lives. A Study of Mainly-White Primary Schools. London, Routledge.

Tyler, I. (2008). "Chav mum chav scum.” Feminist Media Studies 8(I): I7-34.

Tyler, I. (2013a). Revolting Subjects: Social Abjection and Resistance in Neoliberal Britain. London, Zed Books.

Tyler, I. (2013b). "The riots of the underclass?: Stigmatisation, mediation and the government of poverty and disadvantage in neoliberal Britain." Sociological Research Online I8(4): I-6.

Valluvan, S. (20I6). "Conviviality and multiculture: a post-integration sociology of multi-ethnic life." Young 24(3): 204-2I.

Vincent, C., N. Rollock, S. J. Ball and D. Gillborn (20I2). "Intersectional work and precarious positionings: Black middle-class parents and their encounters with schools in England." International Studies in Sociology of Education 22(3): 256-76.

Wallace, D. (20I6). "Reading 'race' in Bourdieu? Examining black cultural capital among black Caribbean youth in south London.” Sociology 5I(5): 907-23.

Waquant, L. (2008). Urban Outcasts: A Comparative Sociology of Advanced Marginality. Cambridge, Polity Press.

Weekes-Bernard, D. (2007). School Choice and Ethnic Segregation. Educational Decision-making among Black and Minority Ethnic Parents. London, The Runnymede Trust.

West, A. and E. Bailey (2013). "The development of the academies programme: 'privatising' school-based education in England I986-2013." British Journal of Educational Studies 6I(2): 137-59.

Wilkins, A. (2010). "Citizens and/or consumers: mutations in the construction of concepts and practices of schooling choice." Journal of Education Policy 25(2): I7I-89.

Williams, K., F. Jamieson and S. Hollingworth (2008). “'He was a bit of a delicate thing': white middle-class boys, gender, school choice and parental anxiety." Gender and Education 20(4): 399-408. 


\section{References}

Wills, W., K. Backett-Milburn, M.-L. Roberts and J. Lawton (20II). "The framing of social class distinctions through family food and eating practices." The Sociological Review 59(4): 725-40.

Wilson, H. (2OI4). "Multicultural learning: parent encounters with difference in a Birmingham primary school." Transactions of the Insitute of British Geographers 39(I): I02-I4.

Wilson, H. (20I7). "On geography and encounter: bodies, borders and difference." Progress in Human Geography 4I(4): 45I-7I.

Yuval-Davis, N. (I992). Fundamentalism, multiculturalism and women in Britain. In 'Race', Culture and Difference, ed. J. Donald and A. Rattansi. London, Sage Publications: 278-92.

Yuval-Davis, N. (2007). "Intersectionality, citizenship and contemporary politics of belonging." Critical Review of International Social and Political Philosophy IO(4): 56I-74. 


\section{Index}

'able student' programmes 15

academies 7, I4-I7, 72, 8I, I57

Adams, M. 7I

affect and place 7, 70, 74-5

affective aspects of school choice

$3-7,77,86,92,93-8$, 103-4,

IO8, IIO, II6-2I, I3O-I, I34,

I4I

affective belonging 4I-2, 50, 5I, 55,

57

Ahmed, Sara 5, 25, 108-9, I35-6

Alexander, Claire 29, I37, I52

Allen, R. 27

appeals procedures I7, 30-I

Archer, L. 9, 23-4, I44

Ashover Primary School 44-5, I48

Asianness I49

assimilationism $\mathrm{I} 36$

Ball, Stephen I5, 2I, 27-30, 97, II4, I4I-2

Bangladeshi ethnicity 8

behaviour of children and their

parents, observation of $5 \mathrm{I}-2$, $\mathrm{I} 2 \mathrm{I}-2, \mathrm{I} 3 \mathrm{O}, \mathrm{I} 62$

belonging, sense of II, 28-9, 33-6, $40,57, \mathrm{I} 60$

see also affective belonging;

elective belonging

Benson, Michaela 4I, 56

Bernstein, B. 9I black and minority ethnic (BME)

groups 29, 32

Blessingham Grammar School I44

Bottero, W. 8

Bourdieu, Pierre Io, I6, 20-4, 27,

$33,35-7,56,85,155-6$

and race and ethnicity $23-4$

and gender $23-4$

branding Io9

definition of 36

Brexit referendum (2016) I36

Briggs, A. 27

Britishness and British values I36-7

bullying 25 , II9-20

Burgess, Simon 26-7, 29, 42

Burnage I50-I

Butler, Judith 24-5

Butler, T. 36

Byrne, Bridget (co-author) 46, 25, 28, 30, IO2, I2I, I54

Cameron, David 136 catchment areas of schools I7-I8, 30, 33, 4I, I06, II9, I26

Cheadle Hulme II, 40-57, 60-3, $66-8,7 \mathrm{I}-2,77,83-4,89$, 106, I20-I, I27-35, I47-52, I58-60, 163

childcare 49 , 100

choice 28 , 7I-I05, I54-5, I62-3 


\section{Index}

choice advisor services I8

Chorlton 40-50, 56-6I, 64-8, 7I-7, 77-83, 88-9, 92, I03, I06, II4, I28-3I, I34-40, I44, I47-8, I52, $158-60,163$

Christianity and Christians 43 , I48-5I, I63-4

Christmas, celebration of 150 'circuits of education' 3, 36

class 3-I2, I5-I6, I9-26, 3I, 36-7,

49-70, I07-8, I2I, I23-33,

II2-30, I56

class and affect 3-7, 107-8, I6o-3

class identity I9-20, 4I, 50, I22 Clayton 63-5

closed-circuit television (CCTV) cameras I

clustering of certain groups of children in particular schools I5, 26, I57

Code of Practice on School

Admissions I7

communities, schools seen as 3-4, I44

competition

between schools 9, I5, 36, I57

in parenting 28

comprehensive schools 27

'concerted cultivation' 27, 57, 7I

'consumers' of education see parents as consumers

contagion and contamination $5^{\mathrm{I}-2}$, IIO, II7, I22, I28-32

cosmopolitanism I40, I43, I46-7

Courtney, S.J. I7, 36, I09

Crossley, N. 5

cultural capital 2I-2, 30, 72, 85, 87, I03, I06, I22-3, I4I, I56

cultural differences and diversity 20 , I34-6, I5I-3, I64 cultures of education, instrumental and expressive 9I

curriculum I4, I5, I36

The Daily Telegraph 30

David, M. I5

De Certeau, M. 2, 33-4

De Tona, Carla (co-author) 30, 46

demographic characteristics 44-5, 66, 158

Didsbury 58

disability 15

discipline 52, II6-2I, I24

distance between home and school

$\mathrm{I7}, 30,33,37,49,70, \mathrm{I} 60$

diversity $132-52, \mathrm{I}_{3}$

degrees of $134-5$

educational policy on 129

language for talking about

I $47-52, \mathrm{I} 64$

limits to 140

Donald, J. 6

drop-off times at schools 52, II9

education

inequalities 7-9

hopes for progressive outcomes from $7-8$

Education Act (I944) I3

Education Act (I980) I3

education market reforms 9-IO, I3-I6, I8

Education Reform Act (I988) I3

elective belonging II, 36, 4I-2, 57, 64 , 106, 140

Eleven-plus examination $76-7$, 89-93, 104, I6I

emotional aspects of education and school choice 2-7, IO-II, 93, I03-4, I08-10, I20, I54

'ethical' differences in approaches to child-rearing and consumption I5I 
ethnic differences and diversity I2, $43-4$, I32-8, I52

ethnic minorities 8-9, I2, 24-5, 28-32, 44-6, I2I, I29, I3I, I33-5, I42-7, I52-3, I6I, I64 ethnicity, concept of I5, 24-5 exclusions from school I4, I5 Exley, S. I8

failed and failing schools I4-I5

fascism I33

fathers, role of Ioo, II3, I57

fear, experience of II6, IIO-2I, I35

'feeder' schools ioo

fieldwork 40-9

'fish out of water' experiences 23, 28-9, 42, 50, 160

Fortier, Anne-Marie 4, 6

Francis, B. 9, 23-4

free school meals (FSM) indicator 26-9, 32, 45, I57-8

free schools I4-I7, I57

'funding following the pupil' principle $\mathrm{I} 3$

'gangs' I20-I, I53n8, I59, I62 gender $9,15,23-4,25,35-6,78$, 98-IO2, I04, I22 I57

gentrification 34

geographic mobility 47-70

Gillborn, David 32

Gilroy, P. I9

'good' schools 3, 40, I24, I62

Gorard, Stephen I5

Gorton 53

governance of schools I3-I4, 38

grammar schools II, 3I, 58, 72,

$$
\begin{aligned}
& 76-7,87-93, \text { I03-4, I2I, } \\
& \text { I57-6I }
\end{aligned}
$$

Greany, T. I57

Greater Manchester Io, 40, 43, 50, 66 see also Cheadle Hulme; Chorlton;

Whalley Range

The Guardian II4

Gunter, H.M. I3

habitus 22-4, 56, 58, 85, 92, I26, I52

Hacker, Richard I5I

Hage, Ghassan 138

Hall, Stuart 24, I37

Hamnett, C. 36

happiness 2-3, I09, II7, I6I

Harries, Bethan 6, I43

Harvey, D. 33-4

Heath Primary School 44-5

Hebden Bridge 58

'hexis' 22

Higham, R. I57

house prices 40,57

Hulme 58

identity

social 40-I, 50

spatial 40-I, 50

inequality $5-8$

in or linked to education $8, \mathrm{I} 5$, I8-I9, 26, I57

social and socio-economic $8, \mathrm{I} 6$

integration in schools $\mathrm{I} 2$

interview-based research 138

interviews for purposes of the present research 46-7

Isin, E.F. 2, 72

Islamic schools 72, 77-80, 99, I6o

Islamophobia 65

Jenkins, Roy 136

Johnston, R. 29

Lareau, A. 27, 57

'league tables' in4

Lefebvre, H. 34-5

'left behind' 32

Lentin, A. 137 


\section{Index}

local authority control of education system I3-I4, I5

local status hierarchies $156-7$

localness of schools 7, 75-6, II9

Longford Primary School 44-5, I27, I39-40, I45

Lovell, Terry 23

Lucey, H. I34

Lupton, R. I6

McGhee, D. I37

McGinty, R. I3

Manchester see Greater

Manchester

masculinities 25, II9

middle-class parents and children

27-32, 36-7, 7I, I07, IIO, I23,

I27-30, I5I, I56-7

migrant parents $30,4 \mathrm{I}, 42,46,6 \mathrm{I}$, 88, II6

'mix' 58, 61, 65, 78-9, 87-8, го7, II7, I26-7, I28-30, I3I, I33-5, I4I, I45-8, I53, I58, I60-4

mobility see moving to a new area; social mobility

Morgan, Nicky I3-I4

Moss Side 52-3, 63, 65

mothers 86, 98-IO2, I57

moving to a new area $4 \mathrm{I}-2,47-5 \mathrm{I}$, 56-7, 62, 67, 70-I, 75-6, 106, I59

'multicultural intimacies' (Fortier) 4, 6

multiculturalism 6-7, I2, 25, 6I, I32-42, I46-53, I59-64 multiculture, questioning of I47-5I

Muslim communities I2, 43, 6I, $63,72,77-9,103,145-6$, I49, 163

narratives $33-5,4 \mathrm{I}-2,52-3,56-6 \mathrm{I}$ nationalism $\mathrm{I} 37$ neo-liberal policies 7, 9, 70, 96

networking

by children, at secondary school I56

for evaluation of schools 30

by parents, at local level I7, 49,

98-9, I04, I57

'neurotic citizen' 2, 7I

occupational groups 20

Office for Standards in Education

(Ofsted) 30, 34, 38ni7, 98, 109, II3-I6, I57

open days/evenings at schools I-2, I09-10, I30, I6I

see also parent-teacher evenings

'otherness' and 'othering' II-I2, I32, I42

Pakistani ethnicity 8

parent-teacher evenings 44-5

see also open days/evenings at schools

parental choice of school 2, 7-18, 32,47

at primary level 29

availability to parents with

financial means 26

lack of $\mathrm{I} 8,68,7 \mathrm{I}-5$, IO6-7, I60, I62

seen as a burden $\mathrm{I} 7$

parenting, different styles of $47-8$, 52, II2

'parentocracy' I5

parents' academic aspiration for children III-I4

parents as citizens 2, I3, I4, 95

parents as consumers 9-10, I3, I4-I6, 37nI, 95, 97, I54-5

parents' experiences when children move to secondary school 4 , II8, I54 
parents' own past experience of schooling 70-I, 89, 9I, I03-4, I08, II4, I6I

parents' responses to particular schools 7, 152

Parkside High School 73, I29

Paton, K. 35

'people like us' 5, 28-30, 34, 4I, 56, 58, I06-9, II5, I2I, I45, I59-60 performative parenting 47-8

Perrier, Maud 7I, 95, IO2

Phillips, Anne I35

Phillips, Trevor I35

pick-up times at schools 52, II9

Pickett, K. 8

place, perceptions and understanding of $2, \mathrm{I} 2,33-5$, $4 \mathrm{I}, \mathrm{I} 58$

'political correctness' I35, I50, I63

'political' nature of discussions about school choice I54

politics of schooling itself 158

Poplar High School I43

post-structuralism 24

'potential', reaching of II2-I3

Power, S. 43

prejudice I45, I47

Prestbury 54

primary schools 40, 44-5, 82

relationships with parents II9

private schools II, 26, 3I, 54, 72, 76-89, 96, I03, I30, I54, I60

qualifications gained at school 22, IIO, II2, I3O

quality of particular schools 5, I5 quality of schools in general I5 'quietness' of an area perceived as either positive or negative $6_{4}$

race $2,4-\mathrm{I} 2, \mathrm{I} 6,23-6,3 \mathrm{I}, 37,63$, I07-8, II7, I2I, I23, I28-9, I33-52, 156 and affect 3-7, I07-8

interaction with gender 25

talking about 63-6

racism $5-7,12,25-32,65,68,135$,

I37, I42-7, I50, I53, I57, I60-4

Rattansi, A. 6, I37

Rayner, Stephen M. I5

'readiness for education' 8

Reay, Diane I8, 22, 26, 30-I, 36, 52, 87,89, I07, I29, I3I, I33-4, I4I

'rebranding' of schools 34 relational processes and perceptions

$4-5,2 \mathrm{I}-2,33-5,77, \mathrm{IO} 2-3$,

107-8, 130, I55-6

relational sociology $4-5$

religious schooling 68, I03

see also Islamic schools

representational space 35

reputations of schools and places 49,56

residential patterns $5,40-\mathrm{I}, 49-70$

see also distance between home and school

respectability, desire for $122-3$, I30-I, I59, I62

Rollock, N. I44

'rough' 52-3, 63-4, I59

rural areas 18

St Catherine's Primary School I44

Savage, M. II, 20, 35-6, 40-I, 57,

Io6

Sayer, Andrew I9, 23, 28

school admissions policies I7, 8I

school choice literature Io, I6,

$25-33,48,57,67$, I07, I33

gaps in 26-33

school uniform I09, I24-5, I3I, I40, I6I-2

secondary schools

children's anxiety on moving to I 54 


\section{Index}

secondary schools (cont.)

relationships with parents II9

size of 74

segregation 9, 15, 26, 29, I49

selective schooling II, I7, 72, 76-9,

$82,87-90$, I03-4, I57-6I

self, parents' sense of IO3

self-management of schools I3

siblings, schooling of $47,86-7$,

I $57-8$

Simkins, T. 7

single parents 99-I00

Skeggs, B. 26, I22

social capital 22, 72, I4I, I56

social construction of differences

25

social context and social structures

2,7

social development of children Io7

social interaction and hierarchies 2I

social mobility 42, 49, 53, II8, I22, I5 6

socio-economic inequalities 8, 26-9

sociological research on school

choice 156

sociology of education 5, I9-20, 26

spatial identities 40-I

spatial inequalities 2, 5, 26-7, 33-6, 40-70

special educational needs (SEN) I5

Stambach, A. I5

state intervention in education 7-10

stereotyping 32, I45, I53

stigma $33-6,5$ I, 54

stigmatised groups I30

Stockport 53

stress connected with schooling 45 , 76, I00-I, 106, I54, I57

Swann Report (I985) I36
Swartz, D. 2I

Swift, A. ${ }_{5} 6$

'tactics' 2, I6, 33, 48

Taylor, Chris $7 \mathrm{I}$

terrorism I35, I45

Thatcher, Margaret I3

Thrift, Nigel 7

tolerance $6,48-\mathrm{I} 5 \mathrm{I}$

Tomlinson, S. 136-7

Trafford 89-90

tutoring 3I, 83, 84, 9I-2, 96, III, I54, I60-I

the underclass, theory of $108, \mathrm{I} 22$, I30-2, I62

'undesirable' areas I59

'undesirable' children Io4

'undesirable' schools II

urban communities 33-4

Vanderbloemen, L. 8

vegetarianism 59, I34-5,

$$
\text { I38-9 }
$$

Weekes-Bernard, Debbie 29, 3I-2, I44

Whalley Range 40-8, 6I-8, 7I-2, $76-7,8 \mathrm{I}-3,89$, 99, по6, I34, I44-8, I52, I6o, I63

whiteness 23, 28, 29, 32, 38ni4, I07, I34, I36, I42, I44-5, I48, I50-I, I52, 156

Wilson, H. 4

women as the primary decisionmakers I00, I57

worrying about schools II, 97, I00-4, I07, II6, I57, I62

Wythenshawe 50-2 